\title{
Self Discharge of Magnesium-Sulfur Batteries Leads to Active Material Loss and Poor Shelf Life
}

\author{
Hunter O. Ford ${ }^{a}$, Emily S. Doyle ${ }^{a}$, Peng He ${ }^{a}$, William C. Boggess ${ }^{b}$, Jennifer L. Schaefer, ${ }^{* a}$
}

a. Department of Chemical and Biomolecular Engineering, University of Notre Dame, Notre Dame, IN, USA. Email: Jennifer.L.Schaefer.43@nd.edu

b. Department of Chemistry, University of Notre Dame, Notre Dame, IN, USA.

\begin{abstract}
Due to its high theoretical energy density and relative abundancy of active materials, the magnesium-sulfur battery has attracted research attention in recent years. A closely related system, the lithium-sulfur battery, can suffer from serious self-discharge behavior. Until now, the self-discharge of Mg-S has been rarely addressed, and even then only indirectly. Herein, we demonstrate for a wide variety of $\mathrm{Mg}$-S electrolytes and conditions that $\mathrm{Mg}$ $\mathrm{S}$ batteries also suffer from serious self-discharge. For a common $\mathrm{Mg}$-S electrolyte, we identify a multi-step selfdischarge pathway. Covalent $\mathrm{S}_{8}$ diffuses to the metal $\mathrm{Mg}$ anode and is converted to ionic $\mathrm{Mg}$ polysulfide in a nonfaradaic reaction. $\mathrm{Mg}$ polysulfides in solution are found to be meta-stable, continuing to react and precipitate as solid $\mathrm{Mg}_{\mathrm{y}} \mathrm{S}_{\mathrm{x}}$ species during both storage and active use. $\mathrm{Mg}$-S electrolytes from the early, middle, and state-of-theart stages of the Mg-S literature are all found to enable the self-discharge. The self discharge behavior is found to decrease first cycle discharge capacity by at least $32 \%$, and in some cases up to $96 \%$, indicating this is a phenomenon of the Mg-S chemistry that deserves focused attention.
\end{abstract}

\section{Broader Context}

To avoid the most catastrophic effects of climate change, transportation must become fully electrified, thereby breaking a significant pillar of our dependence on fossil fuels. To make this transition more economically feasible and therefore more likely to take place, a wide variety of next generation rechargeable battery chemistries are being explored. These new chemistries should be safe, energy dense, and consist of sustainable and abundant materials. One such example of promising next generation chemistries is the magnesium-sulfur battery. Since the first demonstration of the Mg-S battery, progress in improving this technology has been inspired by the lithiumsulfur system, which has received significantly more attention. A well-known challenge for Li-S is the tendency to self-discharge. From a practical standpoint, the importance of battery shelf-life cannot be overstated. In this work we demonstrate that unfortunately the Mg-S system also suffers from severe self-discharge. In screening a wide variety of $\mathrm{Mg}$-S battery conditions and formulations, and finding that all were susceptible to self-discharge, we hope to bring attention to this serious problem facing Mg-S batteries.

\section{Introduction}

Since its initial demonstration, the magnesium-sulfur (Mg-S) battery has received intense research interest due to what it promises: high theoretical energy capacity $\left(3,459 \mathrm{mAh} / \mathrm{cm}^{3}\right)$-and widespread material availability (Mg is $2.1 \mathrm{wt} \%$ of the earth's crust). ${ }^{1,2}$ Compared to lithium-sulfur batteries, where $\mathrm{Li}$ makes up only $0.002 \mathrm{wt} \%$ in the earth's crust, the Mg-S battery is an attractive technology for the largescale electrification of transportation.

However, the Mg-S chemistry is not without its challenges. Similar to the more well-studied Li-S system, Mg-S batteries also suffer from a phenomenon known as the polysulfide shuttle. ${ }^{2}$ The shuttle 
process is well described in the literature for both Mg-S and Li-S, and is one of the major challenges to be overcome for practical use of these technologies, as it contributes to short life-cycle and fast capacity fade in metal-sulfur batteries. ${ }^{3-5}$

A related challenge that has been so-far largely overlooked for Mg-S is the issue of self-discharge, wherein the active material in the cell reacts when the cell is under static conditions, leading to a loss in capacity. For real-world use, cells should ideally retain capacity at any depth of charge/discharge. The challenge of self-discharge in metal-sulfur batteries is intrinsically related to the polysulfide-shuttle phenomenon. Unwanted migration of sulfur species, i.e. the polysulfide shuttle, is responsible for selfdischarge under static conditions and for inefficient charging under dynamic conditions. Some key differences are that under the static condition, the sulfur transport is governed only by concentration gradient driven diffusion and the species in the electrolyte are not electrochemically generated. Under dynamic conditions there is the additional impact of electromigration on polysulfide transport, and the polysulfide speciation is governed by electrochemical and chemical processes. These differences aside, it is expected that approaches for disrupting the static condition self-discharge problem can be useful for overcoming the dynamic-condition challenge, and vice-versa, in addition to improving shelf-life.

Systematic investigations of the self-discharge process in Li-S batteries are numerous, and reveal that self-discharge can exceed $70 \%$ of the cell's capacity if left unchecked. ${ }^{6-13}$ Unfortunately, many of the methods by which the self-discharge is disrupted in Li-S cells, such as the use of $\mathrm{LiNO}_{3}$ to form a protective solid electrolyte interface (SEI) on the anode, are not applicable to Mg-S cells. In other words, solutions for disrupting the metal-sulfur battery discharge must be tailored to each unique chemistry to be effective, underscoring the importance of investigating the self-discharge of $\mathrm{Mg}$-S. Remarkably, reports in the literature of the $\mathrm{Mg}$-S static self-discharge are scarce, especially considering how much selfdischarge has been studied in Li-S systems.

With the use of Raman spectroscopy, Vinayan and colleagues identified the formation of ionic $\mathrm{S}_{8}{ }^{2-}$ under static conditions in Mg-S cells that employed a magnesium tetrakis(hexafluoroisopropyloxy) borate $\left(\mathrm{Mg}\left[\mathrm{B}(\mathrm{hfip})_{4}\right]_{4}\right)$ in 1,2-dimethoxyethane (DME) electrolyte. When the cells were assembled and held at their open circuit potential (OCP), the potential decreased over time and the anode impedance increased dramatically. The increase in impedance was attributed in part to the reaction between the anode and $\mathrm{S}_{8}{ }^{2-}$, which resulted in the formation of a passivation layer. ${ }^{14}$ The authors suggested that $\mathrm{S}_{8}$ was being converted to $\mathrm{S}_{8}{ }^{2-}$ due to an interaction between $\mathrm{S}_{8}$ and the ions in the electrolyte.

During an extensive electrochemical impedance spectroscopy (EIS) investigation on Mg-S cells using the same electrolyte, Hacker and colleagues also discovered a large increase in the charge transfer resistance associated with the $\mathrm{Mg}$ anode when a full cell was assembled and held under static conditions for 50 hours. The increase in resistance was attributed to the diffusion of solubilized $\mathrm{S}_{8}$ to the $\mathrm{Mg}$ anode where it underwent reduction. ${ }^{15}$ Further, at elevated temperatures it was observed that the non-faradaic reduction of $\mathrm{S}_{8}$ under static conditions was enhanced. This result is attributed to the increased solubility of $\mathrm{S}_{8}$ and ionic polysulfides in the electrolyte at elevated temperatures, indicating that solubilized $\mathrm{S}_{8}$ reacts directly with $\mathrm{Mg}$ metal to initiate self-discharge.

To the best of our knowledge, these two reports are the only investigations that deal in any capacity with the self-discharge of Mg-S batteries. In an effort to assess a road-block that has been largely ignored, we directly investigate the self-discharge tendency of $\mathrm{Mg}$-S batteries using a diverse set of electrolytes, and our findings are a wake-up call: every electrolyte investigated allows for self-discharge.

When Mg-S cells are held at OCP, whether they are partially discharged or fully charged, covalent $\mathrm{S}_{8}$ is spontaneously converted to polysulfides through a non-faradaic reaction process. In some cases, the selfdischarge is quite severe. What's more, unlike lithium polysulfides, magnesium polysulfides are found to 
be inherently unstable in solution, leading to the precipitation of active material. The precipitation effect is not limited to the static condition, as it is also found to be relevant at the timescales of active cell discharge. Uncontrolled precipitation of active material can result in permanent capacity loss if the material is inaccessible electronically or ionically, further contributing to the quick capacity fading woes of the Mg-S chemistry. Finally, the seriousness of the self-discharge is evaluated. Cells that self-discharge at OCP for 7 days see at least a $32 \%$ reduction in $1^{\text {st }}$ cycle deliverable capacity. In some cases, depending on the electrolyte, the capacity reduction as a result of self-discharge exceeds $90 \%$.

Given the wide variety of electrolyte chemistries explored and that self-discharge is observed in every case, it is clear that this is a phenomenon of Mg-S cells that should be addressed directly. As a first step in overcoming this problem, we have identified the initial reaction in the self-discharge pathway. The selfdischarge begins when covalent $\mathrm{S}_{8}$ dissolves in the electrolyte, diffuses to the metal $\mathrm{Mg}$ anode, and becomes reduced. For Mg-S compatible electrolytes, the spontaneous conversion of $\mathrm{S}_{8}$ to an ionic form due to interaction with the electrolyte alone appears negligible; the presence of magnesium metal is required. Strategies that prevent contact of all sulfur species, $\mathrm{S}_{8}$ and polysulfides, with the magnesium anode should be explored to help prevent self-discharge initiation. Stabilization of intermediate polysulfide species should be pursued to prevent active material loss via uncontrolled precipitation.

\section{Results and discussion}

\section{Probing the self-discharge of a $0.25 \mathrm{M} \mathrm{MgTFSI}_{2}+0.5 \mathrm{M} \mathrm{MgCl}_{2}+\mathrm{DME}$ electrolyte}

Since the first demonstration of reversible sulfur redox chemistry obtained with magnesium bis(trifluoromethanesulfonimide) $\left(\mathrm{MgTFSI}_{2}\right)+$ magnesium chloride $\left(\mathrm{MgCl}_{2}\right)$ based electrolytes, numerous works have made use of this chemistry for $\mathrm{Mg}-\mathrm{S}$ investigations., ${ }^{3,16-22}$ Owing to the commercial availability and relative ease of preparation of this electrolyte, it has seen widespread use in various forms, i.e. in different ethereal solvents, salt concentrations, salt molar ratios, etc. The particular formulation of 0.25 $\mathrm{M} \mathrm{MgTFSI}_{2}+0.5 \mathrm{M} \mathrm{MgCl}_{2}$ in 1,2-dimethoxyethane (DME) originally reported by Gao and colleagues was selected as the initial electrolyte to be studied for self-discharge. ${ }^{16}$ With this electrolyte, the cell configuration used in this study, and a rate of $0.1 \mathrm{C}$ with respect to sulfur, the average $1^{\text {st }}$ discharge capacity of Mg-S cells was found to be $396 \pm 27 \mathrm{mAh} / \mathrm{g}$ based on 13 cells discharged from OCP to $0.5 \mathrm{~V}$ (Figure S7). The SOC values throughout the rest of manuscript are in reference to this value. Due to wellknown issues with reversibility, which in addition vary greatly for different $\mathrm{Mg}$-S electrolytes, this study is concerned with the self-discharge impact on pristine cells. By this approach, the effects of self-discharge are highlighted and not conflated with other challenges facing the Mg-S chemistry.

A series of cells were assembled using the $0.25 \mathrm{M} \mathrm{MgTFSI}_{2}+0.5 \mathrm{M} \mathrm{MgCl}_{2}$ in DME electrolyte and were discharged to roughly half the average $1^{\text {st }}$ discharge capacity, $200 \mathrm{mAh} / \mathrm{g}$. After discharging to $200 \mathrm{mAh} / \mathrm{g}$ the cells were allowed to age for different periods of time. Analogously, identical cells were assembled and held at OCP for the same amount of total time as the aged discharged cells. After the appropriate amount of time, the cells were opened and extracted with tetrahydrofuran (THF), and the resulting solutions were analyzed via UV/VIS to detect the presence of polysulfides. Additional experimental details are in the supplementary information. The THF extraction procedure was used so there would be a large enough sample volume to analyze, and because both $S_{8}$ and many ionic polysulfide species have sufficient solubility in THF. Solutions of $\mathrm{S}_{8}$ in THF are clear and colorless with absorbance in the UV region, whereas polysulfides of many flavors have absorbance signatures in the UV and near UV regions, making the detection of both neutral and ionic sulfur with UV/VIS spectroscopy straightforward. ${ }^{17,23-28}$

Figure 1 shows the background subtracted absorbance spectra for the $200 \mathrm{mAh} / \mathrm{g}$ discharged cells and the cells held at OCP. The background subtraction (described in detail in the SI) is such that any absorbance from solvent and salts is removed; only newly formed species in the electrolyte remain in the spectra after subtraction. The $200 \mathrm{mAh} / \mathrm{g}$ discharged sample analyzed immediately after discharging 
shows absorbance bands consistent with magnesium polysulfides. The spectrum bears qualitative resemblance to UV spectra collected on a similar system. ${ }^{28}$ From the literature, the peak around $380 \mathrm{~cm}^{-1}$ is likely $\mathrm{S}_{4}{ }^{2-27,28}$ While there remains some discrepancy in the literature about describing the characteristic absorbance wavelengths of other polysulfide species, attempts to identify the speciation in this case are moot anyways. The polysulfide speciation observed is likely not representative of the speciation within the cell, as the change in solvent environment and concentration occurring during sample preparation causes a change in polysulfide speciation. ${ }^{26,27}$

The important point to consider is not the polysulfide speciation, but the total absorbance, as the area under the curve is assumed to be related to the polysulfide concentration. From the inset in Figure 1 it is clear that as a $200 \mathrm{mAh} / \mathrm{g}$ discharged cell ages, the concentration of polysulfide in the cell changes; increasing, peaking, and then decreasing. The increase in concentration is indicative of continued nonfaradaic discharge, where $S_{8}$ that has not been electrochemically reacted is being converted to UV/VIS active polysulfides, i.e. self-discharge. The eventual decline in total absorbance hints at the instability of the formed polysulfides and continued chemical reaction.

Remarkably, an undischarged cell held at OCP for the same total time as the 1 day aged, $200 \mathrm{mAh} / \mathrm{g}$ discharged cell shows almost the same total absorbance and a nearly identical absorption spectrum as the electrochemically discharged cell. Under a static condition, a severe non-faradaic self-discharge process is apparently active for this electrolyte, wherein a substantial amount of covalent sulfur is converted into UV/VIS active polysulfide species. The cells held at OCP follow a similar trend as those that are partially discharged, in that after a certain amount of time spent aging the polysulfide concentration starts to decrease.

These results demonstrate a severe static condition self-discharge problem for cells at various SOC. Further, the process appears to be multi-staged. During the early stages, covalent sulfur is converted to UV/VIS active polysulfides, increasing the polysulfide concentration. These polysulfide intermediates appear meta-stable, converting further to other species that are not active in UV/VIS (or perhaps insoluble in solution), indicated by the decrease in total absorbance over time. At later stages, this

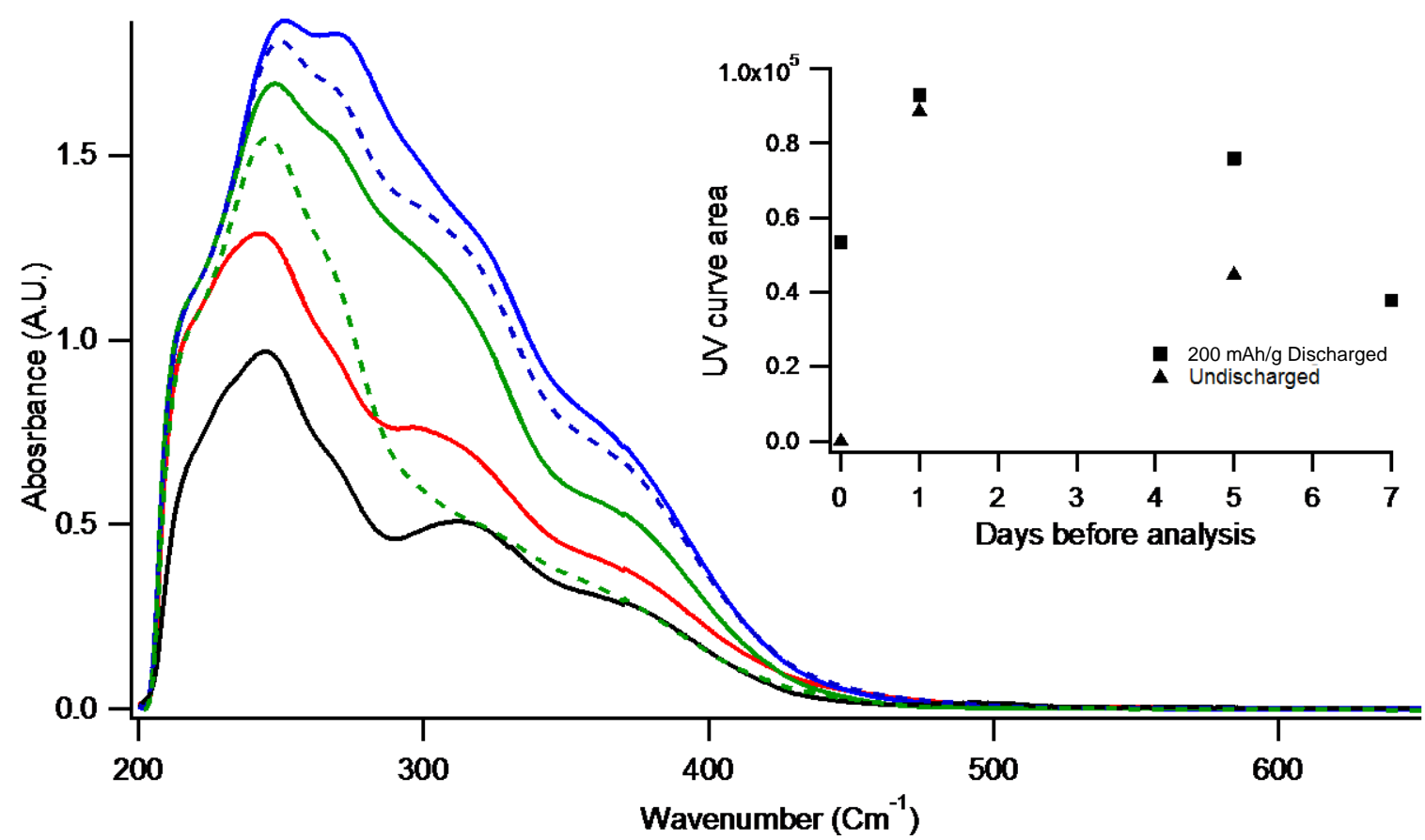

Fig. 1 Background subtracted UV/VIS absorbance spectra for extracted solutions from Mg-S cells using the $0.25 \mathrm{M} \mathrm{MgTFSI}_{2} 0.5 \mathrm{M} \mathrm{MgCl} \mathrm{DME}_{2}$ electrolyte. $200 \mathrm{mAh} / \mathrm{g}$ discharged immediate analysis. — $200 \mathrm{mAh} / \mathrm{g}$ discharged 1 day aged. _— $200 \mathrm{mAh} / \mathrm{g}$ discharged 5 day aged. — $200 \mathrm{mAh} / \mathrm{g}$ discharged 7 day aged. - - Undischarged 1 day aged. - - - Undischarged 5 day aged. Inset shows total area under the spectra curves. 
process results in the polysulfide concentration in solution decreasing.

In the process of opening the coin cells for the UV/VIS sample preparation, yellow-orange deposits visible to the naked eye were noticed on the separators and cathodes of some of the longer aged cells. These deposits are not soluble in pure THF or DME. The deposits were analyzed with scanning electron microscopy - energy dispersive x-ray spectroscopy (SEM-EDX) to understand their chemical composition.

Figure 2A shows a photo of a separator recovered from a cell that was discharged to $200 \mathrm{mAh} / \mathrm{g}$ and aged for 7 days. Figure 2B shows accompanying SEM-EDX results of the large deposit for selected elements. The deposits found on the separator and on the cathode (Figure 2, Figures S3-S5) are chemically distinct from deposits of the electrolyte salts (Figure S6) in that the electrolyte deposits contain large amounts of $\mathrm{Cl}, \mathrm{F}$, and $\mathrm{N}$ whereas the deposit in Figure 2 and Figures S3 - S5 do not. Consisting predominantly of magnesium, sulfur, and oxygen (samples are briefly exposed to air when transferred into the SEM), the deposits are believed to be solid magnesium (poly)sulfides. It has been shown that in addition to the solid discharge products of $\mathrm{MgS}$ and $\mathrm{MgS}_{2}, \mathrm{Mg}$-S cells can produce other solid products such as $\mathrm{Mg}_{3} \mathrm{~S}_{8}{ }^{29}$ If just the atom percentages of the $\mathrm{Mg}, \mathrm{S}$, and $\mathrm{O}$ are considered for the deposit in Figure 3/Figure $\mathrm{S} 3$, and the $\mathrm{O}$ content is assumed to come from the substitution of $\mathrm{S}$ atoms for $\mathrm{O}$ during transfer (hydrolysis of sulfide), the $\mathrm{Mg}$ and $\mathrm{S}$ apparent formula prior to oxidation would be $\mathrm{Mg}_{3} \mathrm{~S}_{10}$, which is close to the reported $\mathrm{Mg}_{3} \mathrm{~S}_{8}$.

Regardless of the exact chemistry, the presence of solid precipitates that contain large amounts of $\mathrm{Mg}$ and $\mathrm{S}$ that are chemically distinct from the electrolyte salts is further evidence of the proposed multistage self-discharge pathway. Magnesium polysulfides formed via both electrochemical and non-faradaic processes spontaneously precipitate from solution all across the cell. Spatially uncontrolled precipitation of active material has serious ramifications for $\mathrm{Mg}-\mathrm{S}$ reversibility, and so to further understand this precipitation process it is studied with an additional technique.

An ultra performance liquid chromatography-mass spectroscopy (UPLC-MS) analysis capable of quantifying total ionic sulfur was applied to the Mg-S system. ${ }^{30}$ This technique uses a derivatizing agent, 4-(dimethylamino)benzoyl chloride, to functionalize magnesium (poly)sulfides and yield a stable and quantifiable compound. According to Scheme S1, ionic magnesium (poly)sulfides are converted to difunctionalized neutral organic sulfides, $D-S_{x}-D$, where $D$ represents the derivatizing agent. The resulting compounds are easily separable by molecular weight using UPLC and facilely ionized with the addition of a proton to one of the dimethylamino groups for MS detection and quantification.

Similar to the UV/VIS experiment, Mg-S cells were discharged to different SOC and rested for different amounts of time. The cathodes and separators from the cells were harvested and rinsed with DME to remove soluble polysulfides, leaving behind only the insoluble (poly)sulfide solids for derivatization and quantification. In the supplementary information (Figure S20) we demonstrate that the derivatizing agent easily reacts with insoluble ionic (poly)sulfide solids, allowing for accurate quantification of solid ionic sulfur. Further, the derivatizing agent has a negligible reaction with covalent sulfur, meaning any unreacted $\mathrm{S}_{8}$ does not appear in this analysis (Figure S21).

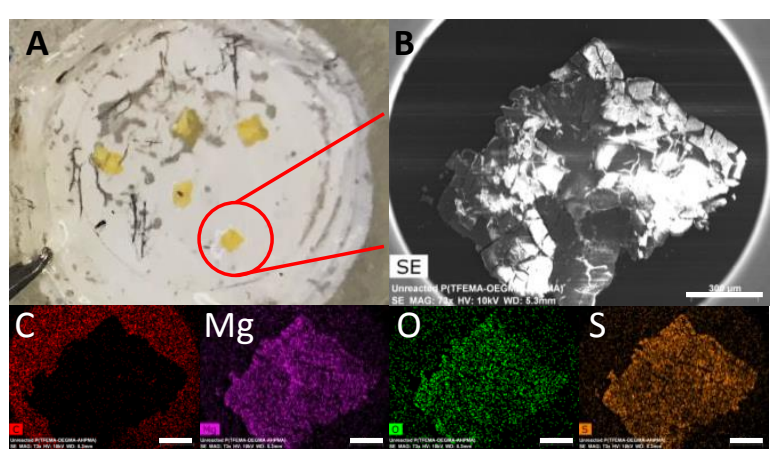

Fig. 2 (A) Photo of separator recovered from $200 \mathrm{mAh} / \mathrm{g}$ discharged cell, 7 day aged. (B) SEM image of highlighted deposit with accompanying EDX. All scale bars are $300 \mathrm{um}$. 
Figure 3 shows the quantified solid sulfur observed for cells discharged to $200 \mathrm{mAh} / \mathrm{g}$, $300 \mathrm{mAh} / \mathrm{g}$, and $0.5 \mathrm{~V}$ (396 mAh/g average). The immediately analyzed $200 \mathrm{mAh} / \mathrm{g}$ discharged cells show a small amount of sulfur (near the technique detection limit) indicating that by $200 \mathrm{mAh} / \mathrm{g}$ only a small amount of the active material has been reduced to a solid form, electrochemically or chemically. Due to the proximity to detection limit, there were more data points taken for this set of samples. Cells that are discharged to $200 \mathrm{mAh} / \mathrm{g}$ and aged for 1 day contain more solid ionic sulfur species than their immediately analyzed counterparts, by almost an order of magnitude. After 7 days of aging, even more sulfur is detected. The increase in detected ionic sulfur can only take place if additional solid (poly)sulfide species are present on the cathode and separator. In as little as 1 day, evidently a significant amount of solubilized polysulfides precipitate from solution.

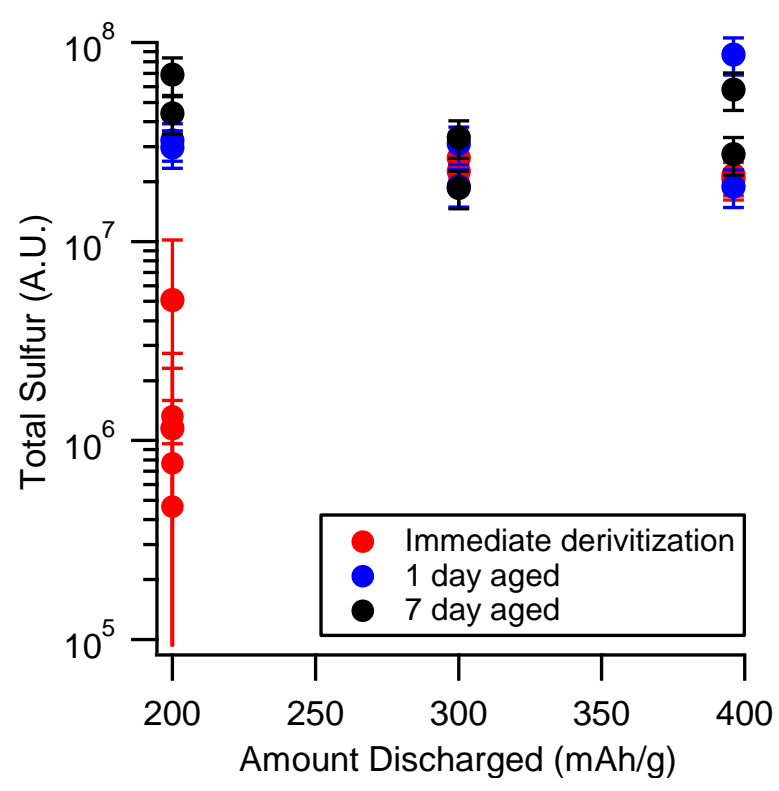

Fig. 3 Total solid ionic sulfur in separator and cathode detected by UPLC-mass spectroscopy method for cells discharged to various SOC and aged for various lengths of time prior to derivatization reaction.

The $300 \mathrm{mAh} / \mathrm{g}$ and fully discharged (to $0.5 \mathrm{~V}$, average $396 \mathrm{mAh} / \mathrm{g}$ ) cells do not show a meaningful change in solid ionic sulfur content with aging, implying that by $300 \mathrm{mAh} / \mathrm{g}$ of discharge the meta-stable species that chemically precipitate upon aging have been precipitated as ionic (poly)sulfides. Additionally, there must be little $S_{8}$ remaining, so the self-discharge pathway that generates the meta-stable species is inactive. An experiment where the separator material is varied (Figures S13, S14) reveals that the precipitation observed as the cell goes from $200 \mathrm{mAh} / \mathrm{g}$ to $300 \mathrm{mAh} / \mathrm{g}$ is a mixture of electrochemically and chemically driven precipitation but is in fact mostly chemical precipitation. Even at the timescales of active discharge, the chemical precipitation of polysulfides resulting in a permanent loss of active material is highly relevant and poses a significant challenge to capacity retention.

From $300 \mathrm{mAh} / \mathrm{g}$ to fully discharged, no change in the amount of solid ionic (poly)sulfides is observed. This result is explained by understanding the last stages of the Mg-S reduction are solid state reactions, and that this mass spectrometry technique cannot distinguish between different ionic (poly)sulfide species. It's possible that by $300 \mathrm{mAh} / \mathrm{g}$ the electrochemically accessible active material is mostly in the $\mathrm{Mg}_{3} \mathrm{~S}_{8}$ state (in agreement with Xu et al) ${ }^{29}$ and this is being converted to species such as $\mathrm{MgS}_{2}$ and $\mathrm{MgS}$ as the cell approaches fully discharged. As far as this mass spectrometry technique is concerned, $\mathrm{Mg}_{3} \mathrm{~S}_{8}$ and $8 \mathrm{MgS}$ will give the same quantitative result for total ionic sulfur.

In summary, the $0.25 \mathrm{M} \mathrm{MgTFSI}_{2}+0.5 \mathrm{M} \mathrm{MgCl}_{2}$ in DME electrolyte suffers a severe self-discharge problem. The self-discharge occurs when the cell is at a full state of charge, or is partially discharged, and is evidenced by the non-faradaic production of polysulfides. The self-discharge appears to be a multistep process. First, covalent $S_{8}$ dissolves in the electrolyte, diffuses to the $\mathrm{Mg}$ anode, and then reacts to form magnesium polysulfides. The spontaneous production of polysulfides under static conditions is observed with the use of UV/VIS spectroscopy and additionally confirmed using the UPLC-MS protocol (Figure S22). The decrease in polysulfide concentration in the UV/VIS with aging, the formation of visible $\mathrm{Mg}_{x} \mathrm{~S}_{y}$ rich deposits in the cell, and increased solid ionic sulfur content with aging as detected with mass spectrometry all point to a second stage in the self-discharge process: continued reaction of meta-stable polysulfides resulting in their eventual precipitation. The large-scale precipitation of active material 
occurs during active discharge in addition to static storage. The degree to which active material is lost due to uncontrolled precipitation appears high, which could make for low sulfur utilization in subsequent cycles. In brief, the shelf-life of an Mg-S battery employing this electrolyte would be impractically short.

\section{Self-discharge tendency of other Mg-S electrolytes}

To evaluate how widespread the self-discharge problem is, a series of other $\mathrm{Mg}$-S relevant electrolytes are evaluated and shown in Figure 4. Three other electrolytes compatible with Mg-S chemistry as well as a solution of chemically synthesized magnesium polysulfides are analyzed using the established UV/VIS approach. The magnesium polysulfides are synthesized according to the literature from magnesium powder and sulfur powder in a solution of $0.25 \mathrm{M} \mathrm{MgTFSI}_{2}+0.5 \mathrm{M} \mathrm{MgCl}_{2}$ in $\mathrm{DME}$, with full details in the experimental section. ${ }^{16}$ The fact that this synthesis is possible is further direct confirmation of $\mathrm{S}_{8}$ conversion to ionic polysulfides through a non-faradaic process. Note, generally methods that are used to synthesize lithium polysulfides are not successful for the synthesis of magnesium polysulfides, especially in ethers. The magnesium polysulfide synthesis used here requires the presence of both the $\mathrm{MgTFSI}_{2}$ and $\mathrm{MgCl}_{2}$ to be successful, indicating the importance of ionic species and a complicated reaction pathway involving the $\mathrm{Mg}$ metal surface, magnesium salts, and sulfur. Formation of ionic polysulfides via this synthetic method was validated with the MS technique (Figure S23).

The other electrolytes studied are a concentrated form of the $\mathrm{MgTFSI}_{2}+\mathrm{MgCl}_{2}$ in DME electrolyte (1 M $\mathrm{MgTFSI}_{2}, 2 \mathrm{M} \mathrm{MgCl}_{2}$ ), an electrolyte based on magnesium bis(hexamethyldisilazide) $\left(\mathrm{MgHMDS}_{2}\right.$ ) and aluminum chloride $\left(\mathrm{AlCl}_{3}\right)$ in THF (0.35 $\mathrm{M}$ total $\left.\mathrm{Mg}, 1: 2 \mathrm{MgHMDS}_{2}: \mathrm{AlCl}_{3}\right)$, and an electrolyte consisting of $0.5 \mathrm{M}$ magnesium fluorinated pinacolatoborate (MgFPB) in diglyme (DEG) that was first reported by Liu and colleagues in 2019. ${ }^{16,31,32}$ The salt and solvent structures, cyclic voltammetry induced $\mathrm{Mg}$ deposition/dissolution, and representative full cell discharges of each electrolyte are shown in the supplementary information in Figures S1, S2, and S10 respectively.

The more concentrated form of the $\mathrm{MgTFSI}_{2} / \mathrm{MgCl}_{2}$ electrolyte is chosen because it has the same salts as the electrolyte investigated in the first part of this study, but has a decreased sulfur and polysulfide solubility owing to the high concentration of the magnesium salts. ${ }^{16}$ The $\mathrm{MgHMDS}_{2} / \mathrm{AlCl}_{3}$ electrolyte is chosen as it is one of the earliest Mg-S compatible electrolytes, with THF selected as the solvent owing to its enhanced $\mathrm{Mg}$ deposition/dissolution reversibility relative to other ethers. ${ }^{31,33}$ The $\mathrm{Mg}$-FPB electrolyte represents a current generation chloride-free and high coulombic efficiency electrolyte, which owing to its chemical similarity to the $\mathrm{Mg}\left[\mathrm{B}(\mathrm{hfip})_{4}\right]_{4}$ based electrolyte and non-nucleophilic nature, is expected to be compatible with sulfur. ${ }^{14,15,32}$

Samples from each electrolyte are prepared with a similar procedure to the previously discussed UV/VIS experiment. An aliquot from the synthesized magnesium polysulfide solutions, of which there are two varying concentrations, is extracted and likewise analyzed by UV/VIS. Figure 4 a-d contains the results for each respective solution/electrolyte, with the inset photographs showing the analyzed solution (black material is cathode undergoing extraction). Compared to Figure $4 b$, c and d, Figure $4 a$ has a different general absorbance pattern due to the background solution used for that set of samples. Figure $4 a$ shows covalent $S_{8}$ in the spectrum in addition to the polysulfides. See Figure S12 for further discussion. 
Although the detailed trends for each electrolyte are different, two major trends are observed in every case. Firstly, all electrolytes show spontaneous formation of polysulfides and therefore suffer from selfdischarge. The cells held at OCP all produce UV active species that more or less resemble the absorbance spectra of the immediately analyzed discharged cells. The self-discharge process is strong enough that a visible color change to characteristic polysulfide yellow is observable with the naked eye in many cases. Secondly, the polysulfides in each solution are metastable, changing in concentration and specific absorbance pattern depending on the age of the cell. This suggests the second portion of the selfdischarge process, precipitation of active material, is also active in these electrolytes. The decrease in absorbance accompanied by formation of precipitate in the synthesized polysulfide solution suggests the instability of the polysulfides is in part inherent, and not totally reliant on the presence of magnesium metal for continued reaction.

The results of Figure 4 suggest that the two stages in the self-discharge process (conversion of covalent sulfur to ionic polysulfides, precipitation of ionic sulfur) have different apparent kinetics, which may be controlled by the nature of the electrolyte. The solubility and diffusivity of covalent sulfur controls the rate by which ionic polysulfides can be produced, i.e. in a low solubility/low diffusivity case, the production of polysulfides becomes mass-transport limited with respect to getting covalent sulfur to the $\mathrm{Mg}$ electrode. The solubility limit and stability of the polysulfides produced is dependent on the chemical environment, influenced by factors such as the salt concentration, solvent donor number, and the electrolyte salts, which is why the detailed trends vary across electrolytes. ${ }^{27,34,35}$
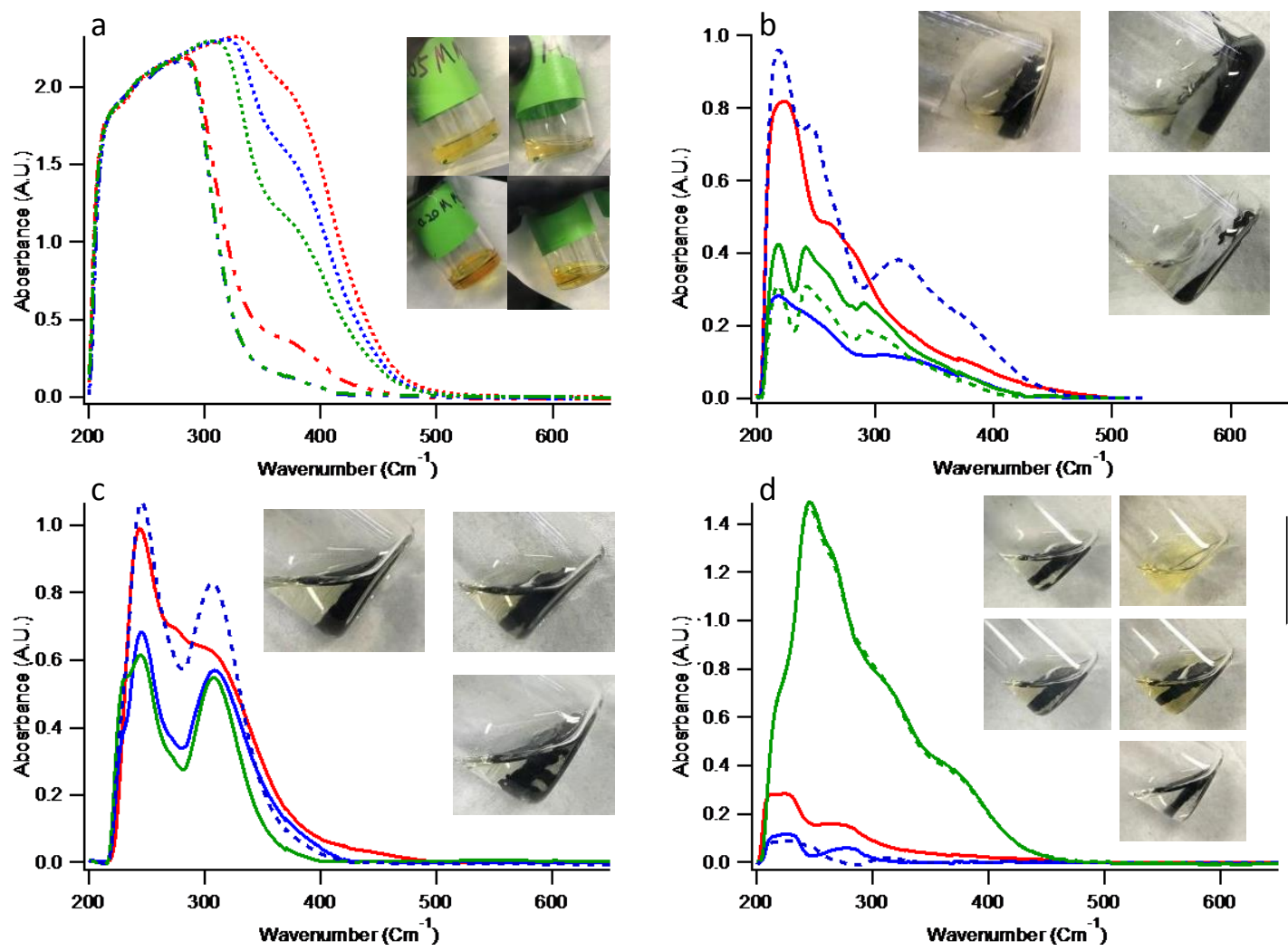

Fig. 1 UV/VIS spectra for (a) Synthesized magnesium polysulfides.

$0.2 \mathrm{M}$ Sulfur as prepared. $0.2 \mathrm{M}$ Sulfur 1 day aged. ......... $0.2 \mathrm{M}$ Sulfur 3 day aged. - - $0.05 \mathrm{M}$ Sulfur as prepared. - - $0.05 \mathrm{M}$ Sulfur 1 day aged. - $0.05 \mathrm{M}$ Sulfur 3 day aged. (b) $1 \mathrm{M} \mathrm{MgTFSI}_{2}+2 \mathrm{M} \mathrm{MgCl}_{2}$ in DME. — $200 \mathrm{mAh} / \mathrm{g}$ discharged immediate analysis. — $200 \mathrm{mAh} / \mathrm{g}$ discharged 1 day aged $200 \mathrm{mAh} / \mathrm{g}$ discharged 3 day aged - - - Undischarged 1 day aged - - - Undischarged 3 day aged (c) $0.35 \mathrm{M} \mathrm{Mg} \mathrm{-} \mathrm{1:2}$ $\mathrm{MgHMDS}_{2}: \mathrm{AlCl}_{3}$. (d) $0.5 \mathrm{M} \mathrm{Mg-FPB}$ in DEG. Insets are photos of selected solutions analyzed by UV/VIS, black material in the photos are the extracted cathodes. Inset (a) Top left $=0.05 \mathrm{M}$ Solution as prepared. Top right $=0.05 \mathrm{M}$ solution 3 day aged. Bottom left $=0.2 \mathrm{M}$ Solution as prepared. Bottom right $=0.05 \mathrm{M}$ solution 3 day aged. Inset $(\mathbf{b} / \mathbf{c})$ Top left $=200 \mathrm{mAh} / \mathrm{g}$ discharged immediate analysis. Top right $=$ Undischarged 1 day aged. Bottom = Reference solution for background subtraction. Inset (d) Top left =200 mAh/g discharge 1 day aged. Top right $=200 \mathrm{mAh} / \mathrm{g}$ discharge 3 day aged. Middle left $=$ Undischarged 1 day aged. Middle right $=$ Undischarged 3 day aged. Bottom $=$ Reference solution for background subtraction. 
Of all the responses, perhaps the most interesting is observed in Figure $4 \mathrm{~d}$ with the Mg-FPB electrolyte, where initially the formation of polysulfides is quite suppressed in both the discharged cells and those held at OCP. At some point between one and three days of aging, a dramatic increase in polysulfide concentration occurs. The absorbance patterns and total concentration of the three day aged $\mathrm{Mg}$-FPB samples are very similar to that of the five day aged, $200 \mathrm{mAh} / \mathrm{g}$ discharged $0.25 \mathrm{M} \mathrm{MgTFSI}_{2} 0.5$ $\mathrm{M} \mathrm{MgCl}_{2}$ electrolyte in Figure 1. This non-linear and dramatic change in the MgFPB solution holds particular importance for cycling this electrolyte, as the evolving cell chemistry would undoubtedly effect the cycling behavior. Depending on the conditions (i.e. cycling rate) the impacts of the changing solution chemistry could be varied and potentially misattributed to other processes in the cell. The non-linear effect of aging on cells using this electrolyte deserves further attention to fully understand.

Having identified self-discharge behavior in a diverse set of electrolytes, the impact of self-discharge on the electrochemical performance of Mg-S cells is examined next and is found to be severe. Fully charged Mg-S cells using two different electrolytes are allowed to age at OCP for 7 days, during which the potential across the cell decreases from the initial OCP (Figure S11). As can be seen in Figure 5, after aging the capacity delivered on the first cycle discharge is decreased significantly compared to pristine cells. After aging, the cells with either electrolyte require a period of activation wherein a massive overpotential for initiating the discharge redox chemistry must first be overcome. As observed previously, this is likely due to increased impedance at the $\mathrm{Mg}$ anode as a result of the formation of a passivation layer. ${ }^{14,15,18,28}$ Evidently, this passivation layer becomes breached after a period of time and the potential stabilizes.

Even though they have similar levels of self-discharge according to the UV/VIS data, the massive capacity fade and decrease of discharge potential of the $\mathrm{MgTFSI} / \mathrm{MgCl}_{2}$ electrolyte compared to the MgFPB hints at what may make for a better electrolyte. Being a complex electrolyte, perhaps the presence of polysulfides in the $\mathrm{MgTFSI}_{2} / \mathrm{MgCl}_{2}$ solution shifts the complex equilibria, resulting in fewer electrochemically active magnesium species. Additionally, the continued breakdown of chemically unstable $\mathrm{MgTFSI}^{+}$resulting in depletion of electrolyte salts over the aging period may be partly to blame for the poor performance. ${ }^{36}$ Finally, it is likely that much of the active material has precipitated by this time, rendering it inaccessible for discharge.

Even though the MgFPB electrolyte loses capacity and suffers a high initial overpotential as a result of self-discharge, after activation the 7 day aged MgFPB discharge profile more or less resembles that of the 1 hour aged. These results suggest that the shelf-life of Mg-S can be enhanced by using simple magnesium salts that are not susceptible to changes in chemical equilibria and that have good stability on the electrode surface.

\section{Conclusions}

Self-discharge of Mg-S cells was observed in every instance for a set of diverse electrolytes. Further, this process decreased cell capacity by $32 \%$ and $96 \%$ for $\mathrm{Mg}$-FPB and $\mathrm{MgTFSI}_{2} / \mathrm{MgCl}_{2}$ based electrolytes, respectively, after a 7 day OCP hold period. It is proposed that $S_{8}$ in the cell undergoes non-faradaic

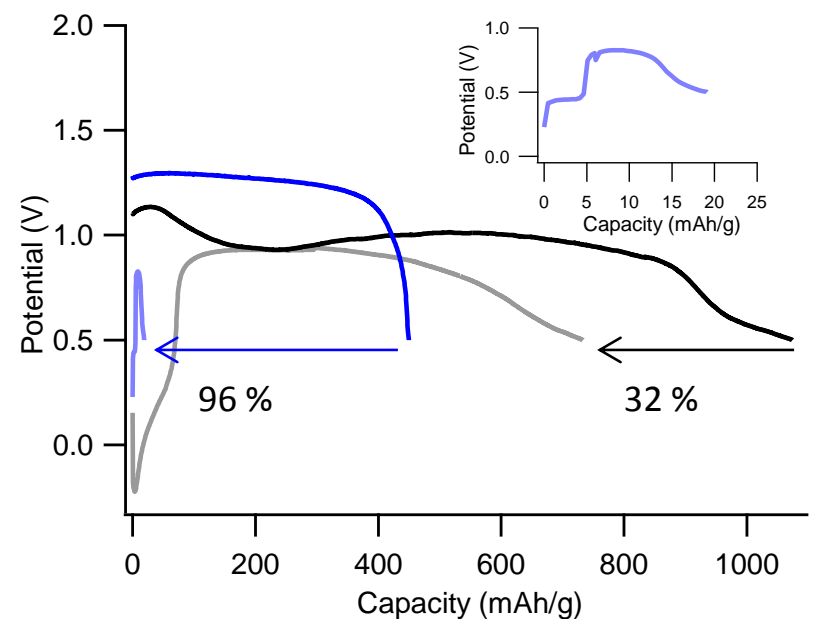

Fig. $51^{\text {st }}$ cycle discharge capacity for Mg-S cells at current rate of $0.1 \mathrm{C}$. 1 hour aged $0.5 \mathrm{M} \mathrm{Mg-FPB}$ in DEG. 7 day aged $0.5 \mathrm{M} \mathrm{Mg-FPB}$ in DEG .1 hour aged $0.25 \mathrm{M} \mathrm{MgTFSI}_{2}+0.5 \mathrm{M} \mathrm{MgCl}_{2}$ in DME. 7 day aged $0.25 \mathrm{M}$ $\mathrm{MgTFSI}_{2}+0.5 \mathrm{M} \mathrm{MgCl}_{2}$ in DME. Inset shows the 7 day aged $\mathrm{MgTFSI} / \mathrm{MgCl}_{2}$ potential curve, enlarged for clarity. 
reduction to ionic polysulfides at the $\mathrm{Mg}$ electrode surface, which then continue to chemically react and precipitate from solution. The active material precipitation is not spatially limited to the electrodes, taking place in the separator and bulk electrolyte as well, which has implications for cell capacity retention. The precipitation effect occurs at timescales relevant even to active discharge, making it a serious challenge to address. The apparent lack of any Mg-S electrolyte that prevents self-discharge is a clear call to researchers to continue electrolyte development and begin examining $\mathrm{Mg}$-S self-discharge. With the work presented herein we hope to offer the tools with which future electrolytes can be screened for self-discharge. Additionally, we believe our results prompt continued investigation in the following areas to address the self-discharge problem:

1. Electrolyte development. Electrolytes that limit (or eliminate) sulfur and polysulfide solubility should be investigated. If polysulfide solubility cannot be eliminated, the polysulfides should be stabilized by electrolyte or cathode additives/components to prevent active material precipitation and loss.

2. Engineered mass transport control. If eliminating sulfur and polysulfide solubility is unfeasible, preventing contact of $\mathrm{S}_{8}$ with the metal anode will prevent the first step of self-discharge. This may be accomplished with molecule selective membranes, an artificial $\mathrm{Mg}$ SEI, advanced cathode architectures, etc.

3. Complete mechanistic, kinetic, and chemical description of the discharge process, especially understanding and disrupting the non-faradaic $\mathrm{S}_{8}$-to-polysulfide reaction pathway. The importance of $\mathrm{Mg}$ surface species $\left(\mathrm{MgCl}_{2}, \mathrm{MgF}_{2}\right)$, various ions such as the role of chloride, solvent, etc. must be understood. Fundamental results from this thrust will influence the direction of points 1 and 2 .

\section{Conflicts of interest}

There are no conflicts to declare.

\section{Acknowledgements}

Funding for this work was received from from the National Science Foundation via award number CBET1706370 , for which the authors are greatly appreciative. HOF gratefully acknowledges The Society Of Schmitt Fellows, the Notre Dame CEST Predoctoral Fellowship, and the Patrick and Jana Eilers Fellowship for additional financial support.

The authors thank the Notre Dame Materials Characterization Facility for UV/VIS instrumentation, the Notre Dame Mass Spectroscopy and Proteomics Facility for UPLC-MS access and support, and the Notre Dame Integrated Imaging Facility for SEM imaging.

\section{Notes and references}

Substantial additional discussion can be found in the Supplementary Information

1 W. M. Haynes, in CRC Handbook of Chemistry and Physics, 97th edition, 2016, pp. 14-17.

2 H. S. Kim, T. S. Arthur, G. D. Allred, J. Zajicek, J. G. Newman, A. E. Rodnyansky, A. G. Oliver, W. C. Boggess and J. Muldoon, Nat. Commun., 2011, 2, 1-6.

3 P. Wang and M. R. Buchmeiser, Adv. Funct. Mater., 2019, 29, 1905248.

4 A. Manthiram, Y. Fu and Y. S. Su, Acc. Chem. Res., 2013, 46, 1125-1134.

5 Y. X. Yin, S. Xin, Y. G. Guo and L. J. Wan, Angew. Chemie - Int. Ed., 2013, 52, 13186-13200. 
J. Zhu, C. Chen, Y. Lu, J. Zang, M. Jiang, D. Kim and X. Zhang, Carbon., 2016, 101, 272-280.

H. S. Ryu, H. J. Ahn, K. W. Kim, J. H. Ahn, K. K. Cho and T. H. Nam, Electrochim. Acta, 2006, 52, 1563-1566. M. L. Gordin, F. Dai, S. Chen, T. Xu, J. Song, D. Tang, N. Azimi, Z. Zhang and D. Wang, ACS Appl. Mater. Interfaces, 2014, 6, 8006-8010.

M. Liu, Q. Li, X. Qin, G. Liang, W. Han, D. Zhou, Y. B. He, B. Li and F. Kang, Small, 2017, 13, 1602539. L. Wang, J. Liu, S. Yuan, Y. Wang and Y. Xia, Energy Environ. Sci., 2016, 9, 224-231.

H. S. Ryu, H. J. Ahn, K. W. Kim, J. H. Ahn, J. Y. Lee and E. J. Cairns, J. Power Sources, 2005, 140, 365-369. J. Q. Huang, T. Z. Zhuang, Q. Zhang, H. J. Peng, C. M. Chen and F. Wei, ACS Nano, 2015, 9, 3002-3011. W. T. Xu, H. J. Peng, J. Q. Huang, C. Z. Zhao, X. B. Cheng and Q. Zhang, ChemSusChem, 2015, 8, 2892-2901. B. P. Vinayan, H. Euchner, Z. Zhao-Karger, M. A. Cambaz, Z. Li, T. Diemant, R. J. Behm, A. Gross and M. Fichtner, J. Mater. Chem. A, 2019, 7, 25490-25502.

J. Häcker, C. Danner, B. Sievert, I. Biswas, Z. Zhao-Karger, N. Wagner and K. A. Friedrich, Electrochim. Acta, 2020, 338, 135787.

T. Gao, S. Hou, F. Wang, Z. Ma, X. Li, K. Xu and C. Wang, Angew. Chemie - Int. Ed., 2017, 56, 13526-13530. H. O. Ford, L. C. Merrill, P. He, S. P. Upadhyay and J. L. Schaefer, Macromolecules, 2018, 51, 8629-8636.

A. Robba, A. Vizintin, J. Bitenc, G. Mali, I. Arčon, M. Kavčič, M. Žitnik, K. Bučar, G. Aquilanti, C. MartineauCorcos, A. Randon-Vitanova and R. Dominko, Chem. Mater., 2017, 29, 9555-9564.

X. Ren, K. C. Lau, M. Yu, X. Bi, E. Kreidler, L. A. Curtiss and Y. Wu, ACS Appl. Mater. Interfaces, 2014, 6, 19299-19307.

Y. Bi, J. Luo, B. Hu, S. He, K. Nielson and T. L. Liu, ECS Trans., 2017, 80, 343-348.

P. He, H. O. Ford, L. C. Merrill and J. L. Schaefer, ACS Appl. Energy Mater., 2019, 2, 6800-6807.

T. Gao, X. Ji, S. Hou, X. Fan, X. Li, C. Yang, F. Han, F. Wang, J. Jiang, K. Xu and C. Wang, Adv. Mater., 2018, 30, 2-9.

M. U. M. Patel, R. Demir-Cakan, M. Morcrette, J. M. Tarascon, M. Gaberscek and R. Dominko, ChemSusChem, 2013, 6, 1177-1181.

N. Xu, T. Qian, X. Liu, J. Liu, Y. Chen and C. Yan, Nano Lett., 2017, 17, 538-543.

Q. Zou and Y. C. Lu, J. Phys. Chem. Lett., 2016, 7, 1518-1525.

G. Bieker, J. Wellmann, M. Kolek, K. Jalkanen, M. Winter and P. Bieker, Phys. Chem. Chem. Phys., 2017, 19, $11152-11162$.

G. Bieker, D. Diddens, M. Kolek, O. Borodin, M. Winter, P. Bieker and K. Jalkanen, J. Phys. Chem. C, 2018, 122, 21770-21783.

M. Salama, R. Attias, B. Hirsch, R. Yemini, Y. Gofer, M. Noked and D. Aurbach, ACS Appl. Mater. Interfaces, 2018, 10, 36910-36917.

Y. Xu, Y. Ye, S. Zhao, J. Feng, J. Li, H. Chen, A. Yang, F. Shi, L. Jia, Y. Wu, X. Yu, P. A. Glans-Suzuki, Y. Cui, J. Guo and Y. Zhang, Nano Lett., 2019, 19, 2928-2934.

D. Qu, D. Zheng, D. Qu, X. Q. Yang, X. Yu and H. S. Lee, Adv. Energy Mater., 2015, 5, 1401888.

Z. Zhao-Karger, X. Zhao, O. Fuhr and M. Fichtner, RSC Adv., 2013, 3, 16330-16335.

J. Luo, Y. Bi, L. Zhang, X. Zhang and T. L. Liu, Angew. Chemie - Int. Ed., 2019, 58, 6967-6971.

L. C. Merrill and J. L. Schaefer, Langmuir, 2017, 33, 9426-9433.

C. W. Lee, Q. Pang, S. Ha, L. Cheng, S. D. Han, K. R. Zavadil, K. G. Gallagher, L. F. Nazar and M. Balasubramanian, ACS Cent. Sci., 2017, 3, 605-613.

A. Gupta, A. Bhargav and A. Manthiram, Adv. Energy Mater., 2019, 9, 1803096.

N. N. Rajput, X. Qu, N. Sa, A. K. Burrell and K. A. Persson, J. Am. Chem. Soc., 2015, 137, 3411-3420. 


\title{
Supplementary Information
}

\section{Self Discharge of Magnesium-Sulfur Batteries Leads to Active Material Loss and Poor Shelf Life}

\author{
Hunter O. Ford ${ }^{a}$, Emily S. Doyle ${ }^{a}$, Peng He ${ }^{a}$, William C. Boggess ${ }^{b}$, Jennifer L. Schaefer, ${ }^{* a}$
}

a. Department of Chemical and Biomolecular Engineering, University of Notre Dame, Notre Dame, IN, USA. *Email: Jennifer.L.Schaefer.43@nd.edu

b. Department of Chemistry, University of Notre Dame, Notre Dame, IN, USA.

\section{Experimental}

Preparation of Electrolytes: $\mathrm{MgTFSI}_{2} / \mathrm{MgCl}_{2}$ in $\mathrm{DME}$. This synthesis was conducted within the glovebox unless noted otherwise. Magnesium bis(trifluoromethanesulfonimide) $\left(\mathrm{MgTFSI}_{2)}\right.$ (Solvionic) is dried at $200^{\circ} \mathrm{C}$ under vacuum on a Schlenk line, and then transferred to an argon filled glovebox. Within the glovebox, the $\mathrm{MgTFSI}_{2}$ is dissolved in 1,2-dimethoxyethane (DME, $99.5 \%$ inhibitor free, Aldrich) that had been stored on activated $3 \AA$ molecular sieves (Aldrich) for at least 3 days, to form either a $0.25 \mathrm{M}$ solution or $1 \mathrm{M}$ solution, depending on the concentration of the electrolyte. After dissolving the $\mathrm{MgTFSI}_{2}$, magnesium chloride $\left(\mathrm{MgCl}_{2}\right.$ ) beads (anhydrous, beads, $99.99 \%$ Aldrich) were added to the solution to yield either a $0.5 \mathrm{M}$ or $2 \mathrm{M} \mathrm{MgCl}_{2}\left(\mathrm{MgTFSI}_{2}: \mathrm{MgCl}_{2}\right.$ is $\left.1: 2\right)$. This procedure was completed according to the literature. ${ }^{1}$ The resulting solution was stirred until the $\mathrm{MgCl}_{2}$ had reacted and fully dissolved. The $\mathrm{MgTFSI}_{2} / \mathrm{MgCl}_{2} \mathrm{DME}$ solution is then stirred on molecular sieves for at least 24 hours prior to use.

$\mathrm{MgHMDS}_{2} / \mathrm{AlCl}_{3}$ in THF. This synthesis was conducted within the glovebox unless noted otherwise. Magnesium bis(hexamethyldisilazide) $\left(\mathrm{MgHMDS}_{2}\right.$ ) $(97 \%$, Aldrich) was recrystallized from heptane (anhydrous, $99 \%$, Aldrich) within an argon filled glovebox by adding to heptane, heating until dissolved, then cooling the heptane to precipitate crystallization. The $\mathrm{MgHMDS}_{2}$ was collected by filtration. For $2.5 \mathrm{~mL}$ scale, $0.302 \mathrm{~g}$ recrystallized $\mathrm{MgHMDS}_{2}$ were dissolved in $0.9 \mathrm{~mL}$ of tetrahydrofuran (THF, anhydrous, $99.9 \%$, inhibitor-free, Aldrich) that had been stored on activated $3 \AA$ molecular sieves for at least 3 days. $0.2335 \mathrm{~g}$ aluminum chloride $\left(\mathrm{AlCl}_{3}\right.$, anhydrous, $99.99 \%$, Aldrich) were dissolved in $1.9 \mathrm{~mL} \mathrm{THF}$ incrementally. The $\mathrm{AlCl}_{3}$ THF solution was added to the $\mathrm{MgHMDS}_{2}$ THF solution, and the resulting solution was stirred overnight to allow the formation of the active magnesium complex. This solution is $0.35 \mathrm{M}$ with respect to magnesium, with a $1: 2$ molar ratio $\mathrm{MgHMDS}_{2}: \mathrm{AlCl}_{3}$.

MgFPB in DEG. This synthesis was conducted according to the literature entirely within the glovebox unless noted otherwise. ${ }^{2}$ First, $100 \mathrm{~mL}$ of DME dried on sieves was stirred over Na metal. The DME and the metal surface turned orange, and the Na was cut to expose fresh $\mathrm{Na}$. This was repeated until the surface of the newly exposed $\mathrm{Na}$ did not change in appearance. The DME was then distilled under $\mathrm{N}_{2}$ using standard Schlenk techniques to avoid exposure to water and oxygen, yielding a clear colorless solvent. $2.81 \mathrm{~g}$ of hexafluoro-2,3-

bis(trifluoromethyl)-2,3-butanediol (hbtp, TCl, $98 \%$ ) were dissolved in $5 \mathrm{~mL}$ of the purified DME, liberating a small amount of vapor. Separately, $108 \mathrm{mg}$ of $\mathrm{MgBH}_{4}$ (95\%, Aldrich) were suspended in $20 \mathrm{~mL}$ of the purified DME. The $5 \mathrm{~mL}$ of hbtp solution were added slowly and dropwise to suspended $\mathrm{MgBH}_{4}$ in $\mathrm{DME}$, liberating $\mathrm{H}_{2}$. After stirring overnight, this colorless and slightly cloudy solution was transferred to the Schlenk line, and then concentrated to about $5 \mathrm{~mL}$ under vacuum. The concentrated solution was brought back into the glovebox, then charged with 30 $\mathrm{mL}$ of hexane (anhydrous, $99 \%$, Aldrich). The formation of two phases was noted, a viscous liquid phase about 4 $\mathrm{mL}$ at the bottom of the flask, and a top liquid phase. The top phase was removed, and the viscous phase was washed twice more with $10 \mathrm{~mL}$ of hexane. The viscous phase was dried under high-vacuum to yield a very fine 
white powder, the magnesium fluorinated pinacolatoborate (MgFPB) salt. This powder was then dried under dynamic vacuum overnight at room temperature.

For a $0.5 \mathrm{M}$ solution, $1.37 \mathrm{~g}$ of MgFPB were dissolved in $2 \mathrm{~mL}$ of diethylene glycol dimethyl ether (DEG, anhydrous, $99.5 \%$, Aldrich) that had been purified with sodium in the same way the DME above was purified, the only difference being that the DEG was distilled under vacuum instead of $\mathrm{N}_{2}$. The resulting solution was colorless and slightly cloudy. The MgFPB solution was charged with $100 \mathrm{mg}$ of magnesium powder (325 mesh, 99.8 \%, Alfa Aesar) then parafilmed and stirred in a $50{ }^{\circ} \mathrm{C}$ oil bath. After stirring for 24 hours, the solution was filtered, rendering it ready for use.

A.<smiles>[Z7]N([Si](C)(C)C)[Si](C)(C)N([Y10])[Si](C)(C)N([N+]([Z7])(C)C)[Si](C)(C)C</smiles>

B.

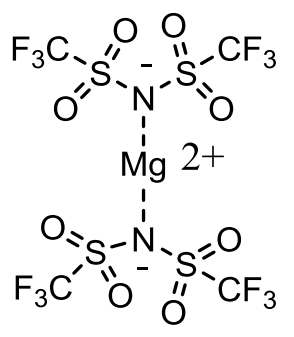

C.

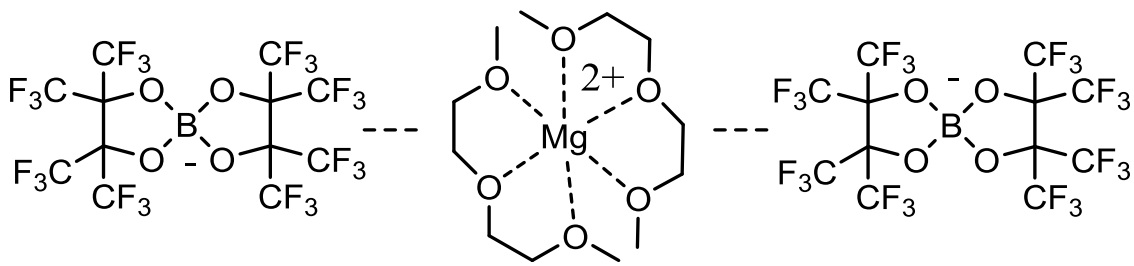

Figure S1. Chemical structures of electrolyte salts. A. MgHMDS 2 B. MgTFSI ${ }_{2}$ C. MgFPB $\bullet \mathrm{DME}_{2}$

\section{Synthesis of magnesium polysulfides}

The Mg polysulfide solution was prepared by mixing $\mathrm{Mg}$ powder and S powder ( $99.98 \%$, Aldrich) in the $0.25 \mathrm{M}$ $\mathrm{Mg}(\mathrm{TFSI})_{2} 0.5 \mathrm{M} \mathrm{MgCl}_{2}$ DME electrolyte that had been stored on sieves. The electrolyte was filtered before use. The Mg powder (2 mg), S powder (16 mg) and electrolyte $(2 \mathrm{~mL}$ ) were added into a $20 \mathrm{~mL}$ vial with a small stir bar. The mixture was stirred for $2 \mathrm{~h}$ under room temperature until the solution turned light orange. After that, the vial was sealed with Teflon tape and parafilm. The solution was stirred overnight at $50^{\circ} \mathrm{C}$, deepening in color. After filtration, the magnesium polysulfide solution was ready for analysis. The nominally $0.2 \mathrm{M}$ (in terms of atomic S) solution is synthesized first, from which the $0.05 \mathrm{M}$ solution is produced via dilution with additional electrolyte.

\section{Electrochemical measurements}

$\mathrm{Mg}$-S cathodes were prepared by punching activated carbon cloth (FM100, double-weave, Charcoal House) into $3 / 8^{\prime \prime}$ diameter disks. Inside an argon filled glovebox, $0.76 \mathrm{mg}$ of $\mathrm{S}$ was added to each carbon disk to yield $1 \mathrm{mg}$ $\mathrm{S} / \mathrm{cm}^{2}$. This was accomplished by dissolving the appropriate amount of sulfur in sieve-dried THF, then adding 60 $\mu \mathrm{L}$ of this solution to the cathode in $15 \mu \mathrm{L}$ increments, $30 \mu \mathrm{L}$ on each side. The THF was evaporated by allowing the cathodes to sit in the open atmosphere of the glovebox. Then, the cathodes were loaded into a Chemglass glass pressure vessel, sealed, then heated at $155^{\circ} \mathrm{C}$ for 12 hours within the glovebox oven to melt infuse the sulfur into the carbon cloth yielding ACC-S. 
Magnesium metal (99.9\%, $0.1 \mathrm{~mm}$ thick, MTI corp.) was punched into disks, from which the oxide layer was removed via scraping. 2032 type coin cells were assembled with Mg anode, separator, ACC-S housed in a Teflon spacer (1/32" thick, McMaster Carr), $160 \mu \mathrm{L}$ of electrolyte added to the ACC-S, stainless steel spacers, wave spring. All cells used one 3/4" diameter Celgard 2325 separator unless otherwise noted. Cells with the $1 \mathrm{M}$ $\mathrm{MgTFSI}_{2} 2 \mathrm{M} \mathrm{MgCl}_{2}$ DME electrolyte which used one 3/4" diameter glass fiber separator $\left(200^{\circ} \mathrm{C}\right.$ vacuum dried, Whatman) as this electrolyte does not wet Celgard.

Assembled cells were rested for an appropriate amount of time (cells that were not aged for a time specified in the manuscript were rested for 1 hour) then discharged at a rate of $0.1 \mathrm{C}$ with respect to sulfur loading using a Neware Battery Tester unless otherwise noted. Discharge was controlled on the basis of potential or capacity, as appropriate.

Lithium-sulfur cells for mass spectrometry technique validation were prepared as follows. Sulfur powder and disordered mesoporous carbon (ACS material, surface area $600 \mathrm{~m}^{2} / \mathrm{g}$ ) were combined in an 80:20 sulfur:carbon mixture, thoroughly ground together with mortar and pestle, loaded into a sealed glass pressure vessel and heated at $155^{\circ} \mathrm{C}$ for 12 hours within the glovebox oven. This resulting S/DMC, super P conductive carbon (MTI corp.), and polyvinylidene fluoride (Arkema) were combined in an 80:10:10 ratio with $n$-methylpyrrolidone (NMP) and stirred for 24 hours. The resulting slurry was cast on carbon coated aluminum (MTI corp.) using a doctor blade, which was then dried at $55^{\circ} \mathrm{C}$ for 12 hours. Cathodes were punched from this material in $3 / 8^{\prime \prime}$ diameter, with loadings of $1.1-1.5 \mathrm{mg} \mathrm{S} / \mathrm{cm}^{2}$. Lithium foil (Alfa Aesar, $0.75 \mathrm{~mm}$ thick, $99.9 \%$ ) was polished to a reflective shine by removing the oxide layer, then cut into $3 / 8^{\prime \prime}$ diameter electrodes. Cells were assembled with the cathode, Celgard 2325 separator, and Li anode. Electrolyte, $1 \mathrm{M} \mathrm{LiTFSI} \mathrm{(TCI,} \mathrm{>98.0 \% ,} \mathrm{dried} \mathrm{in} \mathrm{dynamic} \mathrm{vacuum} 120$ ${ }^{\circ} \mathrm{C}$ for 12 hours) dissolved in sieve dried 1,3-dioxolane (DOL):DME 1:1 v/v, was restricted to $20 \mu \mathrm{L}$ electrolyte / mg sulfur and was added to the cell during assembly. Cells were rested for 1 hour then discharged to $2.2 \mathrm{~V}$. Cells were derivatized for UPLC-MS in the same way as Mg-S cells.

Cyclic voltammetry was carried out using a PARSTAT MC-1000 potentiostat/galvanostat (Princeton Applied Research), where the magnesium electrochemistry of the various electrolytes was evaluated within 2032 coin cells using a magnesium counter/reference electrode and stainless steel working electrode. The potential was swept at a rate of $10 \mathrm{mV} / \mathrm{s}$.

\section{Preparation of UV/VIS samples}

Coin cells that had been discharged and aged or aged at OCP as appropriate were opened within the glovebox, and the cathodes were recovered and placed into $400 \mu \mathrm{L}$ of sieve-dried THF for 5 minutes. The resulting solution was collected, filtered through $0.45 \mu \mathrm{m}$ syringe filters, and added to $1 \mathrm{~mm}$ path-length quartz cuvettes (Type 30 Standard Micro Cuvette with PTFE stopper, Firefly Sciences). The reference/background solution for each electrolyte type was prepared by assembling a full $\mathrm{Mg}$-S cell using that electrolyte, resting it for one hour plus the total amount of time required to discharge an identical cell to $200 \mathrm{mAh} / \mathrm{g}$ (about 2 additional hours), then preparing it as described above. This ensures that the background subtraction solution contains the same concentration of solvent and salts as the sample solutions being analyzed. Therefore everything observed in the UV/VIS spectrum is a result of a chemical/electrochemical reaction. The reference for the synthesized $\mathrm{Mg}$ polysulfides is the electrolyte, $0.25 \mathrm{M} \mathrm{MgTFSI}_{2} 0.5 \mathrm{M} \mathrm{MgCl}_{2}$ in DME. The cuvettes are sealed within the glovebox, and then analyzed using a Jasco V-670 UV-Visible-Near IR Spectrometer from $200 \mathrm{~cm}^{1}$ to $650 \mathrm{~cm}^{-1}$.

\section{Preparation of ultra performance liquid chromatography - mass spectroscopy (UPLC-MS) samples}

Samples for UPLC-MS were prepared similarly to the sample preparation for the UV/VIS samples. In a typical analysis, a coin was opened within the glovebox, with the cathode and separator recovered and added to $400 \mu \mathrm{L}$ 
of sieve-dried DME for 30 seconds. The DME was removed then replaced with fresh DME twice. The cathode and separator were then transferred to a solution of $5 \mathrm{mg}$ of 4-(dimethylamino)benzoyl chloride (DBC) (>99.0\%, for HPLC derivatization, Aldrich) suspended in $100 \mu \mathrm{L}$ of sieve dried DME. The DBC quickly reacts with solid (poly)sulfides in the cathode and separator, yielding a clear yellow solution (Figure S20). After 5 min, this solution was removed from the glovebox, and charged with $200 \mu \mathrm{L}$ of $66: 34$ by vol acetonitrile (ACN) : water (both HPLC grade) both with $1 \mathrm{mM}$ ammonium acetate. After filtration, the clear slightly-yellow solution was analyzed with UPLC-MS. If no polysulfides were present in the cathode, the solution remained colorless and the DBC did not dissolve until the addition of the ACN:water.

A Waters Acquity UPLC system consisting of a sample manager and binary solvent manager was used to inject 20 microliters of sample with water:ACN 90:10 v/v $1 \mathrm{mM}$ ammonium acetate onto a Waters Acquity UPLC BEH C18 column $(1.7 \mathrm{um}, 2.1 \times 100 \mathrm{~mm})$ at a flow rate of $0.4 \mathrm{~mL} / \mathrm{min}$. Column temperature was maintained at $40{ }^{\circ} \mathrm{C}$. During the 20 min operation, the gradient used is as follows: $90 \%$ water $10 \%$ acetonitrile for 2 minutes, then gradient transition to $100 \%$ ACN by 19 minutes, after which there's a gradient transition back to the 90:10 water:ACN ending at 20 minutes. A t-split was used to deliver $50 \%$ flow from the column to the mass spectrometer.

For MS detection, a Waters Acquity TQD Triple Quadrupole was operated in ESI+ mode with the following parameters: Capillary $3.2 \mathrm{kV}$, Cone $15 \mathrm{~V}$, Extractor $3 \mathrm{~V}$, RF lens $0.1 \mathrm{~V}$, Source temp $150{ }^{\circ} \mathrm{C}$, Desolvation temp 350 ${ }^{\circ} \mathrm{C}$. Nitrogen flow is $650 \mathrm{~L} / \mathrm{hr}$ for desolvation, $50 \mathrm{~L} / \mathrm{hr}$ for cone. From the mass spectrum, the masses corresponding to the di-functionalized polysulfides (refer to scheme 1) were detected as a function of retention time. All of the parameters were chosen to maximize analyte signal. Using the Acquity software, the area under the peaks associated with each polysulfide was integrated and recorded. By summing these areas (multiplied by the number of sulfur atoms present in each species) the total ionic sulfur on the basis of sulfur atoms was calculated.

Error was calculated in the following way. Firstly, sets of samples were prepared in triplicate, one set containing a large amounts of solid ionic polysulfides and one containing amounts near the instrument detection limit. From the quantitative results for total sulfur content in these samples, relative standard deviations were calculated and appropriately applied to the data shown in Figure 3 and Figure S13. Additionally, error from noise and nonanalyte ions of matching $\mathrm{m} / \mathrm{z}$ was calculated by obtaining the area in the chromatogram to either side of the analyte peak, over a period of total integration that matches the analyte peak. For example, if the analyte peak was centered at $2.0 \mathrm{~min}$ and was $0.5 \mathrm{~min}$ wide, the area from $1.5 \mathrm{~min}$ to $1.75 \mathrm{~min}$ was summed with the area from $2.25 \mathrm{~min}$ to $2.5 \mathrm{~min}$ and applied as additional error to the result.

\section{SEM-EDX}

Samples were sealed inside a vacuum transfer chamber (PELCO SEM Pin Stub Vacuum Desiccator) for transfer to the SEM facility. Conductive samples were transferred directly from the vacuum chamber into the SEM (Magellan 400 XHR FESEM, equipped with an Everhart-Thornley SE detector and Bruker EDX spectrometer). Non-conductive samples were sputter coated with $2 \mathrm{~nm}$ of iridium using a 208HR High Resolution Sputter Coater (Ted Pella Inc.), then transferred into the SEM. All care to minimize sample exposure to air was taken, but it was impossible to completely avoid air exposure. Samples were analyzed at a working depth of $5 \mathrm{~mm}$, with an operating voltage of $10 \mathrm{kV}$ and current density of $1.6 \mathrm{nA}$.

\section{Further Supporting Figures}



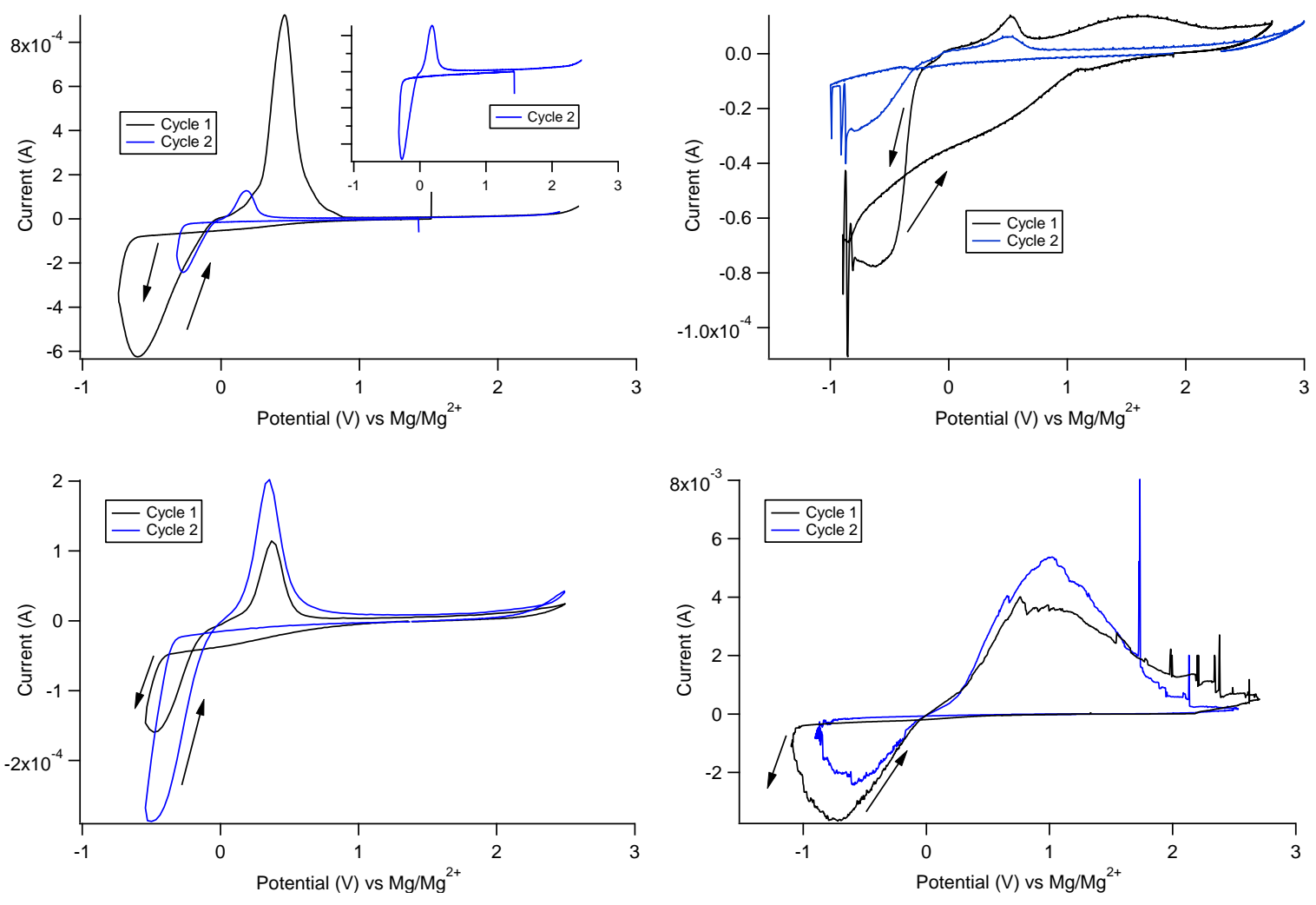

Figure S2. CVs for the four different magnesium electrolytes used in this study. Top left: $0.25 \mathrm{M} \mathrm{MgTFSI}_{2} 0.5 \mathrm{M}$ $\mathrm{MgCl}_{2}$ in DME. Top right: $1 \mathrm{M} \mathrm{MgTFSI}_{2} 2 \mathrm{M} \mathrm{MgCl}_{2}$ in DME. Bottom left: $\mathrm{MgHMDS}_{2} \mathrm{AlCl}_{3}$ in THF. Bottom right: 0.5 $\mathrm{M} \mathrm{MgFPB}$ in DEG. CVs are done in two electrode configuration coin cells, using $100 \mu \mathrm{L}$ of un-conditioned electrolyte, magnesium counter/reference and stainless steel working electrodes at a rate of $10 \mathrm{mV} / \mathrm{s}$.

Figure S2 shows CVs on the studied electrolytes. The overall efficiency and the deposition/stripping overpotential differs for each electrolyte, with each electrolyte showing changes in these parameters from cycle 1 to cycle 2. Of note is that the current density of the MgFPB electrolyte is about an order of magnitude higher than that of the other three electrolytes, the reason for which is unknown at this time. The figures above show each electrolyte, while perhaps not the most efficient, is at least capable of magnesium electrochemistry.

\section{Additional SEM-EDX images}

Figures S3, S4, S5, S5, and S6 contain additional SEM-EDX images of deposits found on the separator and cathode of an Mg-S cell with a $0.25 \mathrm{M} \mathrm{MgTFSI}_{2} 0.5 \mathrm{M} \mathrm{MgCl}_{2}$ DME electrolyte, discharged to $200 \mathrm{mAh} / \mathrm{g}$, then aged 7 days. Figure $\mathrm{S} 6$ shows how the morphology and elemental composition of the electrolyte salts differ from that of the deposits observed in Figure 3 and Figures S3, S4, and S5. The lack of $\mathrm{Cl}, \mathrm{F}$, and $\mathrm{N}$ and difference of structure in Figure 3 and Figures S3, S4, and S5 compared to S6 indicate the deposits observed are not simply deposits of electrolyte salts. 


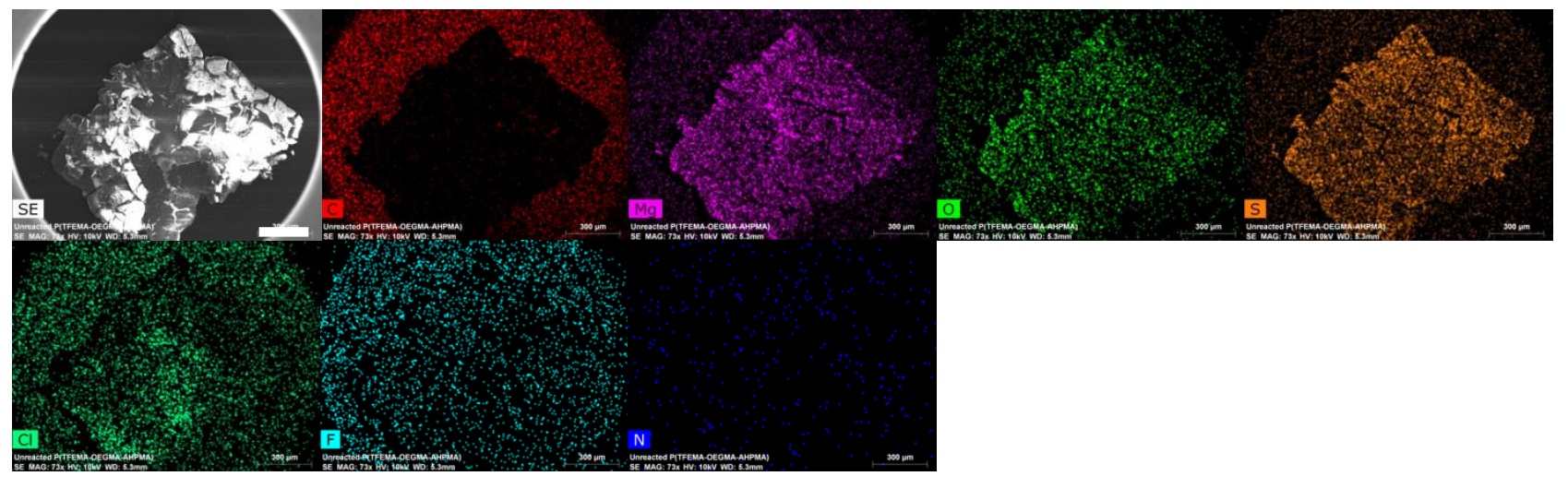

Figure S3. Reproduction of Figure 3 from the main text but with additional elements as detected by EDX (Cl, F, N). Scale bar is $300 \mu \mathrm{m}$

\begin{tabular}{rr} 
Element & [norm. at.\%] \\
\hline Oxygen & 35.91876 \\
Magnesium & 22.90417 \\
Sulfur & 41.17707
\end{tabular}

Table S1. Normalized atom percentages of $\mathrm{Mg}$, $\mathrm{O}$, and $\mathrm{S}$ for deposit shown in Figure $\mathrm{S} 3$. Remaining \% is $\mathrm{C}$ and $\mathrm{Cl}$.

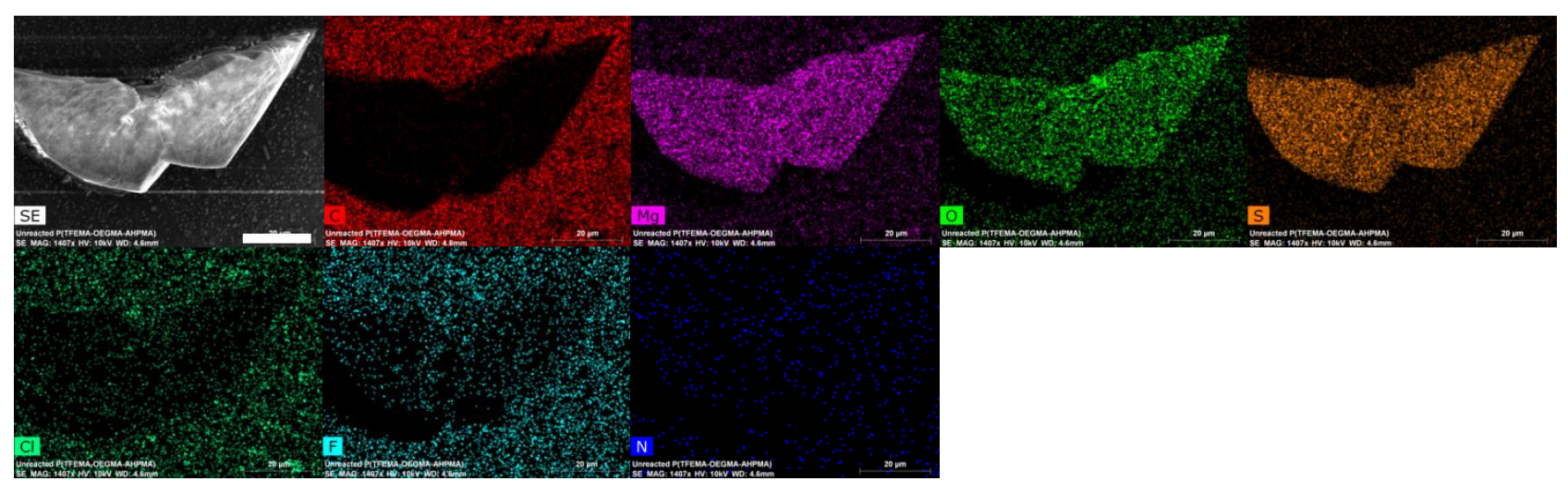

Figure S4. Another deposit on the separator that is primarily Mg, S, O. Scale bar is $20 \mu \mathrm{m}$. 


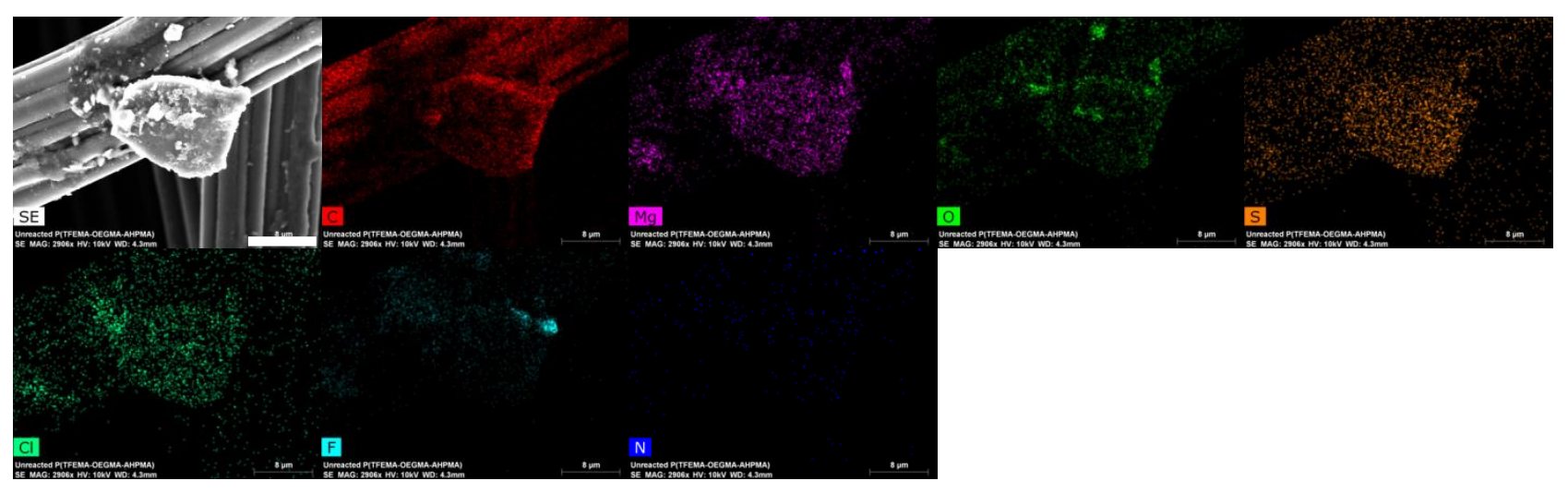

Figure S5. A deposit on the ACC-S cathode that is primarily $\mathrm{Mg}, \mathrm{S}, \mathrm{O}$, with some $\mathrm{C}, \mathrm{Cl}, \mathrm{F}$, and a small amount of $\mathrm{N}$. Scale bar is $8 \mu \mathrm{m}$.

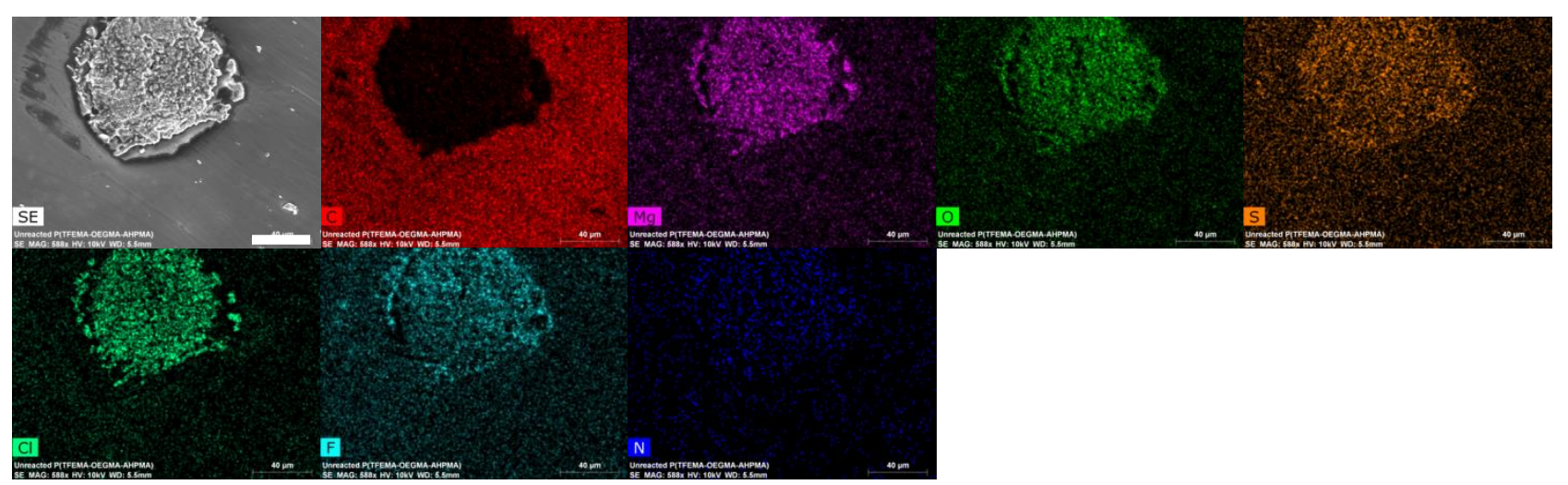

Figure S6. Deposit on separator that is a combination of the electrolyte salts $\mathrm{MgTFSI}_{2}$ and $\mathrm{MgCl}_{2}$ according to the elemental mapping. Scale bar is $40 \mu \mathrm{m}$.

Further Electrochemical Data - Discharge Potential Curves 


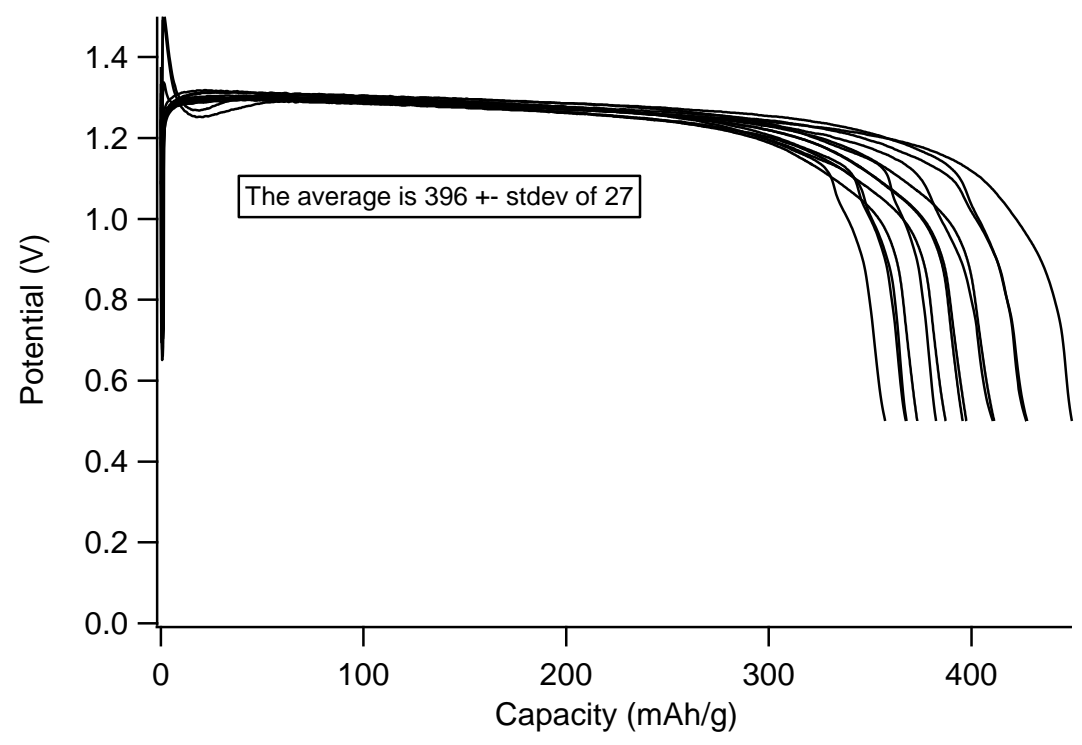

Figure S7. Discharge profiles of all cells used in this study that were $0.25 \mathrm{M} \mathrm{MgTFSI}_{2} 0.5 \mathrm{M} \mathrm{MgCl}_{2}$ in DME, that were discharged to a cutoff potential of $0.5 \mathrm{~V}$. The average capacity, $396 \mathrm{mAh} / \mathrm{g}$, was used to calculate $\mathrm{SOC}$ for all cells in the manuscript, where $50 \% \mathrm{SOC}=200 \mathrm{mAh} / \mathrm{g}$, etc. The plateau voltage is highly consistent, while the capacity varies slightly cell to cell.

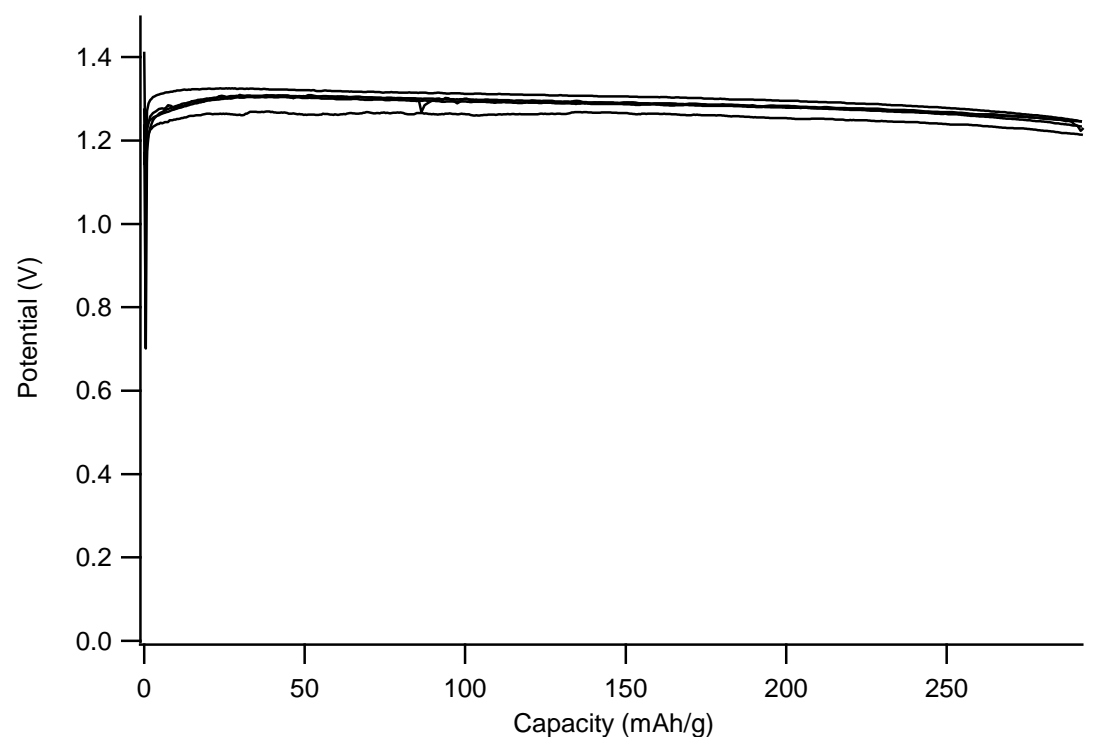

Figure S8. Discharge profiles of all cells used in this study that were $0.25 \mathrm{M} \mathrm{MgTFSI}_{2} 0.5 \mathrm{M} \mathrm{MgCl}_{2}$ in DME, that were discharged to $300 \mathrm{mAh} / \mathrm{g}$ for use in the UPLC-MS experiment. The plateau voltage is highly consistent. 


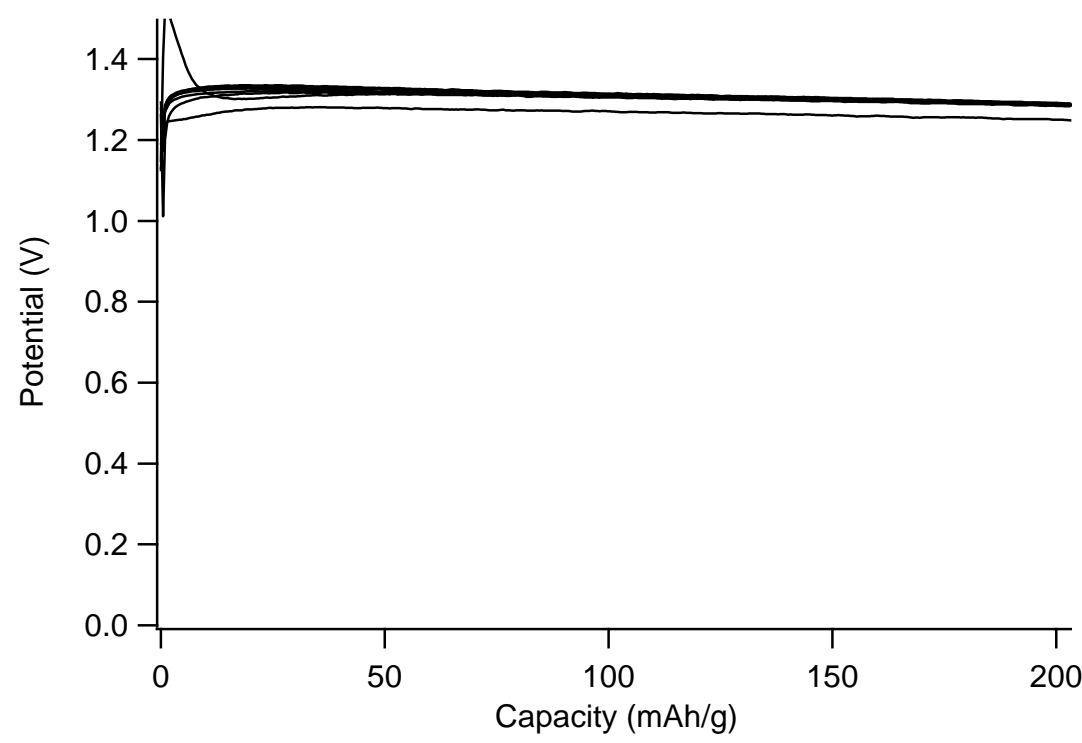

Figure S9. Discharge profiles of all cells used in this study that were $0.25 \mathrm{M} \mathrm{MgTFSI}_{2} 0.5 \mathrm{M} \mathrm{MgCl}_{2}$ in DME, that were discharged to $200 \mathrm{mAh} / \mathrm{g}$ for use in the UPLC-MS experiment and UV/VIS experiment. The plateau voltage is highly consistent.

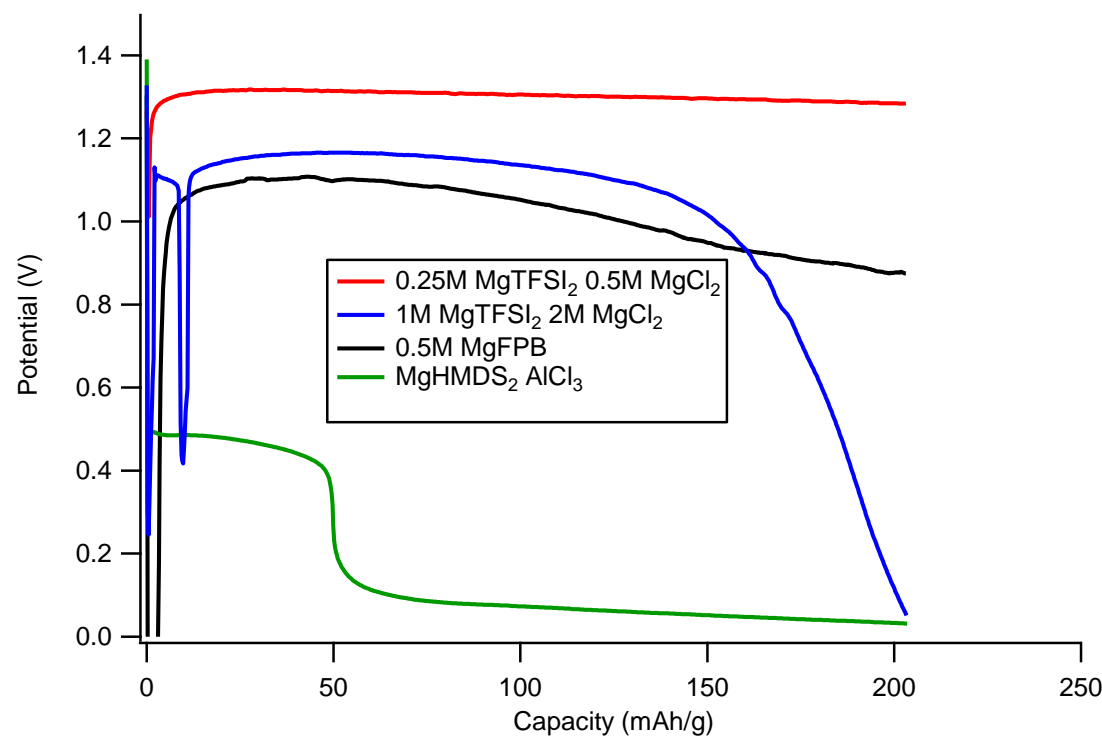

Figure S10. Representative discharge profiles for the different $\mathrm{Mg}$ electrolytes for cells discharged to $200 \mathrm{mAh} / \mathrm{g}$ at a rate of $0.1 \mathrm{C}$. 


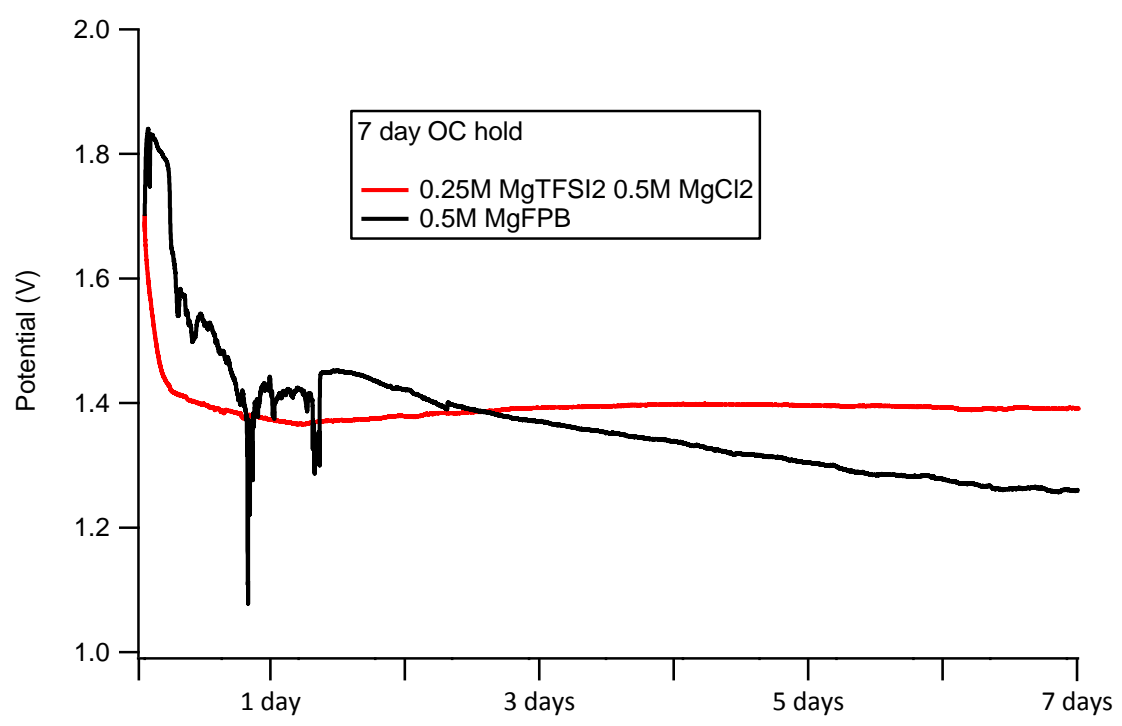

Figure S11. Open circuit potential of Mg-S cells held for 7 days prior to discharge.

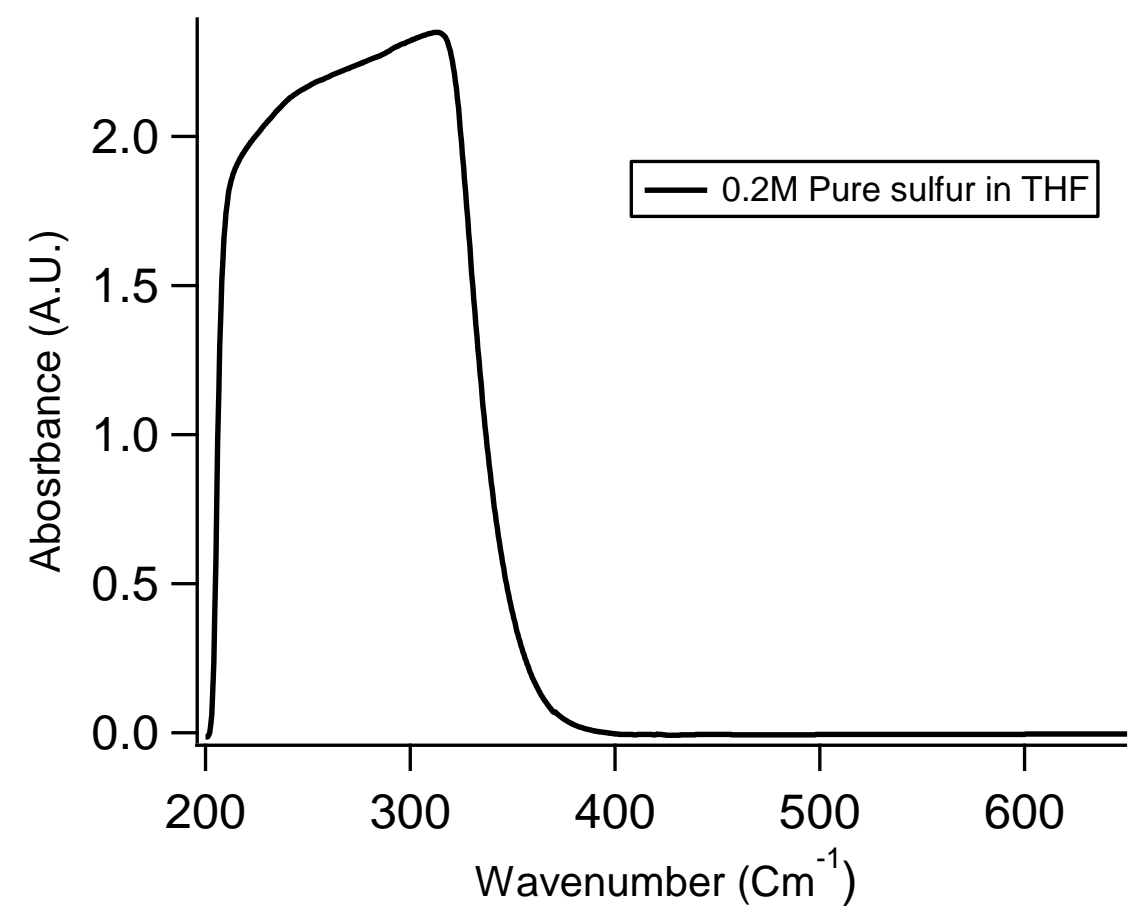

Figure S12. UV/VIS absorbance of a $0.2 \mathrm{M}$ solution of $\mathrm{S}_{8}$ dissolved in sieves-dried THF (reference $=$ pure THF).

The solution of synthesized Mg-PS shown in the main text Figure 4a also contains dissolved, unreacted $\mathrm{S}_{8}$. The presence of the polysulfides and the elevated synthesis temperature increases the solubility of $S_{8}$ (even after cooling), which is why $\mathrm{S}_{8}$ is seen in the spectrum. The background subtraction used for Figure $4 a$ is just the electrolyte (0.25M MgTFSI $20.5 \mathrm{M} \mathrm{MgCl}_{2}$ in DME) which contains no $\mathrm{S}_{8}$. Figure $\mathrm{S} 12$ shows the absorbance pattern of pure $S_{8}$ dissolved in THF. Some of the absorbance bands $\left(220 \mathrm{~cm}^{-1}, 250 \mathrm{~cm}^{-1}, 320 \mathrm{~cm}^{-1}\right)$ are not unique to $S_{8}$; they are also exhibited by polysulfides. The unique feature of $\mathrm{S}_{8}$ is the "blockiness" of the spectra, for lack of a 
better word, i.e. how it absorbs strongly and almost uniformly over the whole $200-320 \mathrm{~cm}^{-1}$ range. This peak characteristic is visible in Figure 4 a because the $S_{8}$ contribution is not subtracted from Figure 4a. This feature is not visible in Figure $4 b, c$, and $d$ because the $S_{8}$ is effectively subtracted because of how those background solutions were made. The peak at $380 \mathrm{~cm}^{-1}$ observed in Figure $4 a$ is well described as $\mathrm{S}_{4}^{-2}$ by the literature, demonstrating these solutions do indeed contain synthesized Mg-PS. ${ }^{3,4}$ The synthesis of the Mg-PS is further validated using the UPLC-MS method described in the main text, with the results shown in Figure S23.

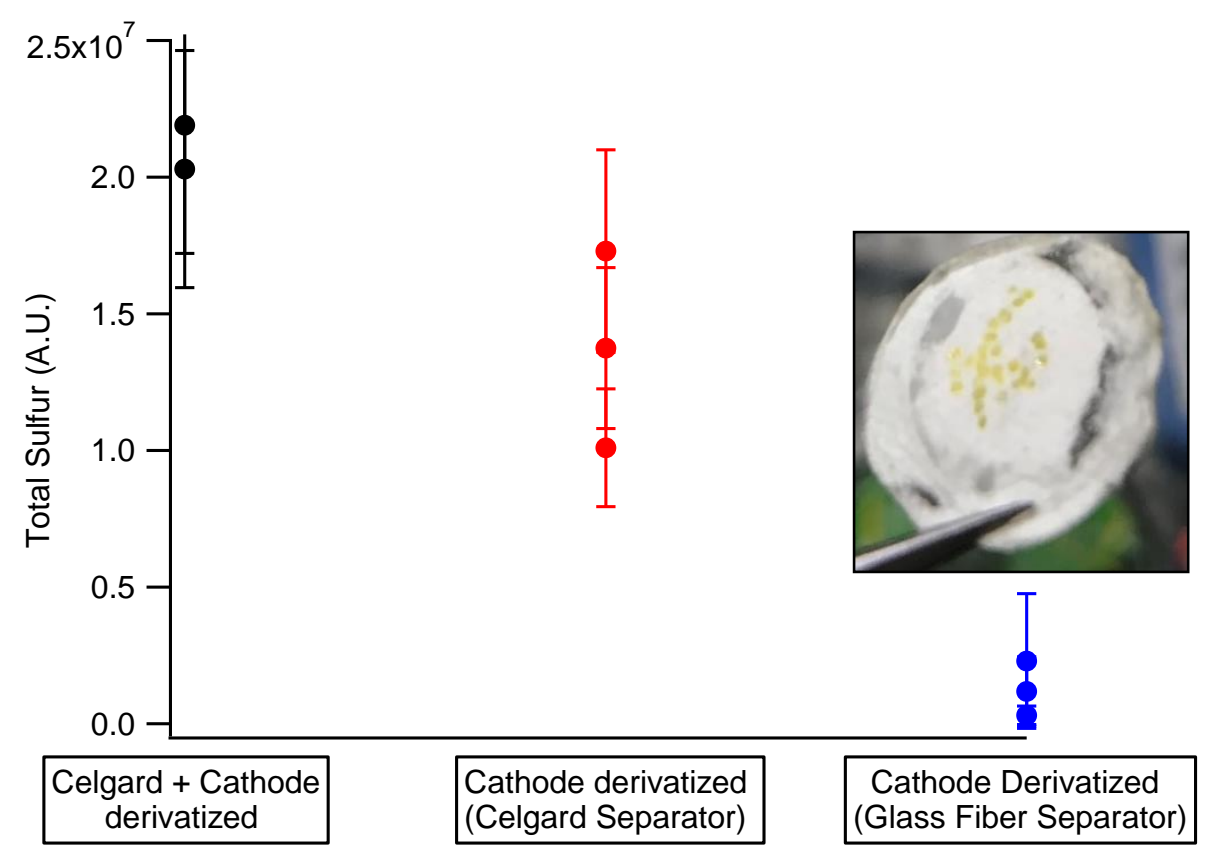

Figure S13. Total solid ionic sulfur quantified by UPLC-MS method for different cell components, either both the separator and cathode or just the cathode. Cells are full Mg-S cells using the $0.25 \mathrm{M} \mathrm{MgTFSI}_{2} 0.5 \mathrm{M} \mathrm{MgCl}_{2}$ in DME electrolyte discharged to $0.5 \mathrm{~V}$ (396 mAh/g on average). Inset photo shows a glass fiber separator recovered from a discharged cell. 


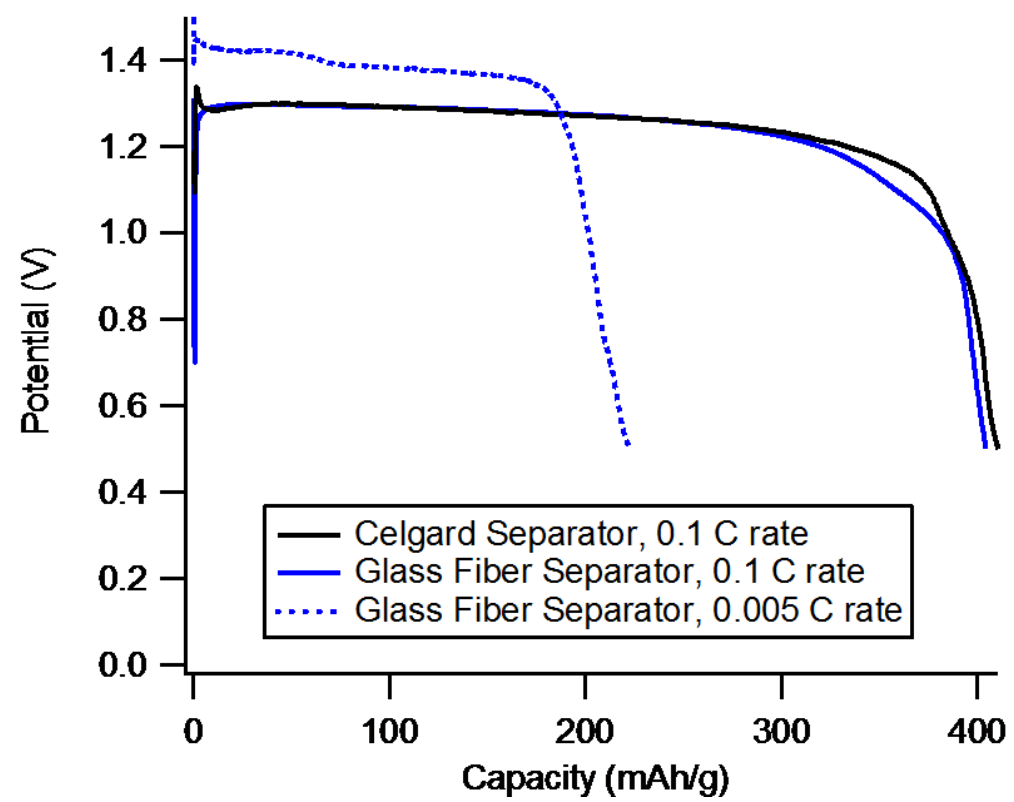

Figure S14. $1^{\text {st }}$ cycle discharge profiles for various Mg-S cells using the $0.25 \mathrm{M} \mathrm{MgTFSI}_{2} 0.5 \mathrm{M} \mathrm{MgCl}_{2}$ in DME electrolyte.

Figures S13 and S14 demonstrate that the chemical precipitation of polysulfides, the second aspect of selfdischarge, happens on time-scales relevant to active cell discharge. Figure S13 shows that the amount of solid ionic sulfur in the cathode measured by the UPLC-MS method differs depending on what separator is used. In the case of cells using Celgard, roughly half of the solid (poly)sulfides precipitate on the cathode, and half in the Celgard separator. In the case of cells that use glass fiber, the amount of solids detected on the cathode is greatly decreased, implying large precipitation within the separator. These deposits are in fact seen easily in the inset photo shown in the inset of Figure S13. However, because the potential profiles of the cells using the two types of separators are nearly identical at $0.1 \mathrm{C}$ (Figure S14), in both cases the same amount of sulfur is electrochemically accessible.

So why does one case result in a large amount of solid sulfur precipitates on the cathode, while the other does not? The two separators are quite different in size and porosity (Celgard is $25 \mu \mathrm{m}$ thick and microporous, glass fiber is $200 \mu \mathrm{m}$ thick and macroporous) meaning the proportion of electrolyte absorbed by each separator is different. As both cells use $160 \mu \mathrm{L}$ of electrolyte, the higher volume glass fiber separator will absorb more of the electrolyte, meaning there is less in direct contact with the cathode.

Combining the facts that the spatial location of the (poly)sulfide deposits can be changed by changing the electrolyte distribution in the cell (i.e. changing the separator), and that changing this distribution does not impact the electrochemical capacity delivered by the cell, a major amount of the solid ionic (poly)sulfides formed as the cell discharges come not from electrochemical reduction, but from the chemical precipitation process. The chemical precipitation process results in a major non-faradaic loss of active material as the cell discharges. Even when the precipitation happens in the cathode region and not in the separator, the precipitates do not have good electronic contact and therefore are electronically inaccessible.

The cells run at $0.1 \mathrm{C}$ take just over two hours to fully discharge to $0.5 \mathrm{~V}$, which means the kinetics of the precipitation process must be fast. Even more so because the precipitation process is not yet highly active when the cell has been discharged to $200 \mathrm{mAh} / \mathrm{g}$ (half-way) as seen in Figure 3. Likely, once the average chain length of polysulfides in solution is sufficiently lowered (by combination of non-faradaic reduction at the anode and faradaic reduction at the cathode), the precipitation process ensues rapidly. In theory then, if the cell is 
discharged faster, more sulfur should be accessible electrochemically before it precipitates. Conversely, if the cell is discharged more slowly, more sulfur is lost due to chemical precipitation and the discharge capacity will be lowered. This is exactly the case, as can be seen in the $0.005 \mathrm{C}$ rate cell shown in Figure S14. In this cell, the discharge is so slow that essentially only the capacity associated with converting covalent $S_{8}$ to $S_{8}{ }^{2-}$ is accessed; all the produced $\mathrm{S}_{8}{ }^{2-}$ diffuses from the cathode where it can be reduced via the non-faradaic process at the anode until it precipitates, rendering it inaccessible.

These results drive home the importance of considering the precipitation aspect of the self-discharge pathway. Without addressing this phenomenon, after one cycle most of the cell active material will be lost. Future work should involve looking at published Mg-S literature that demonstrates good capacity retention with cycling, and interpreting those results within this framework and specifically asking the question: What about the cell design, electrolyte, cathode, etc. prevents the loss of active material via the precipitation route? An answer to this question will point the way towards highly reversible, and therefore practical, Mg-S batteries.

\section{Further discussion of the UPLC-MS - Method development}

This section contains a more detailed description of the UPLC-MS technique. The chemistry of functionalization is presented in Scheme S1. Ionic polysulfides are converted to organic polysulfides, which due to the dimethylamino aromatic components have good affinity with the UPLC column. This allows for the separation of the organic polysulfides on the basis of molecular weight, with a logarithmic relationship between retention time and number of sulfur atoms in the compound. ${ }^{5}$ Clear separation of the compounds on the basis of the number of sulfur atoms they contain allows for accurate quantification of each compound.

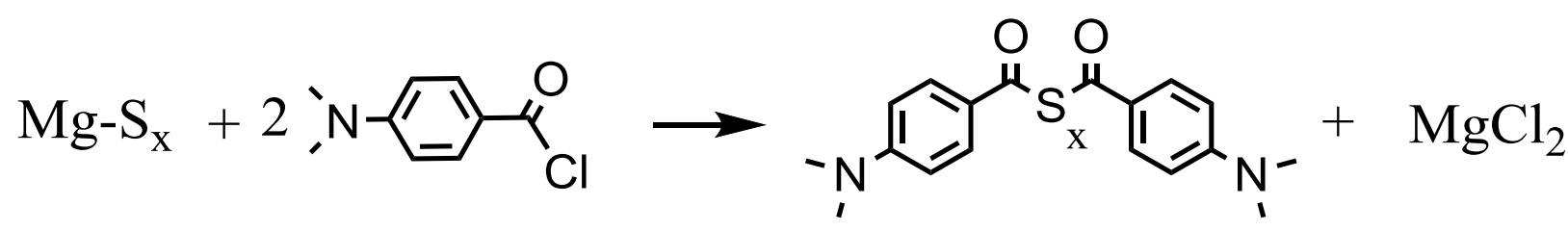

Scheme S1. Derivatization reaction of magnesium polysulfides.

A representative chromatogram is presented below in Figure S15. The logarithmic relationship between the number of sulfur atoms per each compound and retention time is clearly present. The total sulfur content of the cell is found by integrating the area under the appropriate peaks (denoted with *), multiplying by the number of sulfur atoms in that specific compound, and summing the results. 


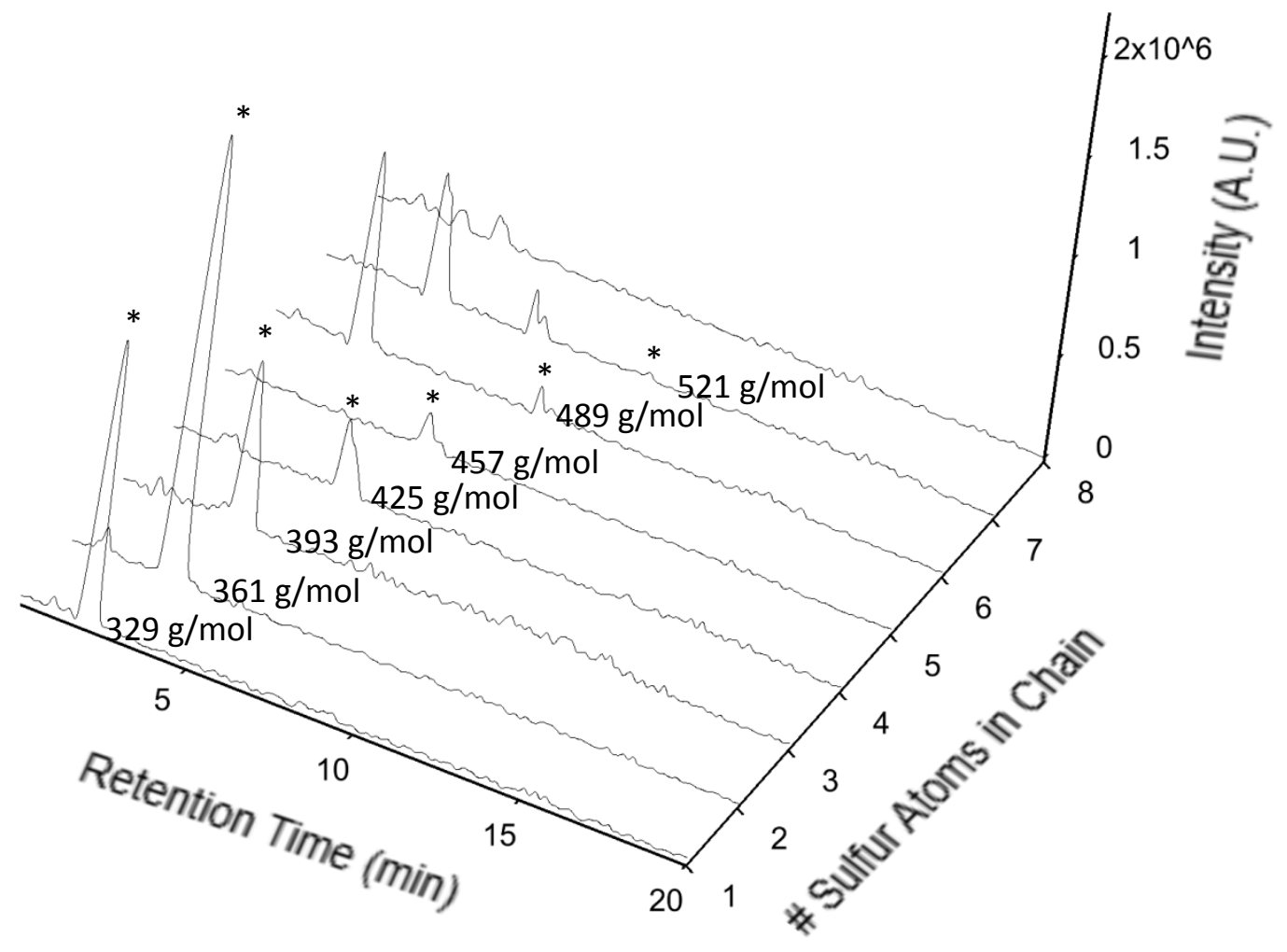

Figure S15. Mass specific chromatograms of a derivatized Mg-S cell (200 mAh/g discharged, no rest, sample \#1). Peaks corresponding to the derivatized compounds marked with *.

The peaks are correctly identified as the proposed compound on the basis of isotope pattern, an example of which is shown in Figure S16 for D-S1-D-H+ $(329 \mathrm{~g} / \mathrm{mol})$. By the same approach, the peaks at $2.47 \mathrm{~min}$ in the S6 chromatogram and at $3.2 \mathrm{~min}$ and $6.2 \mathrm{~min}$ in the $\mathrm{S} 7$ chromatogram (and any other peaks in a chromatogram) are shown not to be derivatized polysulfides. If the isotope pattern does not match the expected organic polysulfide pattern, the peak is not included in the calculation of total sulfur. The raw chromatograms for all the data shown in the main text Figure 3 and Figure S13 are presented at the end of the supporting information in Appendix 1. 


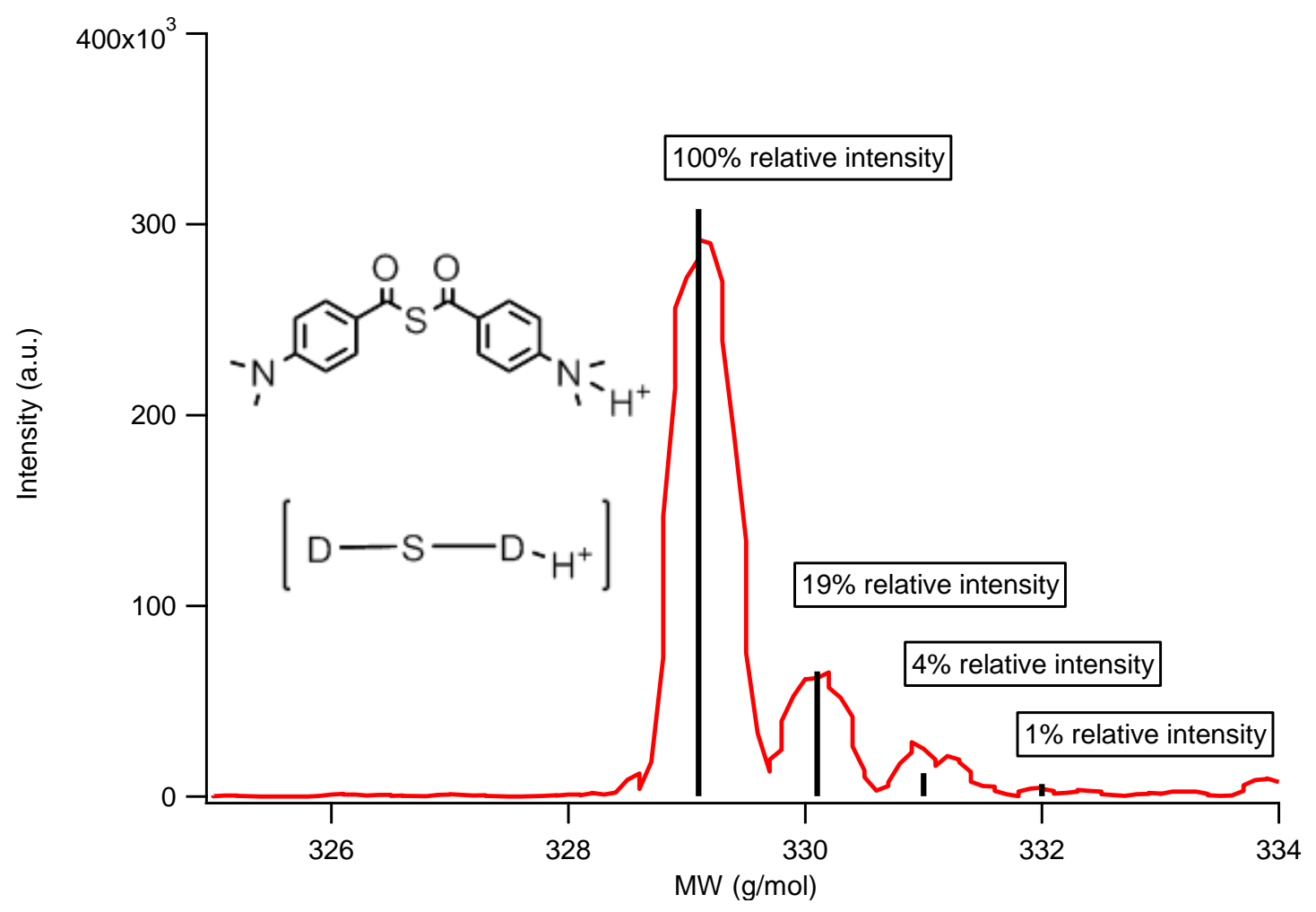

Figure S16. Mass Spectrum for $329 \mathrm{~g} / \mathrm{mol}$, D-S-D-H+ (red), with calculated isotope pattern (black bars).

This technique has previously been used to determine the speciation of polysulfides in Li-S batteries at a given state of discharge..$^{5}$ In attempting to reproduce this experiment, we found that our mass spectrometry results did not reflect the actual cell polysulfide chain length distribution. The experimental procedure reported in the above reference was repeated as faithfully as possible, and when that did not reproduce the expected results, the parameters of the technique were systematically varied. We found that our results were sensitive to experimental parameters such as the amount of derivatizing agent used in the work-up, selection of the mobile phase, column, and sample dilution/preparation. Unfortunately no combination of parameters yielded believable results for the polysulfide speciation within the cell.

This result, that the speciation observed with the UPLC-MS does not reflect the cell speciation, is realized in numerous ways. First, the amount of derivatizing agent used changes the observed organic polysulfide speciation chain length. Second, the chain length speciation observed for a partially discharged Li-S cell does not match with the known polysulfide speciation for Li-S cells at this stage of discharge. Third, higher order (S9 +) organic polysulfides are observed in cases with high initial ionic polysulfide concentration. Finally, the detected amount of a compound of a given chain length has a logarithmic relationship to the number of $\mathrm{S}$ atoms in the compound. These points are explored in detail in the following section.

Effect of derivatizer amount and Li-S mismatch: Two identical Li-S cells, the discharge profiles of which are presented in Figure S17, were discharged to $2.2 \mathrm{~V}$. Each cell was then derivatized with a procedure similar to that of the Mg-S cells, except the first Li-S cell was treated with $1.5 \mathrm{mg}$ of derivatizing agent and the second cell with $2.0 \mathrm{mg}$ of derivatizing agent. The full chromatogram of these two samples is presented in Figure S18. 


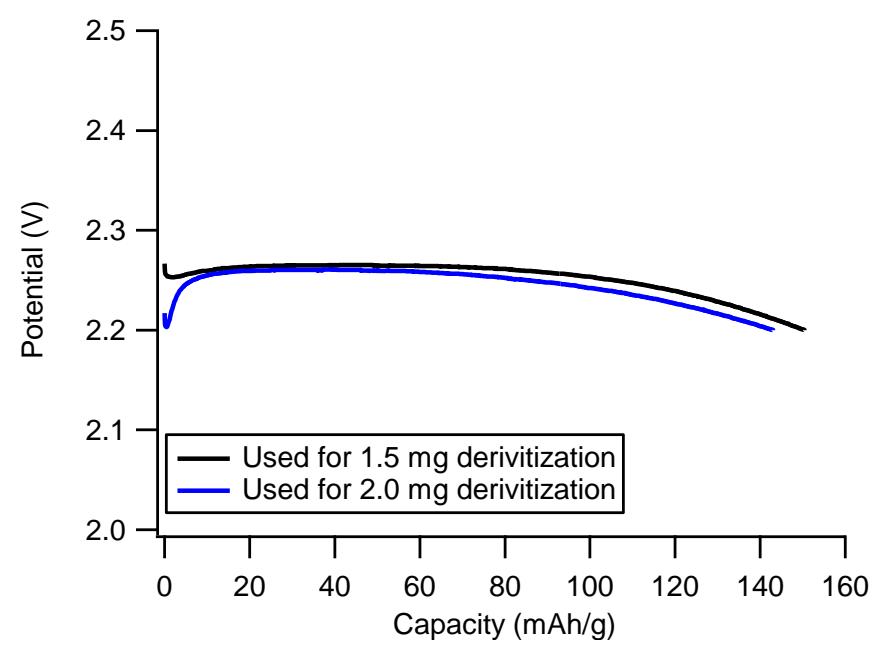

Figure S17. Li-S cells discharged to $2.2 \mathrm{~V}$ for MS derivatization.

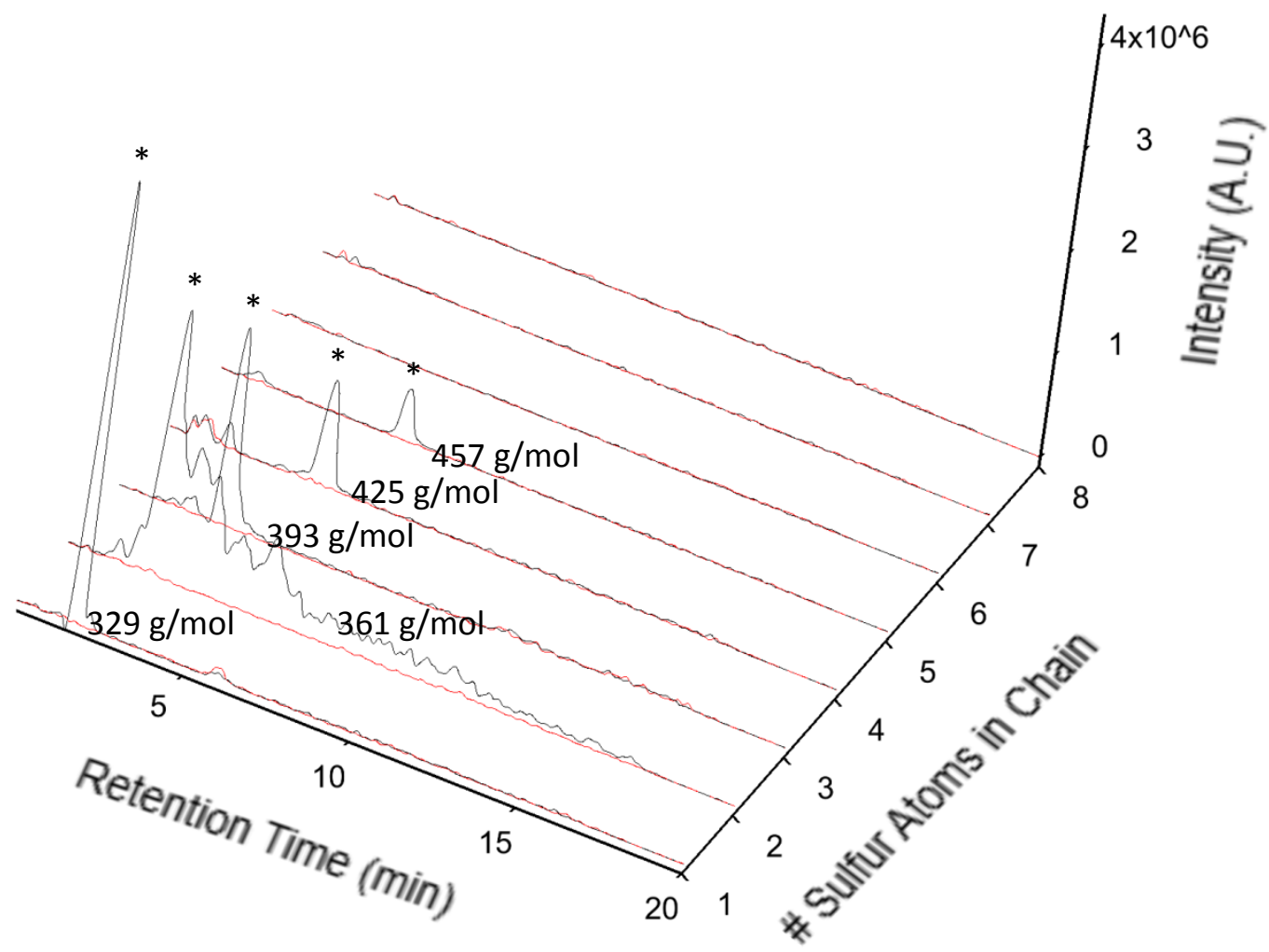

Figure S18. Mass specific chromatogram of derivatized Li-S cells, prepared with different amounts of derivatizing agent. Red Chromatogram = cell prepared with $1.5 \mathrm{mg}$ derivatizing agent. Black Chromatogram = cell prepared with $2.0 \mathrm{mg}$ derivatizing agent. Peaks corresponding to the derivatized compounds marked with *.

Immediately apparent is the impact of derivatizer amount on the mass spectrometry results, in that $1.5 \mathrm{mg}$ does not appear to be enough to produce any D-Sx-D species. Perhaps the first functionalization of an ionic polysulfide is more favorable than the second functionalization, and if $1.5 \mathrm{mg}$ is not enough to functionalize every species at least once, then no D-Sx-D compounds would be observed in the chromatogram. At any rate, the apparent 
sensitivity of the experiment to derivatizer amount led to the standard use of $5 \mathrm{mg}$ of derivatizer for each Mg-S sample. If the sensitivity of the MS results to the derivatizer amount used was not enough to call into question the accuracy of polysulfide speciation, then the speciation observed in the $2.0 \mathrm{mg}$ Li-S cell can leave no doubt. The speciation observed in the chromatogram indicates a high concentration of monosulfide, disulfide, and short chain polysulfides. A Li-S cell typically exhibits two distinct discharge plateaus, one from about $2.5 \mathrm{~V}$ to $2 \mathrm{~V}$, and another from about $1.9 \mathrm{~V}$ to $1.7 \mathrm{~V}$. When the cell is still in the first plateau stage, it is well known that the lithium polysulfide speciation consists of long-chain polysulfides. ${ }^{6}$ If the results of the $2.0 \mathrm{mg}$ Li-S MS cell were representative of the true cell speciation, the observed species would be $D-S x-D$ for $x=8,7,6,5$, as opposed to the short chain species that were observed.

Higher order (S9+) organic polysulfides: In some cases, the formation of higher order organic polysulfides S9, S10, and S11 were observed. An example is visible in Figure A8. This speciation is impossible to form electrochemically when starting from covalent $\mathrm{S}_{8}$, further indicating that the derivatization process alters the polysulfide speciation. The higher order organic sulfides were only observed in samples that had displayed high concentrations of ionic sulfur. In general, S9 is only observed if S8 was present, S8 only if S7 was present, and so on. The derivatization procedure appears to bias the formation of S1 first, forming higher order species as the initial ionic polysulfide concentration increases. The reason for this is unknown, but may stem from decreased stability of the higher order compounds. If more sulfur is initially present, the activity of sulfur atoms in solution are increased, which may help stabilize the higher order polysulfides. This is related to the final point.

Logarithmic dependence of compound concentration on sulfur atom chain length: Figure S19 shows the roughly logarithmic dependence of the amount of a given organic polysulfide on the number of sulfur atoms it contains. This relationship is most strongly observed for samples with high initial concentrations of ionic polysulfides. This relationship points to the speciation being governed by processes that influence the derivatization reaction, such as compound solubility, sulfur activity, etc. as opposed to the true cell speciation. Alternatively, this result could be a reflection of technique bias; larger compounds may decompose or get stuck on the UPLC column or have decreased solubility in the mobile phase.

Given these reasons, the polysulfide speciation observed is assumed to not be representative of the cell speciation. However, even though the true cell speciation cannot be obtained with this mass spectrometry method, the relative number of sulfur atoms in the form of ionic poly(sulfides) in a cell can be conclusively determined. It is on this basis that the self-discharge process of $\mathrm{Mg}$-S batteries is investigated.

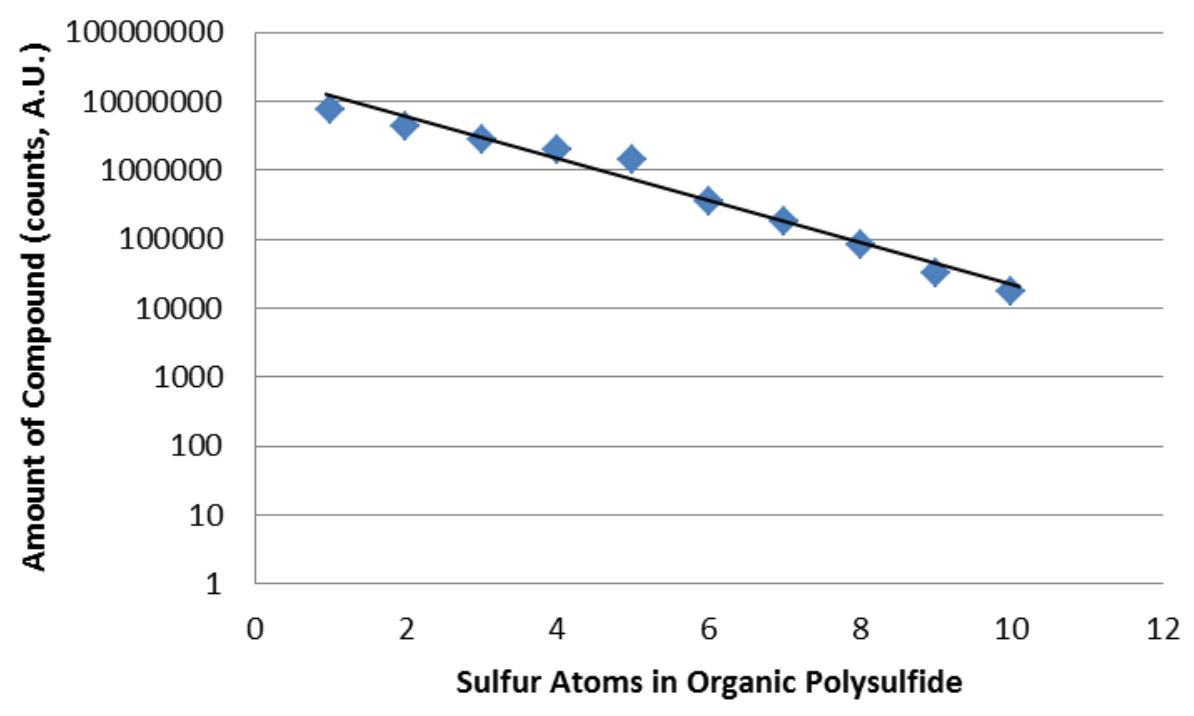

Figure S19. Amount of organic polysulfide compound D-S - -D detected as function of number of sulfur atoms $X$. 


\section{Further verification of UPLC-MS method applied to Mg-S chemistry}

\section{Derivatization of solid $\mathrm{Mg}_{\mathrm{x}} \mathrm{S}_{\mathrm{y}}$}

Figure S20 demonstrates proof that the derivatization reaction successfully reacts with the solid poly(sulfide) species observed as precipitation on the cell separators and cathode. In the upper left photograph, yellow solid deposits are visible on the separator even after the separator has been washed with DME. In the upper right photograph, the separator has been placed in a solution containing DME with derivatizing agent DBC. The previously solid precipitates can be seen reacting and dissolving, evidenced by the spread of yellow across the separator. In the bottom photograph, the separator was removed from the solution and dried without any further rinsing, revealing the now pristine separator and clear yellow solution of organic polysulfides.

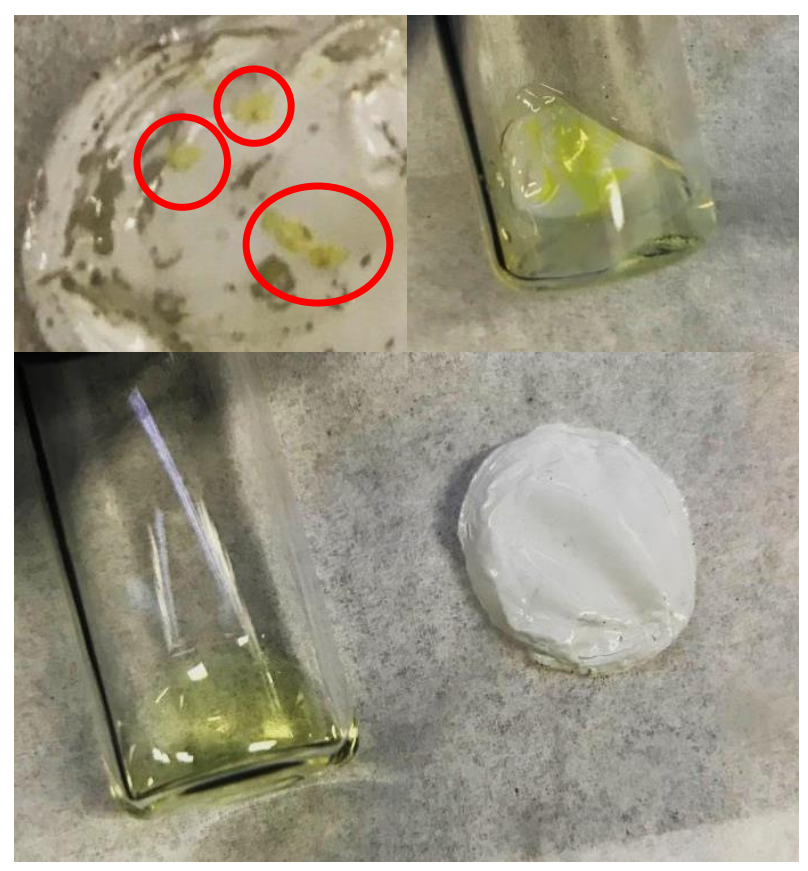

Figure S20. Dissolution of solid magnesium (poly)sulfide species via reaction with derivatizer. Upper left, separator with deposits circled. Top right, separator in solution of derivatizing agent + DME. Bottom, dried separator after removing from solution and yellow derivatized polysulfides.

\section{Identifying the first step in the Mg-S self-discharge}

In one of the two literature studies that had previously observed $\mathrm{Mg}$-S self discharge, the first step of the process, conversion of $\mathrm{S}_{8}$ to $\mathrm{S}_{8}{ }^{-2}$, was proposed to be a result of $\mathrm{S}_{8}$ reacting with the electrolyte. ${ }^{7}$ In the other study, the first step was proposed to be a result of $\mathrm{S}_{8}$ directly reacting with $\mathrm{Mg}$ metal. ${ }^{8}$ With use of the UPLC-MS technique, we are able to definitively establish that $\mathrm{Mg}$ metal must be present for the self-discharge process to begin, at least in an $\mathrm{MgTFSI}_{2} / \mathrm{MgCl}_{2}$ based electrolyte.

Two samples were prepared and run on the UPLC-MS. The first sample consisted of $0.76 \mathrm{mg}$ of sulfur powder stirred into $160 \mu \mathrm{L}$ of $0.25 \mathrm{M} \mathrm{MgTFSI}_{2}+0.5 \mathrm{M} \mathrm{MgCl}_{2}$ in DME. This solution was stirred for an hour, then transferred to a solution of $5 \mathrm{mg}$ derivatizing agent (DBC) suspended in $100 \mu \mathrm{L}$ of DME. The solution was then processed per the standard UPLC-MS workup outlined in the experimental section. The chromatogram for this sample is shown in Figure S21. 
The second sample was prepared from an $\mathrm{Mg}$-S cell that had not been discharged. Just as described in the experimental for all of the Mg-S cells, this cell consisted of a cathode containing $0.76 \mathrm{mg}$ sulfur, $160 \mu \mathrm{L}$ of $0.25 \mathrm{M}$ $\mathrm{MgTFSI}_{2}+0.5 \mathrm{M} \mathrm{MgCl}_{2}$ in DME, a Celgard separator, and an $\mathrm{Mg}$ anode. This cell was assembled, rested at OCP for 1 hour, then disassembled and processed per the standard technique. The chromatogram for this sample is shown in Figure S22.

Considering Figures S21 and S22, both samples contain a low concentration of analyte compared to the innate noise of the technique. When there were peaks that matched the known retention times for the derivatized organic sulfides of various chain lengths, the peak is highlighted with red to make it easier to see. Unfortunately, in both cases the concentration is so low that there is not a strong enough signal to definitively identify the analyte on the basis of isotope pattern. On the basis of retention time the peaks are assumed to be the derivatized compounds. Comparing the relative intensities, it is clear that a much lower, essentially negligible, amount of ionic polysulfides are formed when the sulfur powder is stirred with the electrolyte and derivatizer. By contrast, in the sample where $\mathrm{Mg}$ metal is present the logarithmic sulfur atom : retention time relationship is observed for peaks with non-negligible peak area. This result demonstrates that $\mathrm{Mg}$ metal is reacting with solubilized $\mathrm{S}_{8}$ and converting it into $\mathrm{S}_{8}^{-2}$ in a non-faradaic self-discharge process.

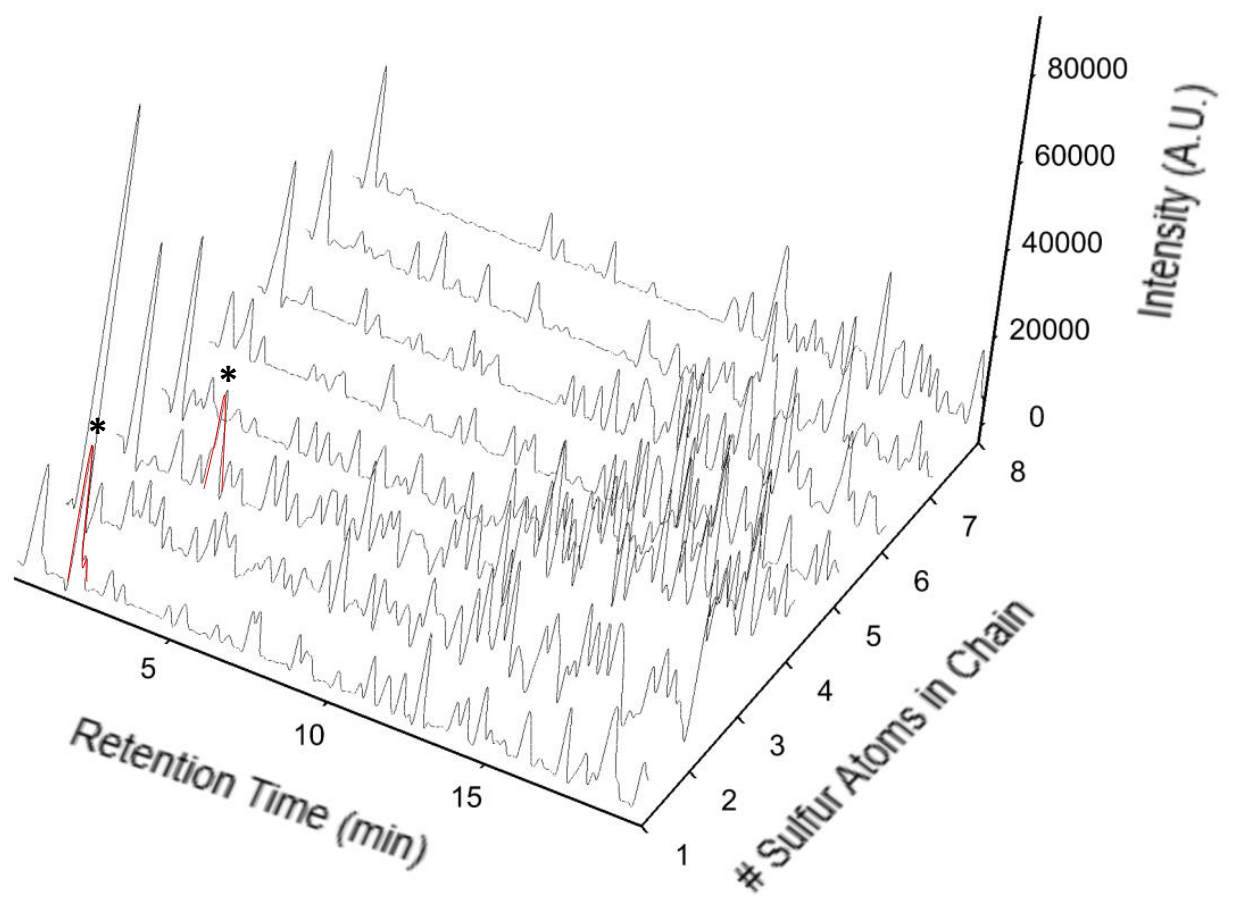

Figure S21. Mass specific chromatogram for sample of sulfur powder + electrolyte. Peaks corresponding to the derivatized compounds marked with * based on retention times from other chromatograms. 


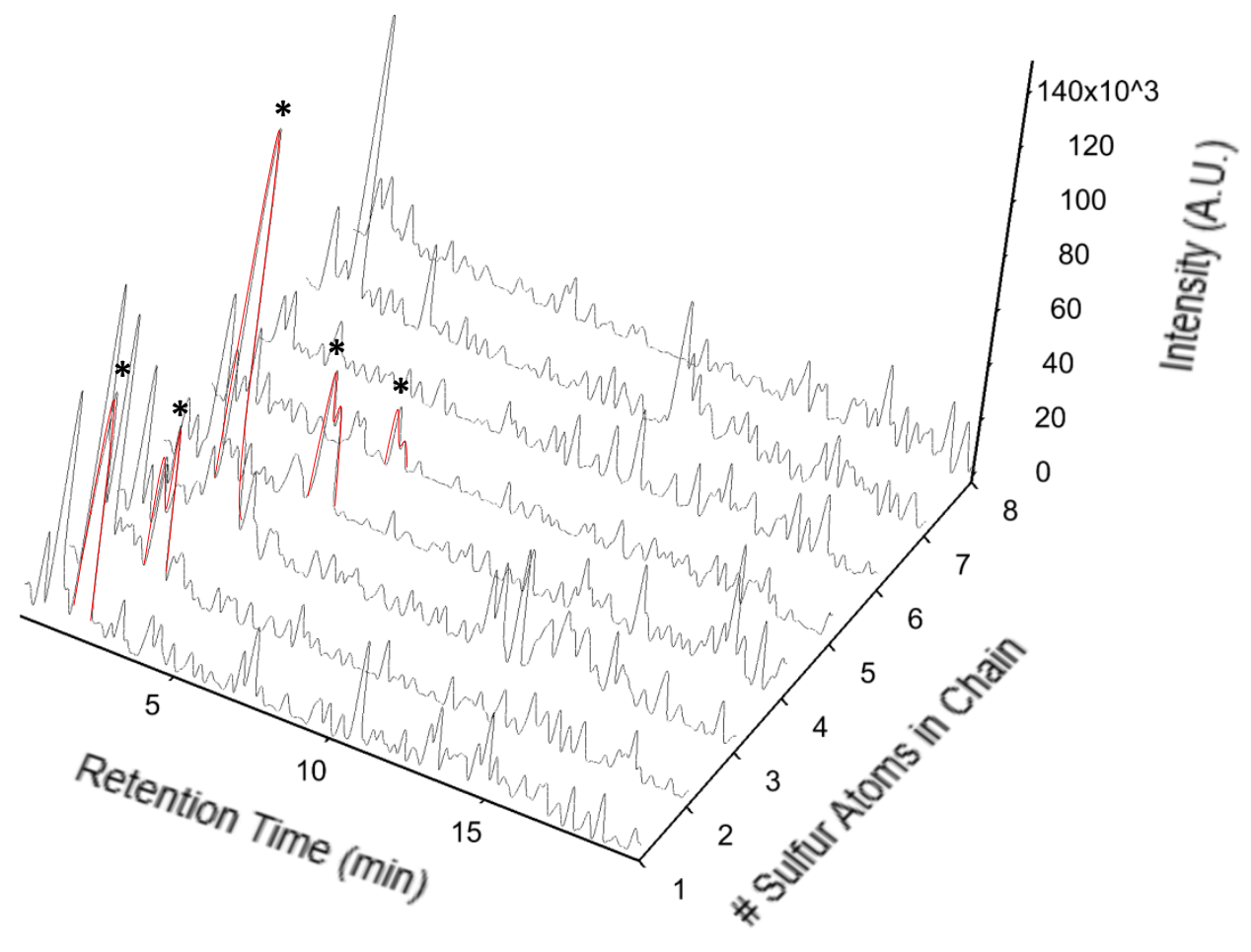

Figure S22. Mass specific chromatogram for sample harvested from full Mg-S cell held at OCP. Peaks corresponding to the derivatized compounds marked with *.

As one final demonstration, the synthesized solution of magnesium polysulfides (sulfur powder + of $0.25 \mathrm{M}$ $\mathrm{MgTFSI}_{2}+0.5 \mathrm{M} \mathrm{MgCl}_{2}$ in DME + magnesium powder) is derivatized and analyzed with UPLC-MS, which is shown in Figure S23. The presence of organic polysulfides in the chromatogram proves the synthesis of magnesium polysulfides is successful and that once again $\mathrm{Mg}$ metal is required for the spontaneous formation of ionic polysulfides. These peaks are definitively identified with isotope patterns. It should be noted that the $\mathrm{MgTFSI}_{2}$ and $\mathrm{MgCl}_{2}$ salts are also required for this direct synthesis to be successful. 


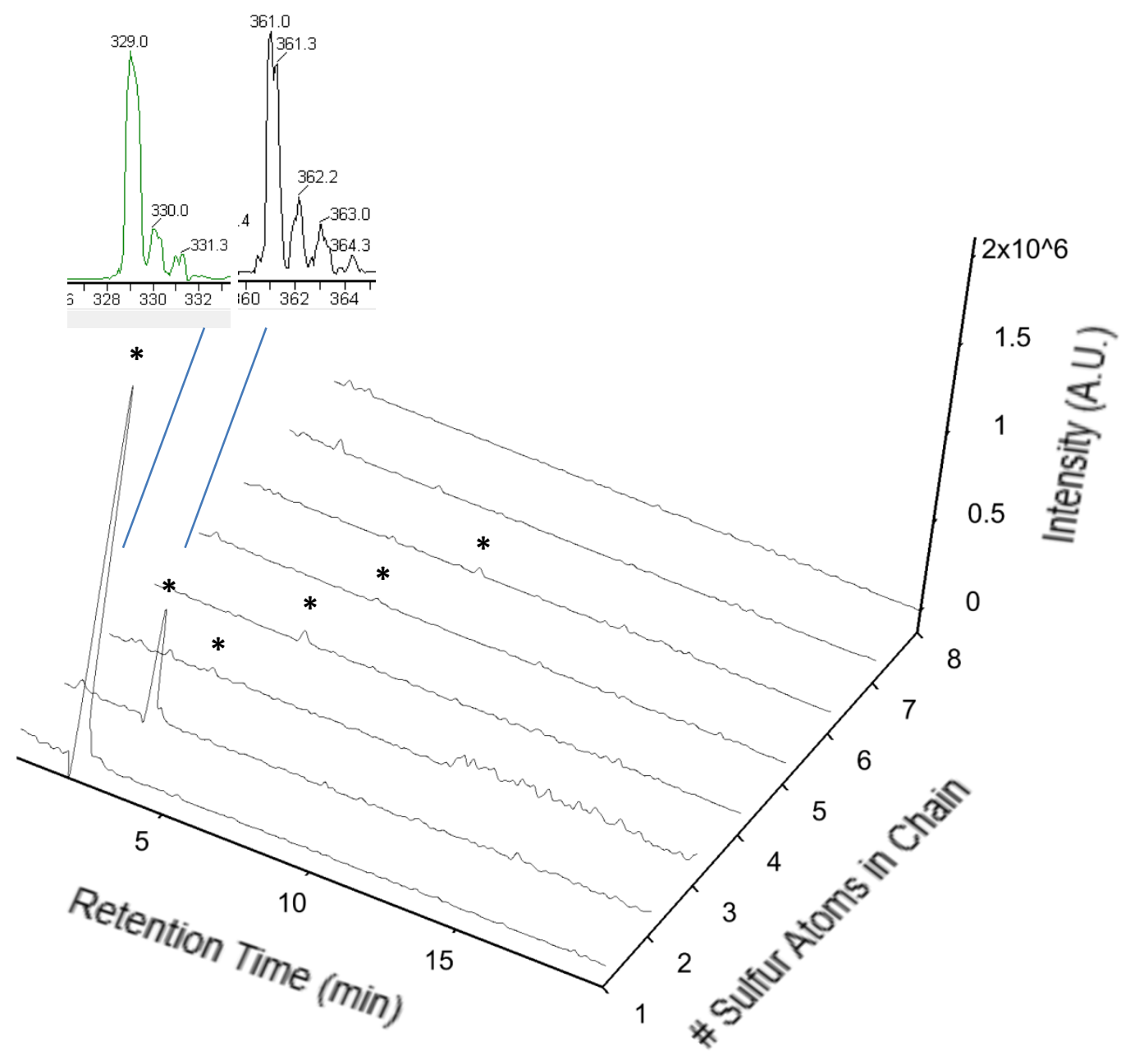

Figure S23. Chromatogram of derivatized solution of synthesized magnesium polysulfides (sulfur powder + of 0.25 $\mathrm{M} \mathrm{MgTFSI}{ }_{2}+0.5 \mathrm{M} \mathrm{MgCl}_{2}$ in DME + magnesium powder). Peaks corresponding to the derivatized compounds marked with *. Inset shows isotope pattern of first two peaks.

\section{References}

1 T. Gao, S. Hou, F. Wang, Z. Ma, X. Li, K. Xu and C. Wang, Angew. Chemie - Int. Ed., 2017, 56, 13526-13530.

2 J. Luo, Y. Bi, L. Zhang, X. Zhang and T. L. Liu, Angew. Chemie - Int. Ed., 2019, 58, 6967-6971.

3 G. Bieker, D. Diddens, M. Kolek, O. Borodin, M. Winter, P. Bieker and K. Jalkanen, J. Phys. Chem. C, 2018, 122, 21770-21783.

4 M. Salama, R. Attias, B. Hirsch, R. Yemini, Y. Gofer, M. Noked and D. Aurbach, ACS Appl. Mater. Interfaces, 2018, 10, 36910-36917.

5 D. Qu, D. Zheng, D. Qu, X. Q. Yang, X. Yu and H. S. Lee, Adv. Energy Mater., 2015, 5, 1401888.

6 A. Manthiram, Y. Fu and Y. S. Su, Acc. Chem. Res., 2013, 46, 1125-1134.

7 B. P. Vinayan, H. Euchner, Z. Zhao-Karger, M. A. Cambaz, Z. Li, T. Diemant, R. J. Behm, A. Gross and M. Fichtner, J. Mater. Chem. A, 2019, 7, 25490-25502. 

2020, 338, 135787. 
Appendix 1. Raw mass spec chromatograms for data points shown in Figure $\mathbf{3}$ in main text and Figure S13 in Supplementary Information. Peaks identified with both a retention time and area are verified to be $D-S_{x}-D$ with isotope pattern, and used for calculation of the total ionic sulfur.

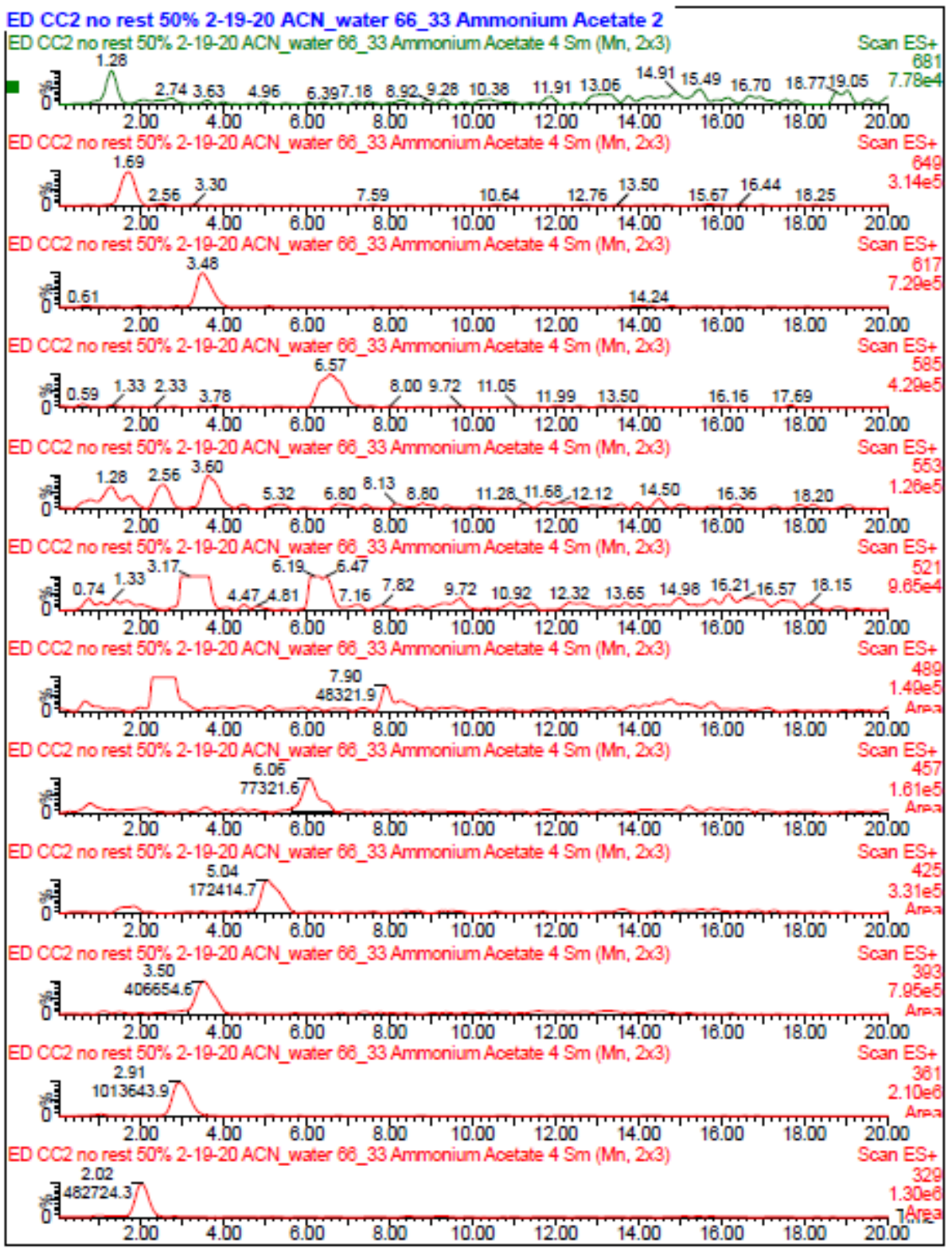

Figure A1. $200 \mathrm{mAh} / \mathrm{g}$ discharged, no rest, sample \#1. 


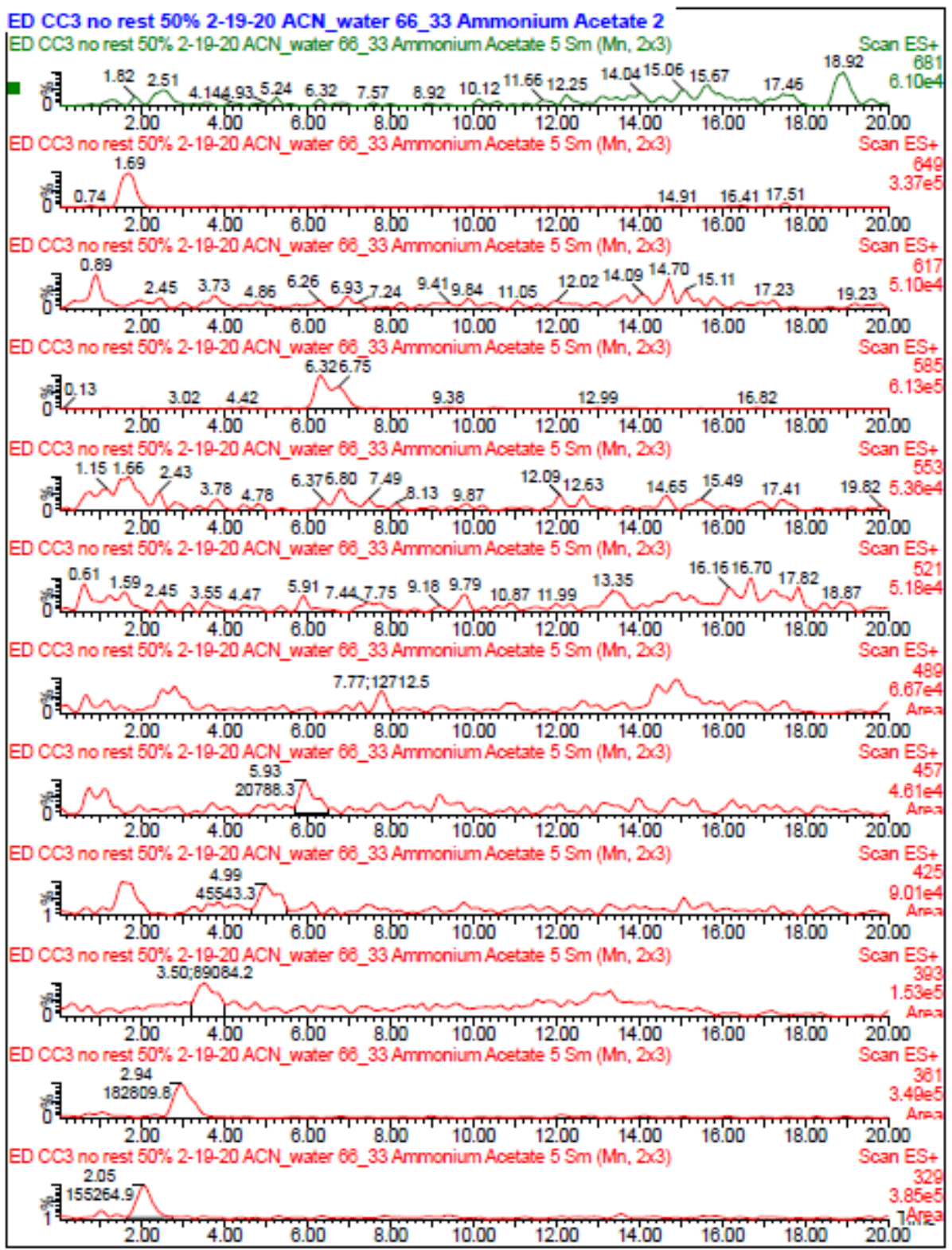

Figure A2. 200 mAh/g discharged, no rest, sample \#2. 


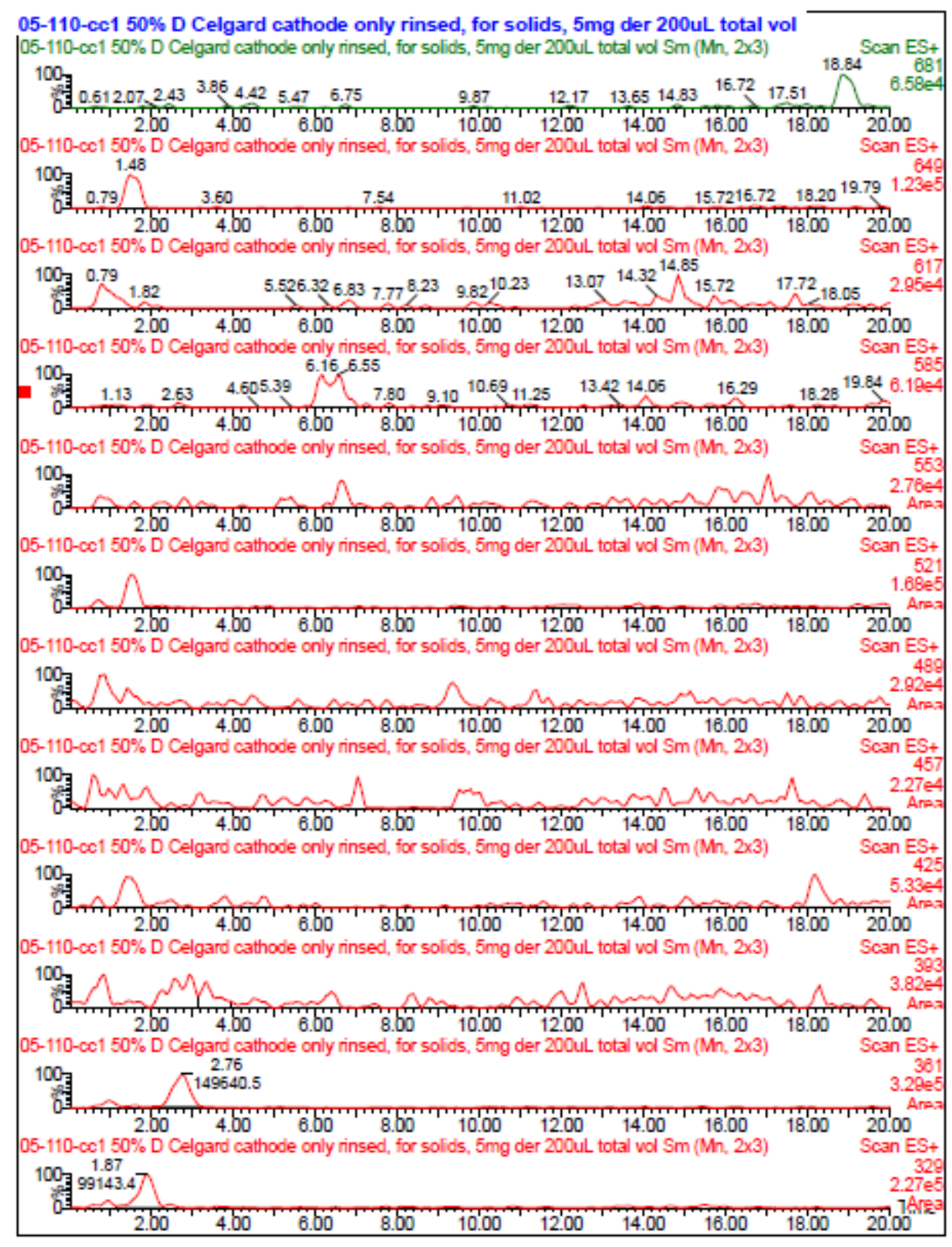

Figure A3. $200 \mathrm{mAh} / \mathrm{g}$ discharged, no rest, sample \#3 


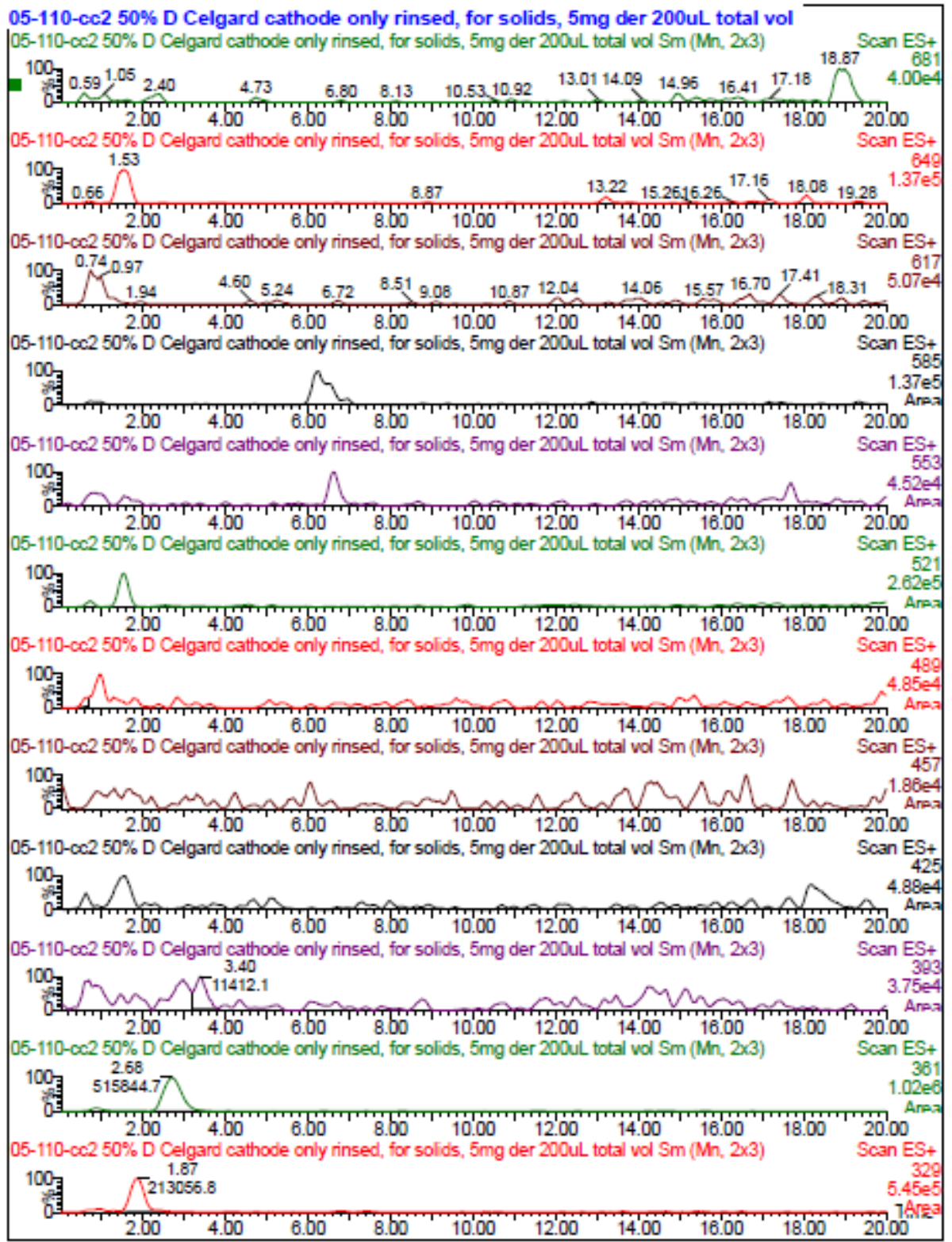

Figure A4. $200 \mathrm{mAh} / \mathrm{g}$ discharged, no rest, sample \#4 
05-110-cc3 50\% D Celgard cathode only rinsed, for solids, $5 \mathrm{mg}$ der 200uL total vol 05-110-co3 50\% D Celgard cathode only rinsed, for solids, $5 \mathrm{mg}$ der 200uL total vol $\mathrm{Sm}$ (Mn, 2×3)

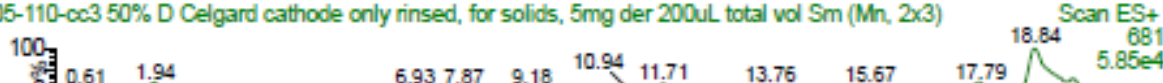

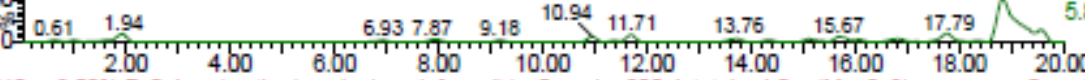
$05-110-\cos 50 \%$ D Celgard cathode only rinsed, for solids, $5 \mathrm{mg}$ der $200 \mathrm{uL}$ total vol Sm (Mn, 2x3) Scan ES+
1.51

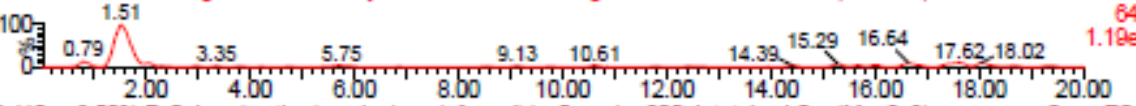
05-110-co3 50\% D Celgard cathode only rinsed, for solids, $5 \mathrm{mg}$ der $200 \mathrm{uL}$ total vol Sm (Mn, 2x3) Scan ES+

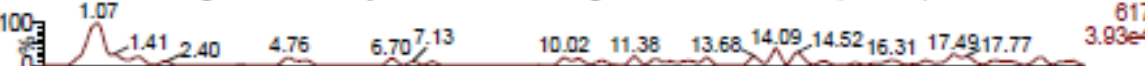
$\begin{array}{llllllllll}2.00 & 4.00 & 6.00 & 8.00 & 10.00 & 12.00 & 14.00 & 16.00 & 18.00 & 20.00\end{array}$ 05-110- $\cos 50 \%$ D Celgard cathode only rinsed, for solids, $5 \mathrm{mg}$ der $200 \mathrm{uL}$ total vol $\mathrm{Sm}(\mathrm{Mn}, 2 \times 3)$ Scan ES+

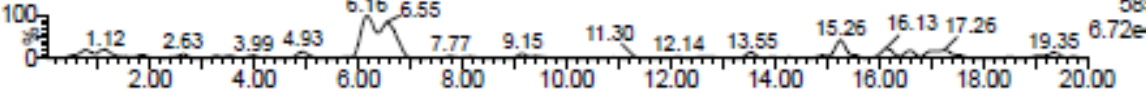

05-110-co3 50\% D Celgard cathode only rinsed, for solids, $5 \mathrm{mg}$ der $200 \mathrm{uL}$ total vol Sm (Mn, 2×3) Scan ES+

${ }^{100}$ 省

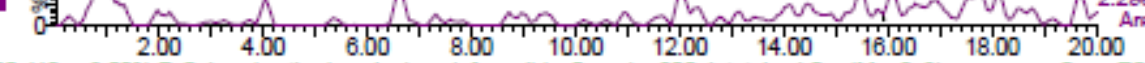
05-110-co3 50\% D Celgard cathode only rinsed, for solids, $5 \mathrm{mg}$ der $200 \mathrm{uL}$ total wol Sm (Mn, 2x3) Scan ES+ 2.03e

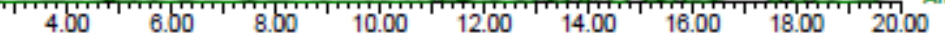
05-110-co3 50\% D Celgard cathode only rinsed, for solids, $5 \mathrm{mg}$ der 200uL total vol Sm (Mn, 2x3) Scan ES+ 1007 M 05-110-co3 50\% D Celgard cathode only rinsed, for solids, $5 \mathrm{mg}$ der $200 \mathrm{uL}$ total vol Sm (Mn, 2x3) Scan ES+

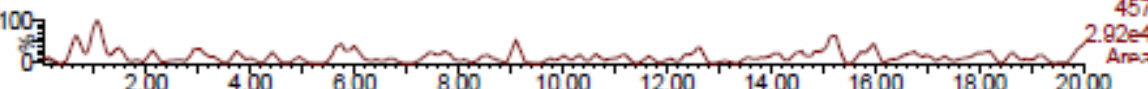
05-110-co3 50\% D Celgard cathode only rinsed, for solids, $5 \mathrm{mg}$ der $200 \mathrm{uL}$ total vol Sm (Mn, 2x3) Scan ES+

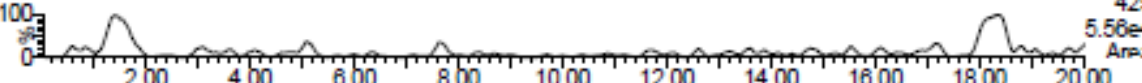

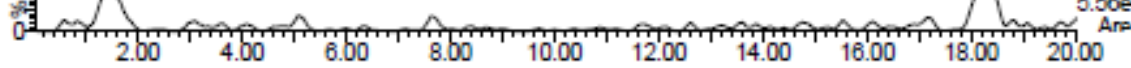
05-110-co3 50\% D Celgard cathode only rinsed, for solids, $5 \mathrm{mg}$ der 200uL total vol Sm (Mn, 2×3) Scan ES+

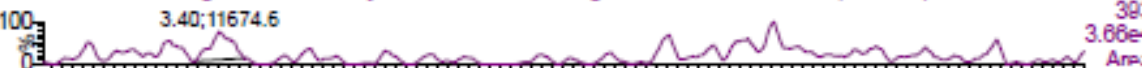

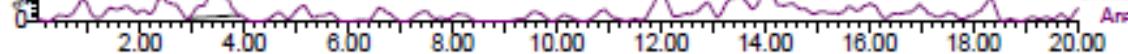
$05-110-\cos 350 \%$ D Celgard cathode only rinsed, for solids, $5 \mathrm{mg}$ der $200 \mathrm{uL}$ total wol Sm (Mn, 2x3)

Figure A5. $200 \mathrm{mAh} / \mathrm{g}$ discharged, no rest, sample \#5 


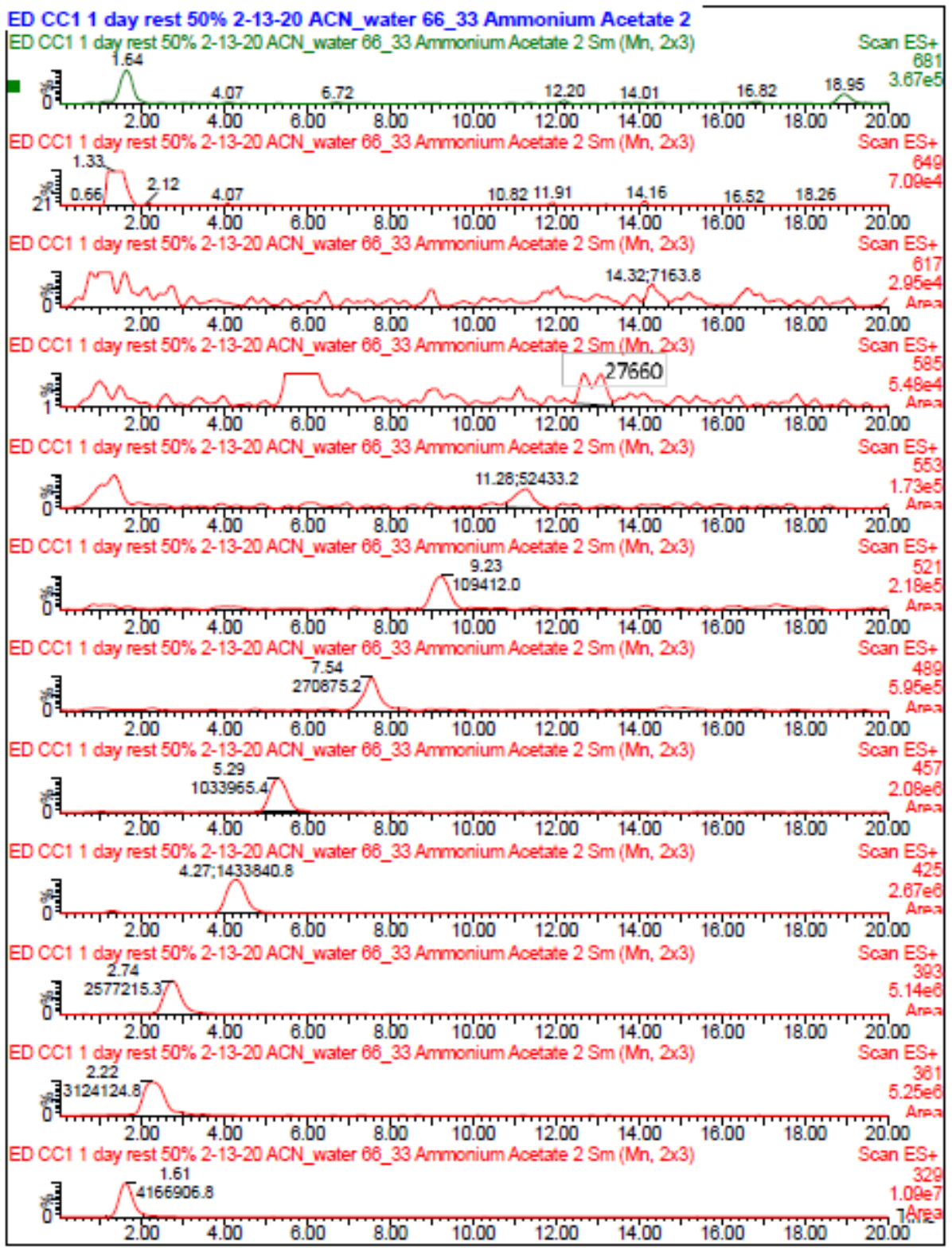

Figure A6. 200 mAh/g discharged, 1 day aged, sample \#1. 


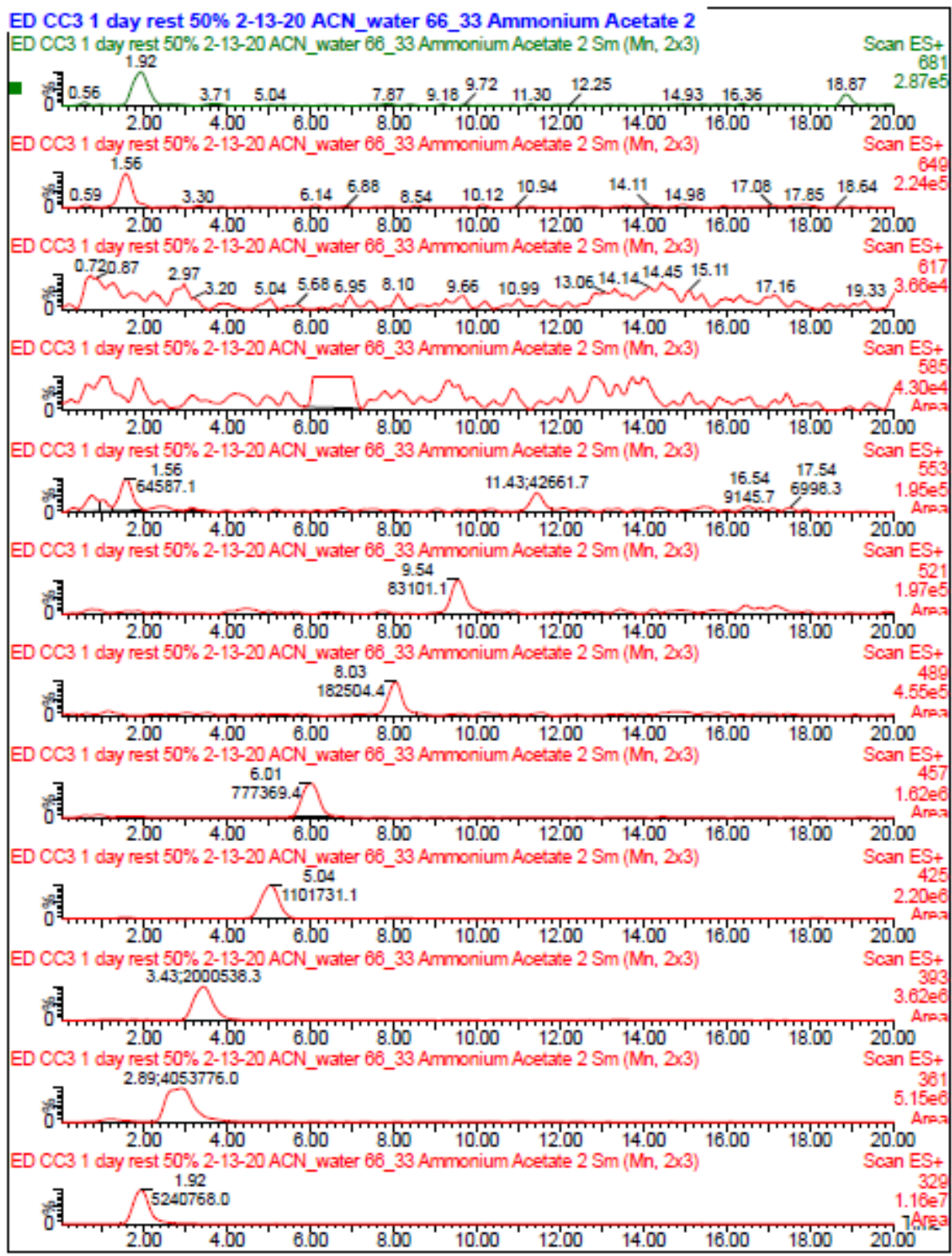

Figure A7. 200 mAh/g discharged, 1 day aged, sample \#2. 


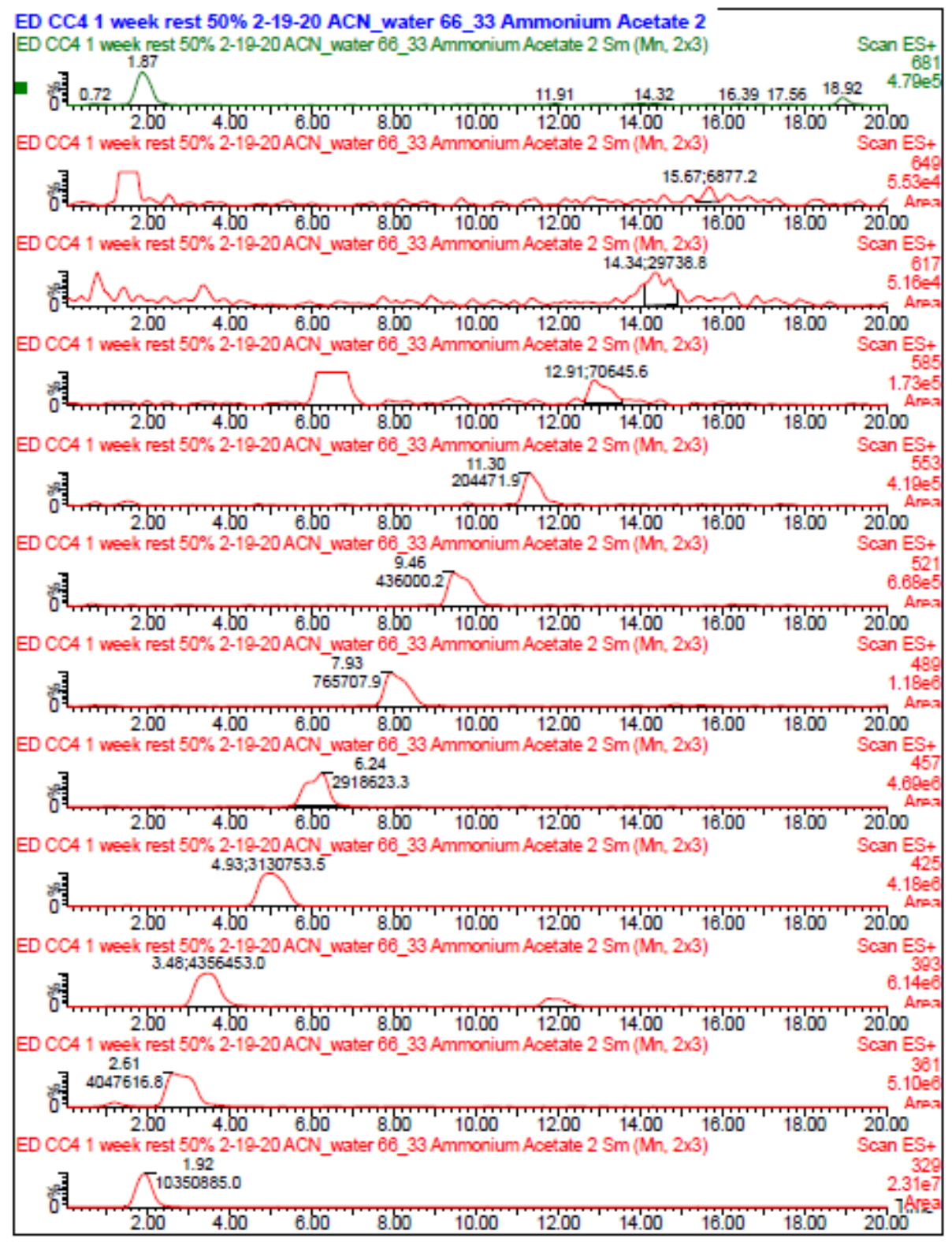

Figure A8. 200 mAh/g discharged, 1 week aged, sample \#1. 


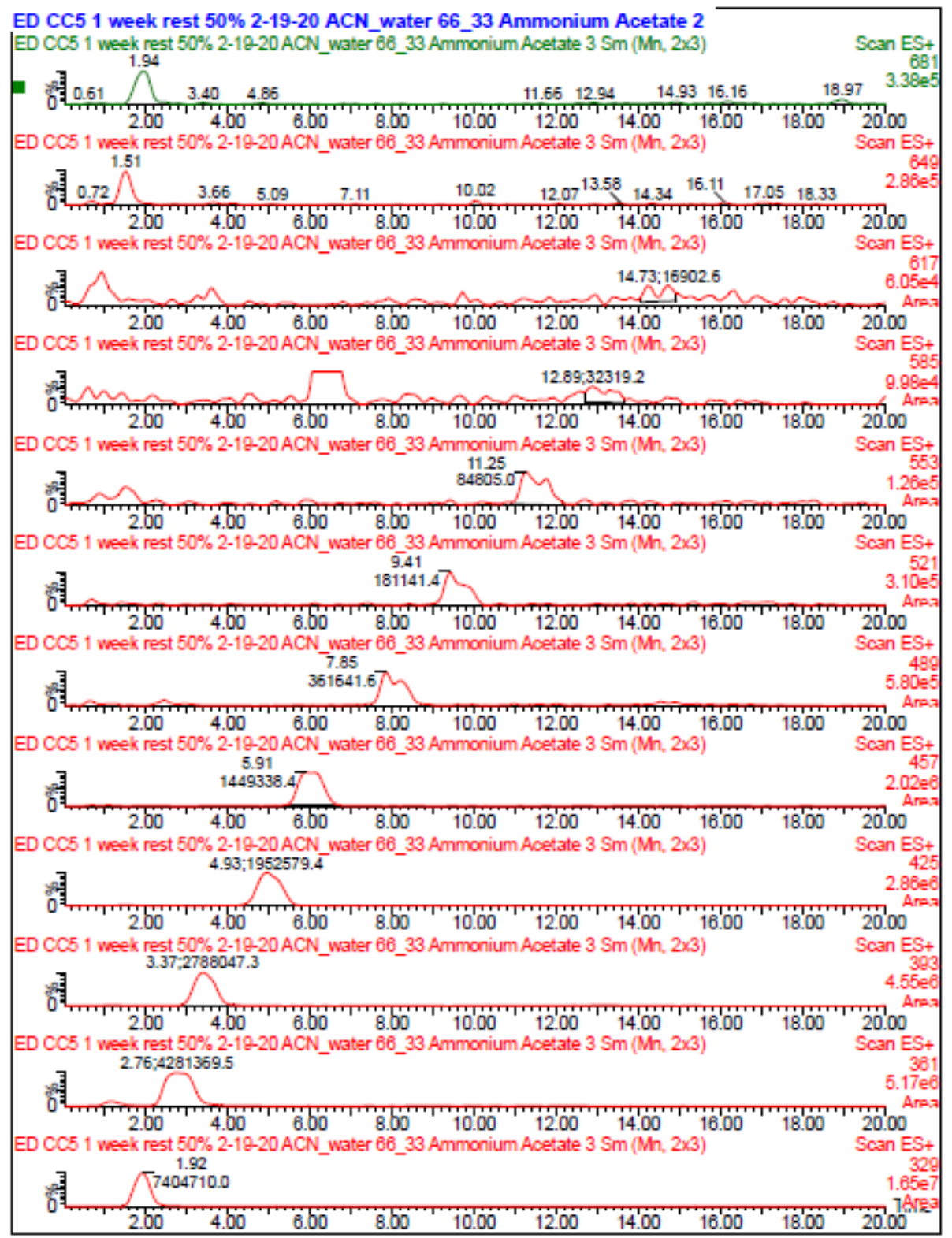

Figure A9. 200 mAh/g discharged, 1 week aged, sample \#2. 


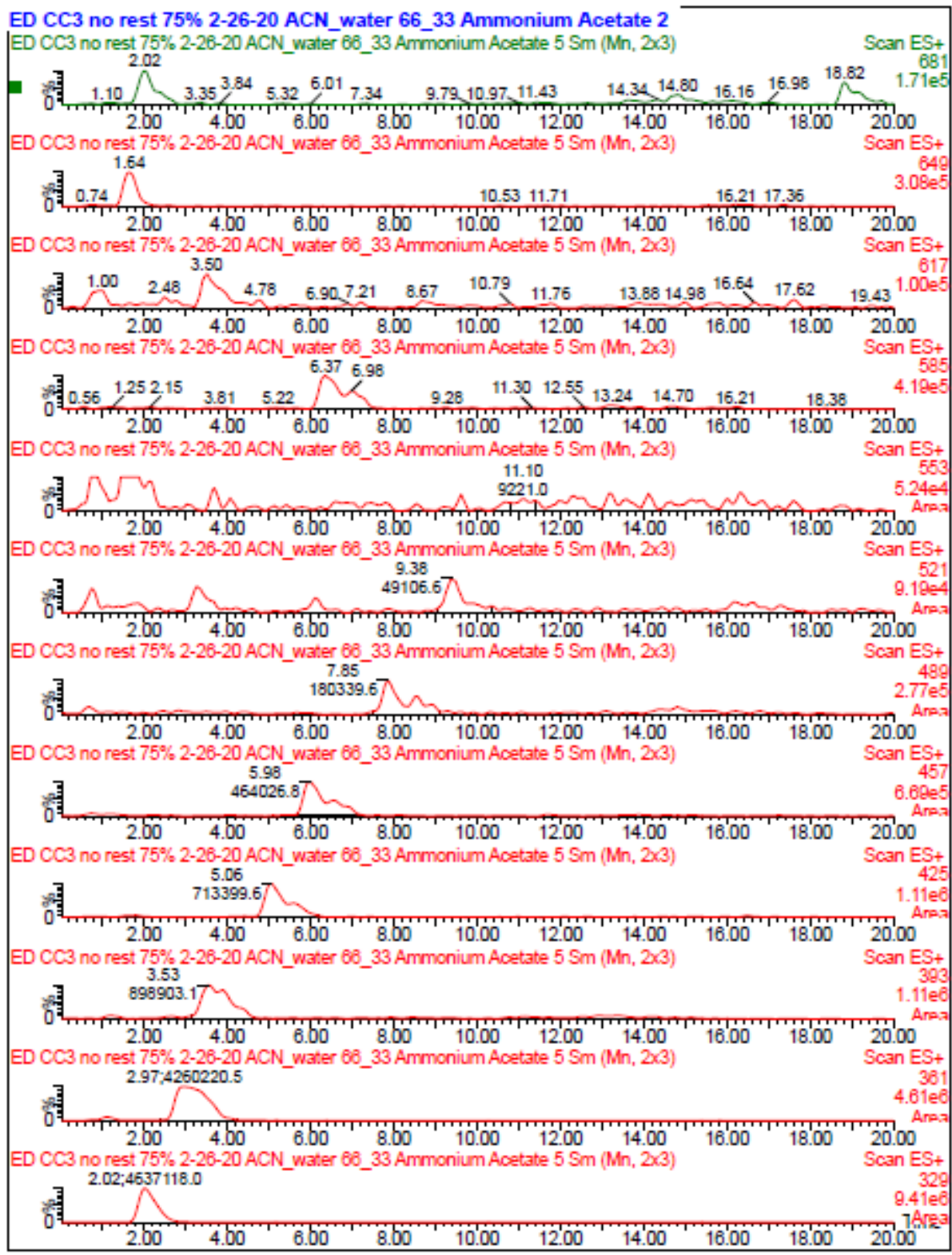

Figure A10. $300 \mathrm{mAh} / \mathrm{g}$ discharged, no rest, sample \#1. 


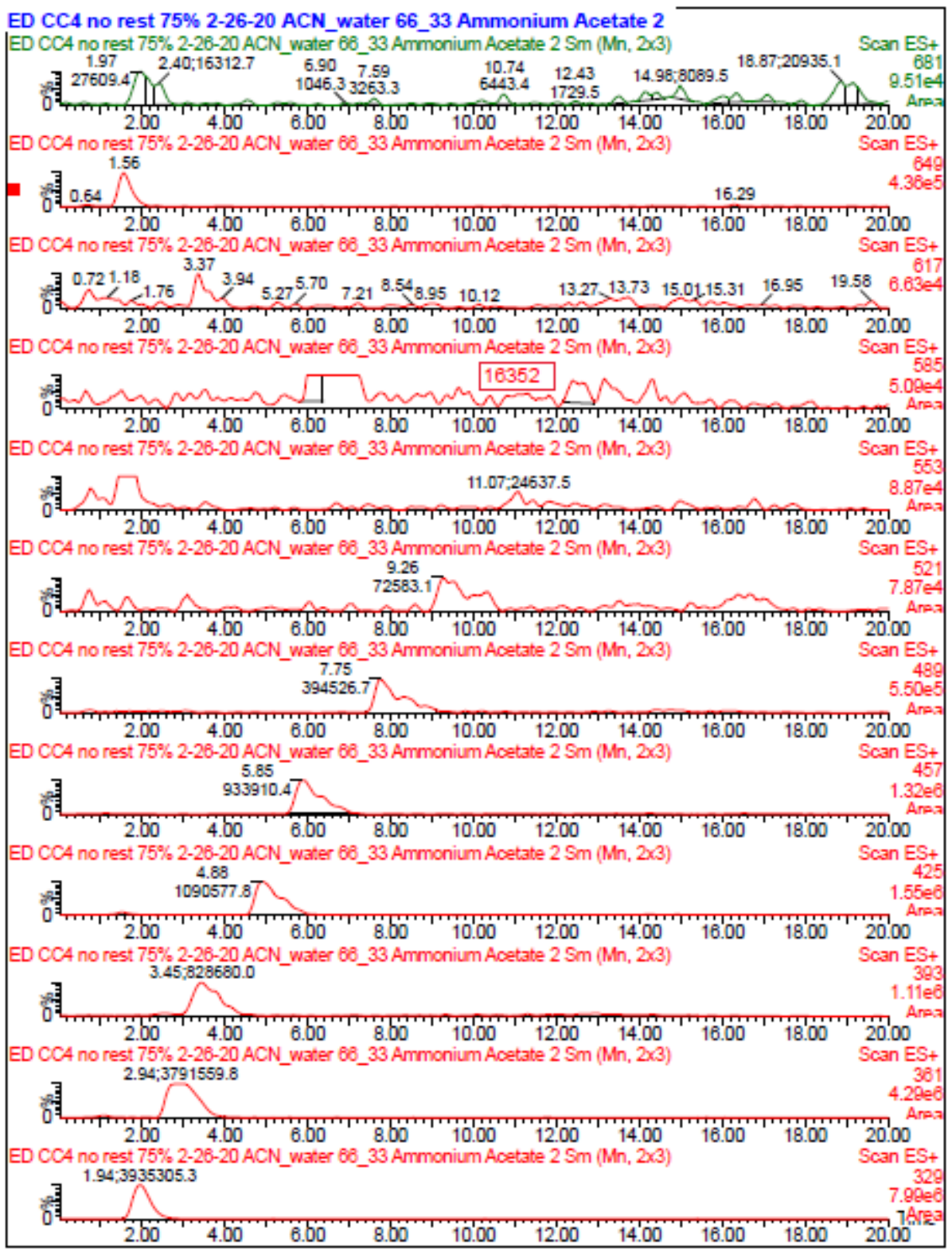

Figure A11. 300 mAh/g discharged, no rest, sample \#2. 


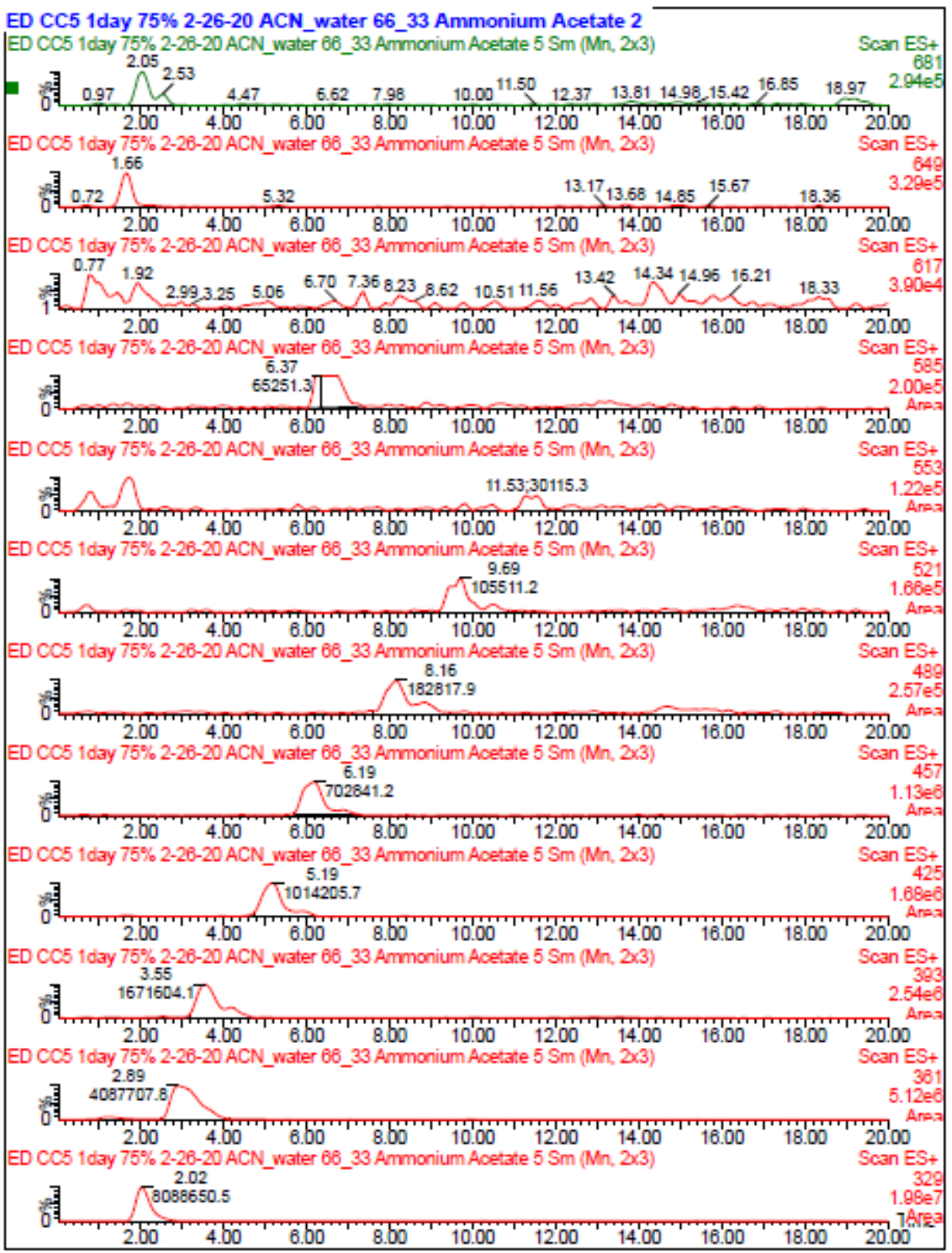

Figure A12. 300 mAh/g discharged, 1 day aged, sample \#1. 


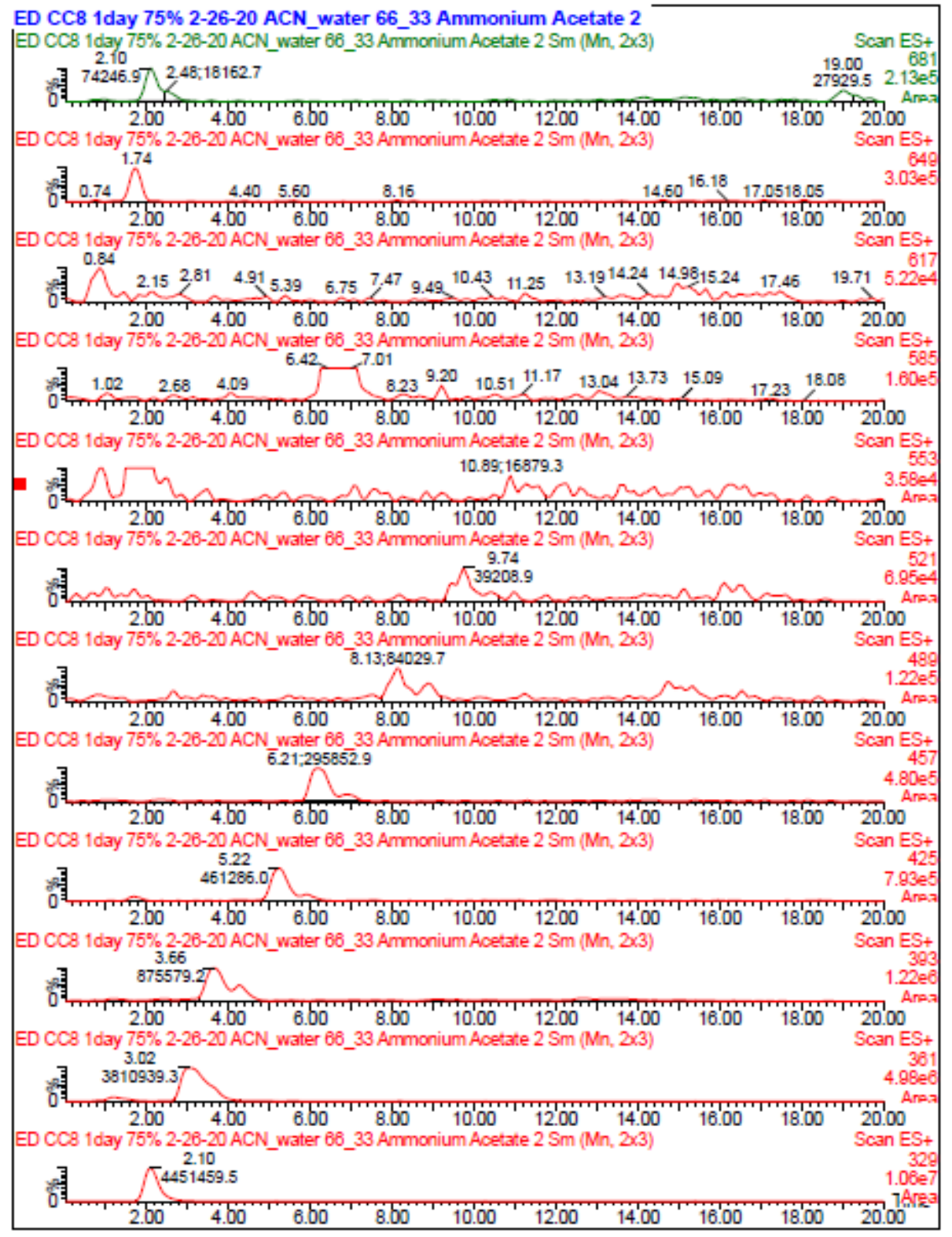

Figure A13. $300 \mathrm{mAh} / \mathrm{g}$ discharged, 1 day aged, sample \#2. 


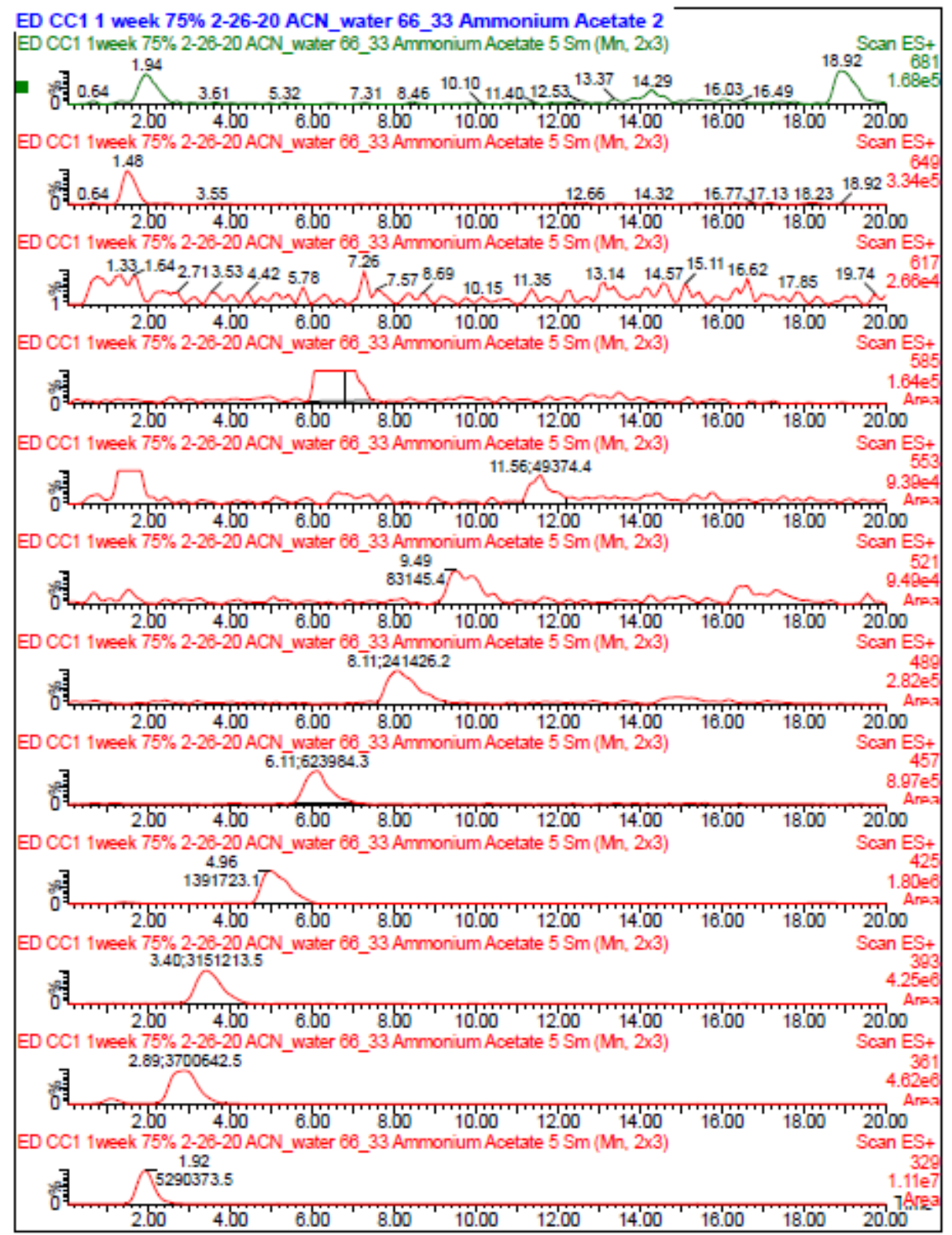

Figure A14. 300 mAh/g discharged, 1 week aged, sample \#1. 


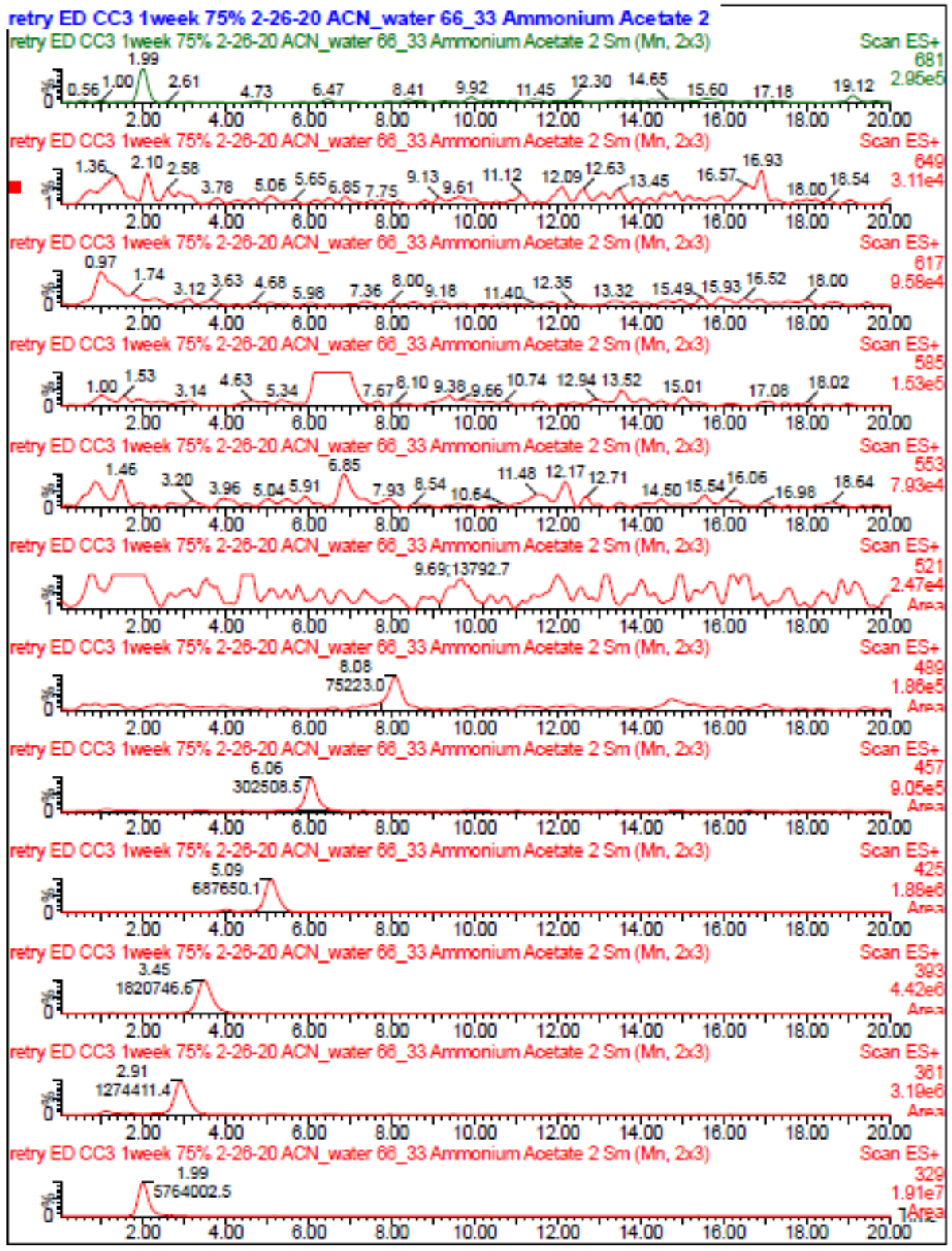

Figure A15. 300 mAh/g discharged, 1 week aged, sample \#2. 


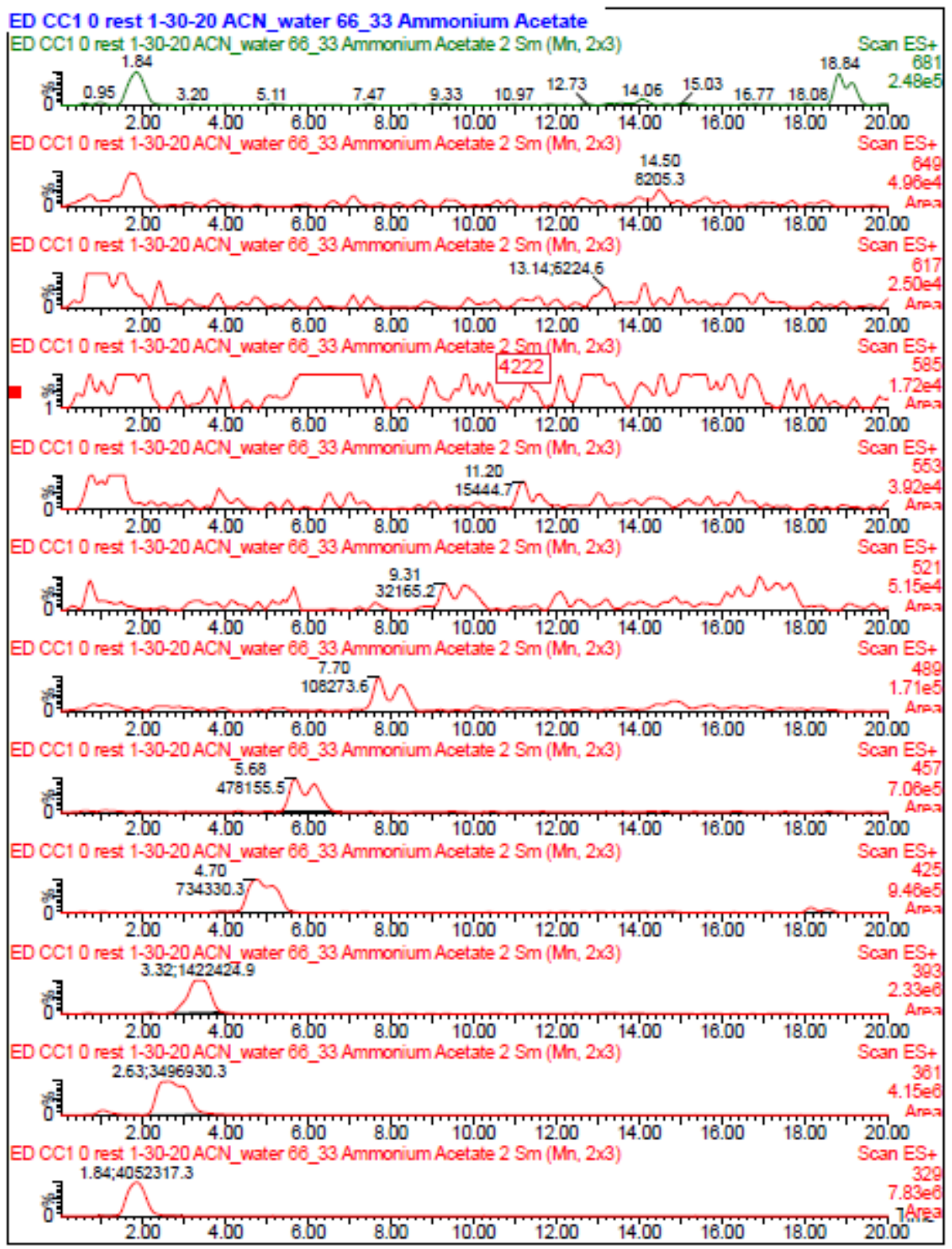

Figure A16. 400 mAh/g discharged, no rest, sample \#1. 


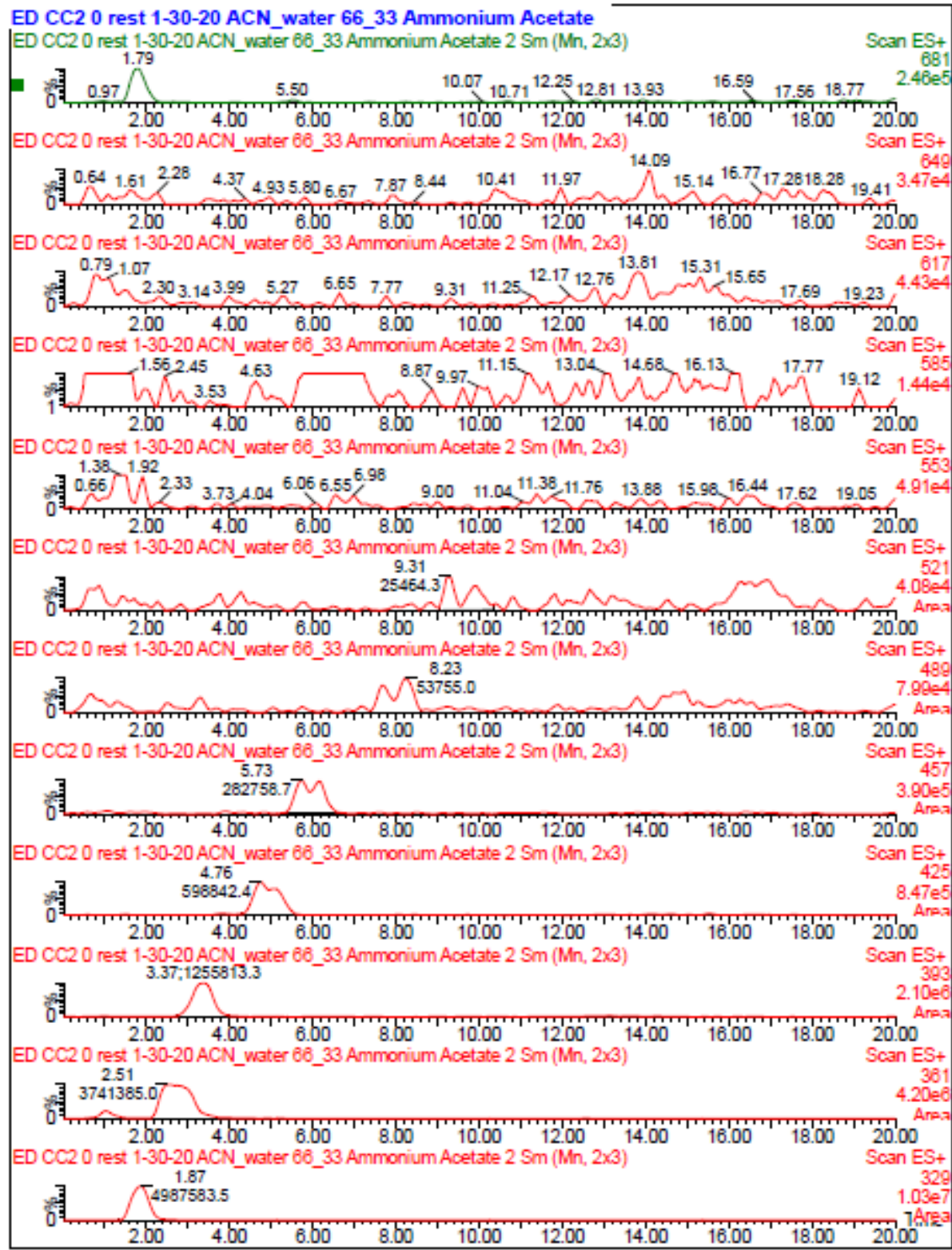

Figure A17. $400 \mathrm{mAh} / \mathrm{g}$ discharged, no rest, sample \#2. 


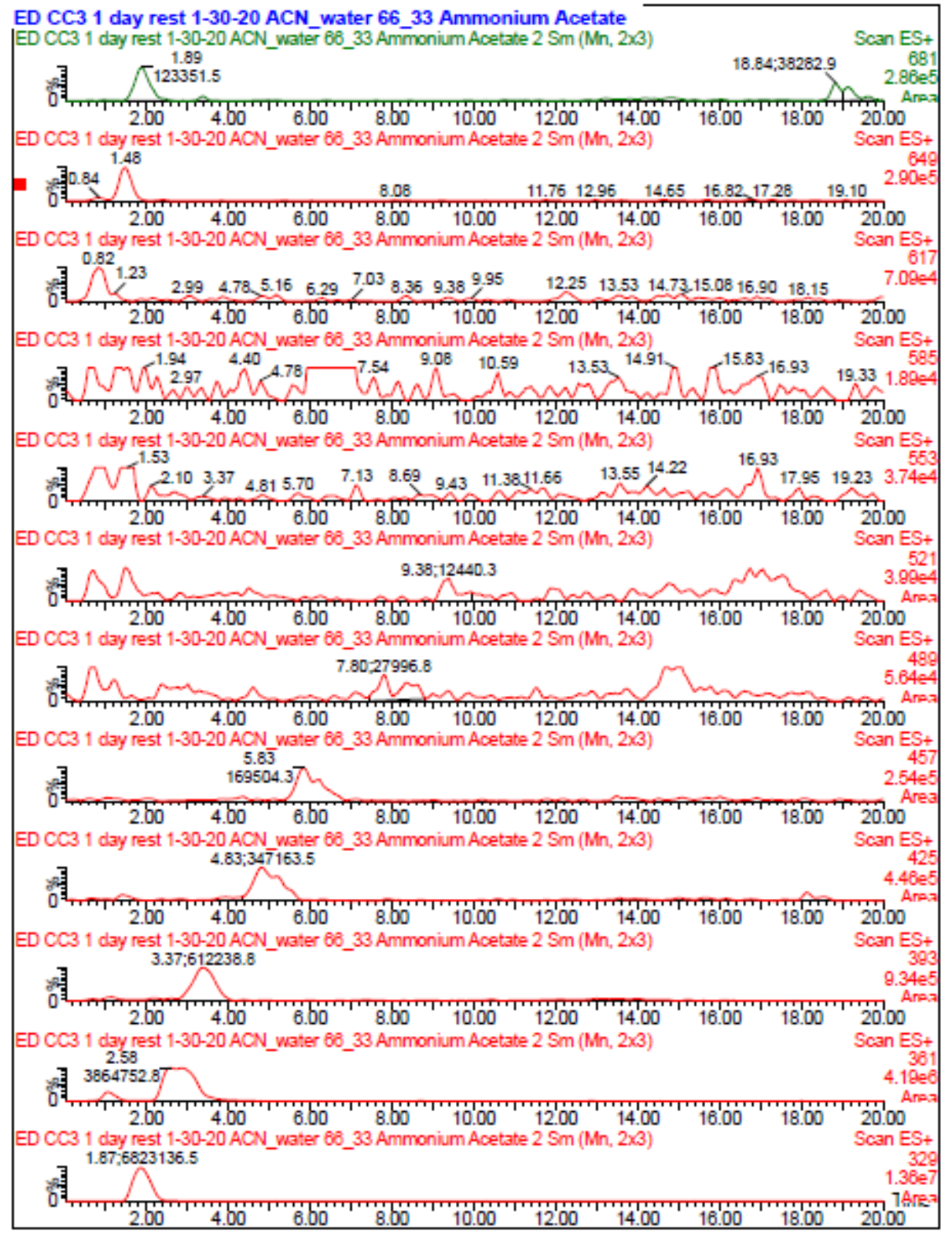

Figure A18. 400 mAh/g discharged, 1 day aged, sample \#1. 


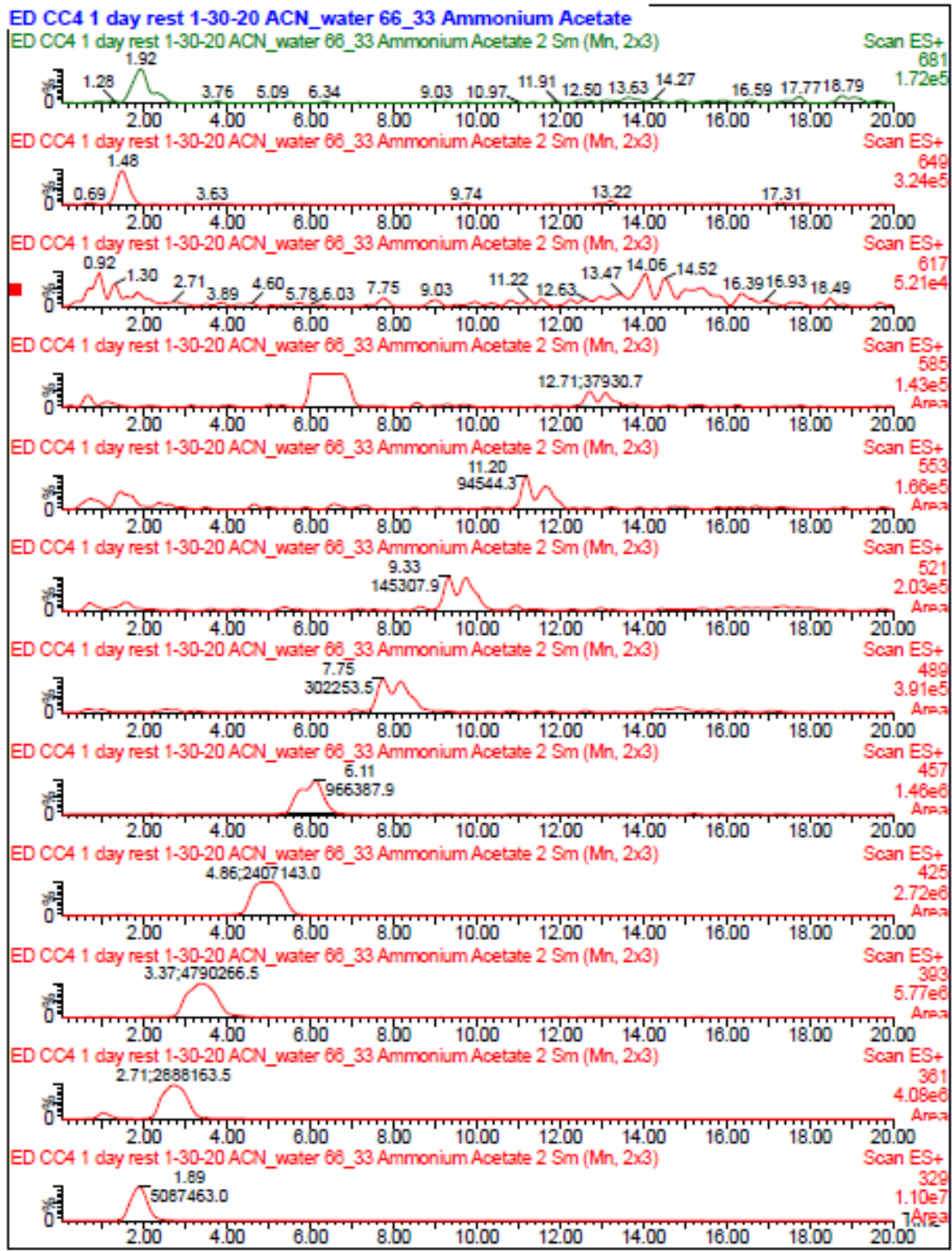

Figure A19. 400 mAh/g discharged, 1 day aged, sample \#2. 


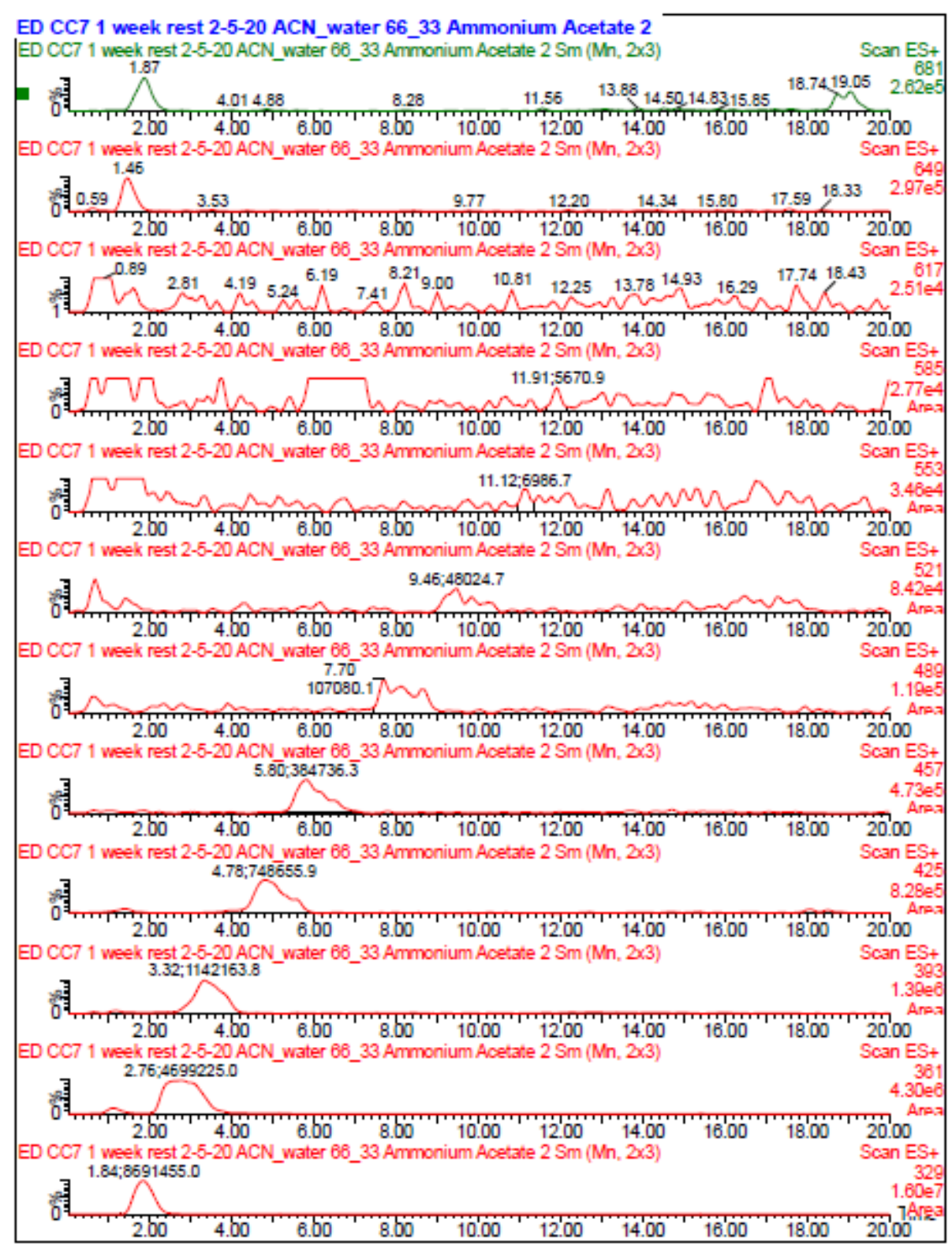

Figure A20. 400 mAh/g discharged, 1 week aged, sample \#1. 


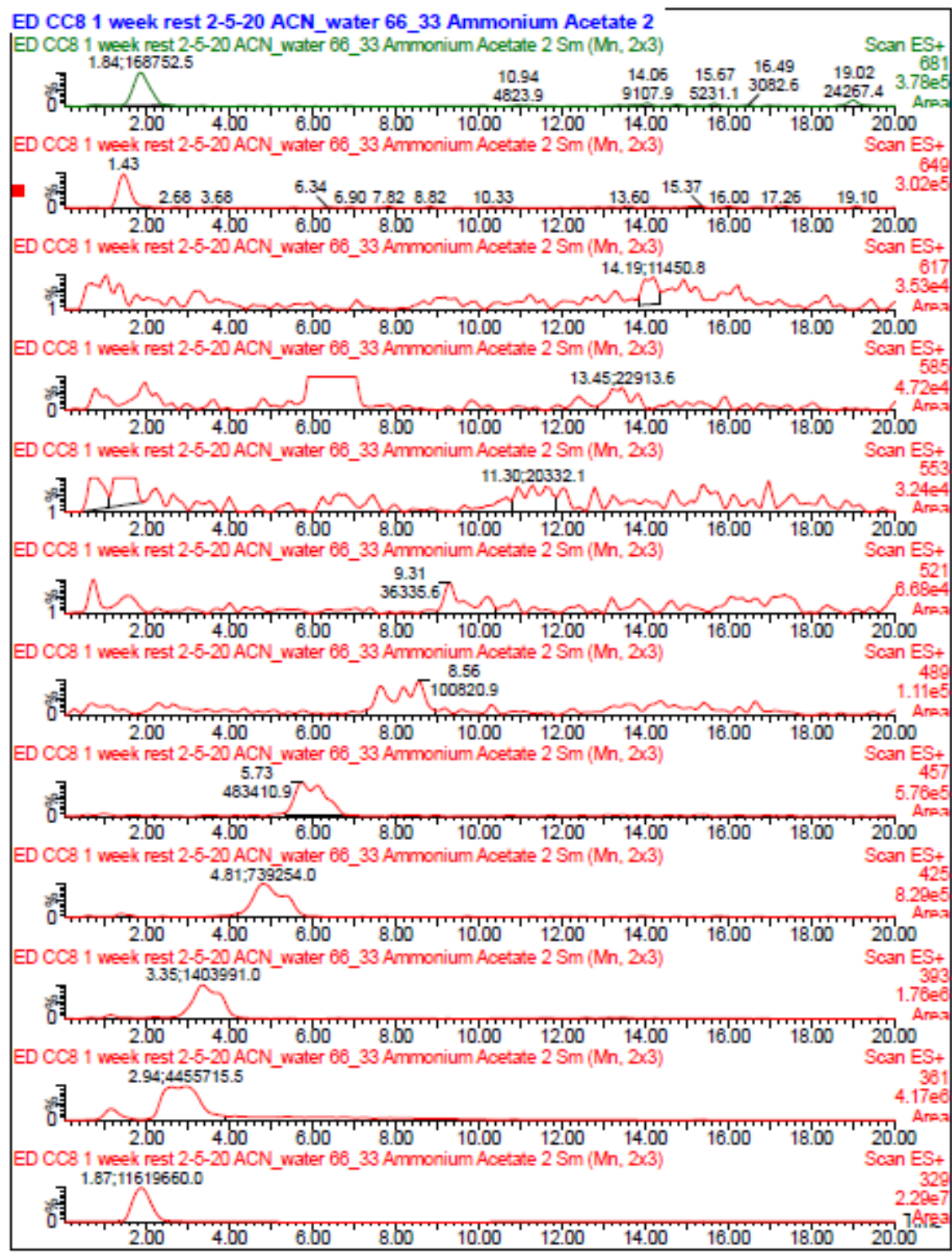

Figure A21. 400 mAh/g discharged, 1 week aged, sample \#2. 